Article

\title{
Substituted 3-Benzylcoumarins as Allosteric MEK1 Inhibitors: Design, Synthesis and Biological Evaluation as Antiviral Agents
}

Chao Wang ${ }^{1}$, Hao Zhang ${ }^{2}$, Fengrong Xu ${ }^{1}$, Yan Niu ${ }^{1, *}$, Yun Wu ${ }^{1}$, Xin Wang ${ }^{2}$, Yihong Peng ${ }^{2}$, Jing Sun ${ }^{1}$, Lei Liang ${ }^{1}$ and Ping $\mathrm{Xu}^{1}{ }^{1, *}$

1 State Key Laboratory of Natural and Biomimetic Drugs, Department of Medicinal Chemistry, School of Pharmaceutical Science, Peking University Health Science Center, Beijing 100191, China

2 Department of Microbiology, School of Basic Medical Sciences, Peking University, Beijing 100191, China

* Authors to whom correspondence should be addressed; E-Mails: yanniu@bjmu.edu.cn (Y.N.); pingxu@bjmu.edu.cn (P.X.); Tel./Fax: +86-10-8280-1505 (Y.N.); Tel.: +86-10-8280-2632 (P.X.); Fax: +86-10-8280-1117 (P.X.).

Received: 25 April 2013; in revised form: 10 May 2013 / Accepted: 14 May 2013 /

Published: 21 May 2013

\begin{abstract}
In order to find novel antiviral agents, a series of allosteric MEK1 inhibitors were designed and synthesized. Based on docking results, multiple optimizations were made on the coumarin scaffold. Some of the derivatives showed excellent MEK1 binding affinity in the appropriate enzymatic assays and displayed obvious inhibitory effects on the ERK pathway in a cellular assay. These compounds also significantly inhibited virus (EV71) replication in HEK293 and RD cells. Several compounds showed potential as agents for the treatment of viral infective diseases, with the most potent compound $\mathbf{1 8}$ showing an $\mathrm{IC}_{50}$ value of $54.57 \mathrm{nM}$ in the MEK1 binding assay.
\end{abstract}

Keywords: MEK1 inhibitor; coumarin; antiviral

Abbreviations: MAPK, Mitogen-activated protein kinase; MAP3K, Mitogen-activated protein kinase kinase kinase; MEK, mitogen-activated protein kinase/extracellular signal regulated kinase kinase; ERK, mitogen-activated protein kinase/extracellular signal-regulated kinase; EV71, Enterovirus 71; HEK293, human embryonic kidney293; RD cell: rhabdomyosarcoma cell; PDB: protein data bank; HTRF, homogeneous time-resolved fluorescence; FRET, Förster (Fluorescence) 
resonance energy transfer; TPA, 12-O-tetradecanoylphorbol-13-acetate; AP-1, activating protein-1; PE: petroleum ether; EA: ethyl acetate; Ts: tosyl; $t$-Bu: tert-butyl.

\section{Introduction}

According to WHO statistics, almost $75 \%$ of infectious diseases are caused by viruses, yet R\&D efforts related to the discovery and development of novel and potent antiviral agents have obviously lagged behind. A major difficulty in developing antiviral agents is drug resistance caused by virus variation. To the best of our knowledge, most studies of viruses and viral diseases focused on "viruses" themselves and ignored the interactions between viruses and their host cells. Several studies have reported that the RAF/MEK/ERK pathway plays a very important role in virus infection and replication. Selective blocking of the pathway can prevent the virus proliferation [1-4].

The RAF/MEK/ERK pathway belongs to mitogen-activated protein kinase (MAPK) pathways which are key intracellular signaling pathways involved in the regulation of a wide range of cellular events, including cell proliferation, differentiation, survival, apoptosis, etc. Functionally, the RAF/MEK/ERK pathway of normal cells is in a resting state, and this low activity state is sufficient to maintain the basic requirements of normal cell metabolism. As viruses need to activate ERK pathway continually when they replicate in cells [3,5], blocking of the pathway has a strong inhibitory effect on viral replication. Since the ERK pathway is coded by host genes, antiviral drugs targeting the ERK pathway can significantly overcome the drug resistance problems caused by virus variation.

MEK1 and MEK2 are closely related, dual-specificity tyrosine/threonine protein kinases that have an integral role in the ERK signaling pathway by phosphorylating the downstream ERK1 and ERK2. Since ERK1 and ERK2 are known to be the only substrates for MEK1 and MEK2 [6,7], targeting these two receptors had been an attractive approach for new therapy development. Lots of MEK1/2 inhibitors have been reported in the last twenty years, and Hasemann et al. have reported the crystal structure of ternary complex of MEK1 bound to its biarylamine inhibitor PD318088 and MgATP [8]. Most of the efficient MEK1/2 inhibitors are designed as non-ATP-competitive allosteric inhibitors [9-12]. They bind in a unique inhibitor-binding pocket adjacent to the ATP binding site, inducing conformational changes in the unphosphorylated MEK1/2 enzymes that lock them into a closed but catalytically inactive species [8]. This unique binding mode offers the non-ATP-competitive allosteric inhibitors better specificity and selectivity compared to the ATP-competitive inhibitors, which share a common ATP binding pocket and negatively influenced by the inhibition of other kinases.

Till now, most reported allosteric MEK1/2 inhibitors bear a biarylamine scaffold $[6,13]$ and there are 13 MEK inhibitors at different stages of clinical evaluations [14] although none of them has been approved yet for clinical use. On the other hand, very limited types of non-biarylamines have been identified as MEK1/2 inhibitors, such as PD98059, U0126 and G8935 [15]. PD98059 was the first synthetic MEK inhibitor which only had activities in vitro [16]. Similarly, U0126, the second MEK inhibitor with better potency, was mostly used in vitro at research labs due to its serious toxicity issues [10]. The coumarin derivative G8935 was also identified as MEK inhibitor by TR-FRET-based in vitro assay, however, no more functional evaluations have been reported [15].

For years, we have been focusing on the discovery and development of novel MEK1/2 inhibitors, the evaluation of their biological activities and the mechanisms of their usage as antivirus agents. Our 
early studies showed that in cell-based assays replication of enterovirus EV71, borna virus and herpes simplex virus HSV2 could be effectively suppressed by the MEK1/2 inhibitor U0126 [17-22] Selective blocking of mRNA expression of MEK1 could significantly inhibit virus replication, by contrast, knockdown of MEK2 expression showed dispensable effect, suggesting distinct functions of MEK1 and MEK2 in virus replication [22,23]. MEK1 might be a potential broad antiviral molecular target. Herein, we report the discovery of a series of novel 3-benzylcoumarins as allosteric MEK1 inhibitors. Multiple in vitro biological evaluations, including binding affinity to phosphorylated MEK1, ERK pathway inhibition and antiviral effects were performed, which demonstrated that these compounds were active MEK1 inhibitors and potential antiviral agent candidates.

\section{Results and Discussion}

\subsection{Molecular Design}

According to the report by Gu et al. [23], a series of coumarin derivatives could potently inhibit the activation of the unphosphorylated human MEK1. Molecular modeling studies suggested that the best inhibitor, G8935 (Figure 1) with an $\mathrm{IC}_{50}$ of $0.3 \mu \mathrm{M}$, bound to the allosteric site in the unphosphorylated conformation of MEK1. We used G8935 as a lead compound and docked G8935 into the allosteric site of the MEK1 structure (PDB code: 1S9J) using the docking program GOLD [23] and compared its binding mode with the host biarylamine allosteric inhibitor PD318088 (Figure 1).

Figure 1. Structures of PD318088 and G8935.
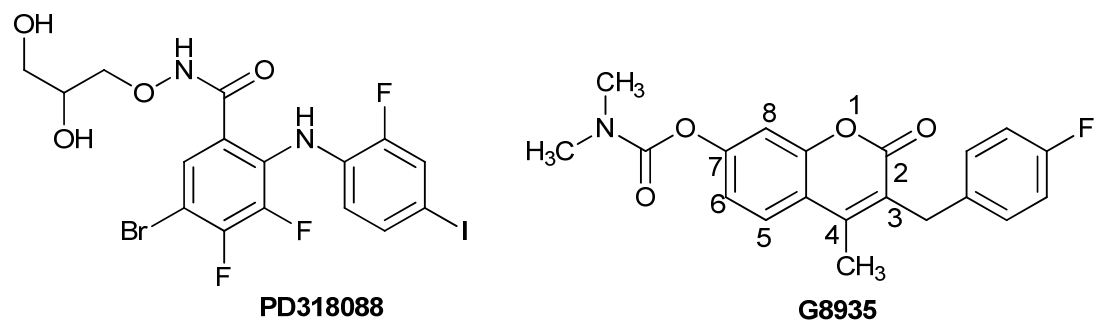

Their docking energy scores were similar to each other and the docked G8935 (docking score: 67.14) overlapped very well with the active conformation of PD318088 (docking score: 66.01) (Figure 2). Compared with the biarylamine skeleton, the 3-benzyl group is positioned in a lipophilic pocket formed by Met219, Ile216, Gly210, Arg189, and Asp190 that is not occupied by PD318088 (Figure 3) and the distance between the fluorine at the para-position of the 3-benzyl group and the terminal hydrogen of $\operatorname{Arg} 234$ is $3.30 \AA$, therefore structure modification at $\mathrm{C} 3$ to improve the affinity could be a very promising approach. The oxygen of the coumarin ring formed strong hydrogen bonds with Val 211 and Ser212, and the methyl group at C4 extended in the same direction as the side chain on the aromatic ring of PD318088, so optimization can be performed at the $\mathrm{C} 4$ position to enhance proteininhibitor interactions. Moreover, the carbonyl group of the carbamoyloxyl moiety substituted at the C7 position also formed a strong hydrogen bond with the backbone of Asp208 in the DFG motif and the distance between the hydrogen of the methyl group in the $\mathrm{C} 7$ substituent and the carbonyl oxygen of Val127 is only $2.15 \AA$, so optimization at the $\mathrm{C} 7$ position can also be performed to enhance the interaction between the inhibitor and these two residues. 
Figure 2. Superposition of the docked conformation of PD318088 (yellow) and the active conformation of G8935 (pink) (PDB code: 1S9J). Yellow dotted lines: hydrogen bonds between compounds and MEK1; green dotted lines: illustrative distance between compounds and MEK1.

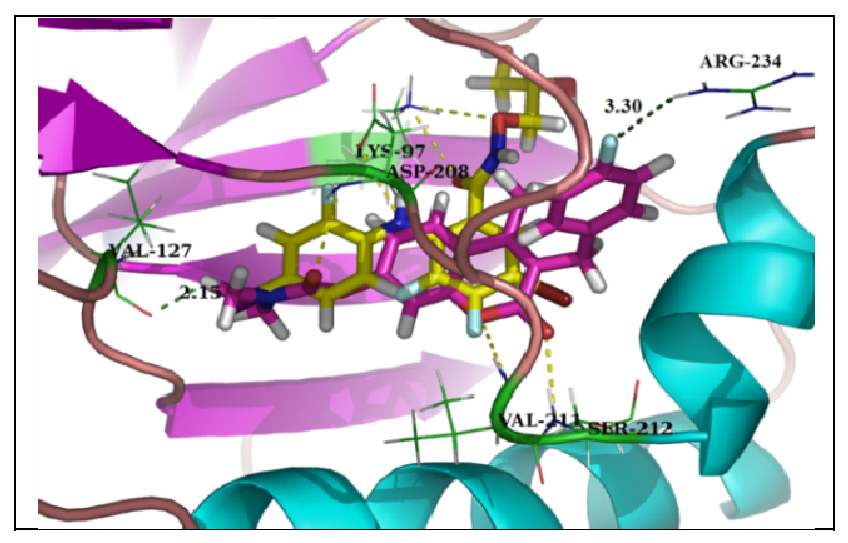

Figure 3. Close-up view of the 3-benzyl group fitting into the lipophilic pocket of MEK1 unoccupied by PD318088. Pink: G8935; Yellow: PD318088.

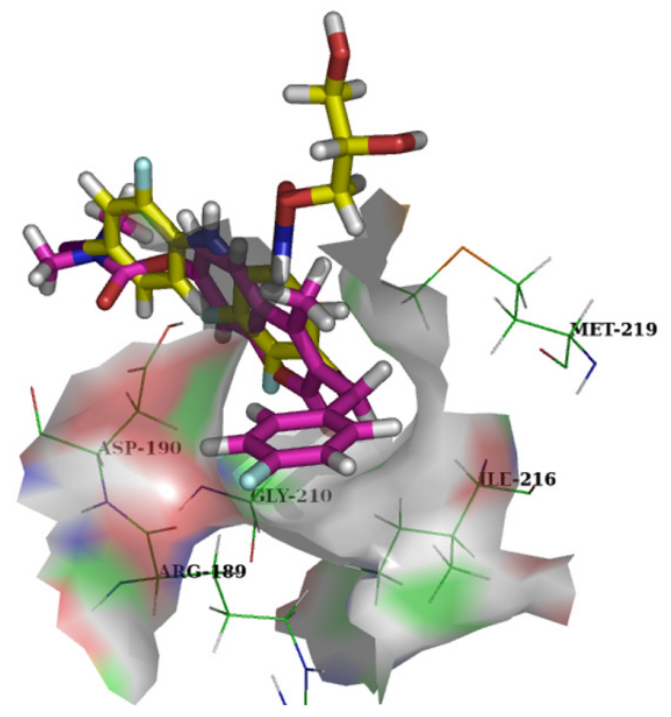

Based on the above observations, 3-benzyl- coumarin may represent a better scaffold for novel MEK1 inhibitor design compared with the biarylamines. As most reported allosteric MEK1/2 inhibitors bear a biarylamine scaffold and coumarin is one of the very limited types of non-biarylamine scaffold without further functional evaluations, we selected coumarin as the key moiety and performed structure optimization at the 3, 4, 7-postions to break though the biarylamine limitation and also evaluated biological functions of these compounds. This scaffold has following advantages: (1) the docking results suggested that the coumarin derivative overlapped very well with the biarylamine, suggesting a high possibility of similar MEK-inhibitory potency; (2) coumarin derivatives can be easily synthesized; (3) lots of studies could be done for coumarin-based MEK inhibitors since only one report [23] about coumarin structural modifications has been published and the highest potency could still be improved. Besides benzyl, a derivative with a benzoyl at the $\mathrm{C} 3$ position was also designed for comparison. Finally, a series of coumarin derivatives with benzyls or benzoyls at C3, various alkyl, 
cyano or carboxyl groups at $\mathrm{C} 4$ and different types of ester group at the $\mathrm{C} 7$ position were designed and synthesized (Figure 4).

Figure 4. Structure and substituent groups of designed coumarin derivatives.<smiles>[R]c1cc2oc(=O)c([R])c([R])c2cc1[R]</smiles>

$\mathbf{R}_{\mathbf{1}}=\mathrm{OH} ; \mathrm{OCH}_{3} ; \mathrm{CH}_{3} \mathrm{COO}$; EtCOO; (Me) $)_{2} \mathrm{NCOO} ;(\mathrm{Et})_{2} \mathrm{NCOO} ; n$-PrCOO; BuCOO; $t$-BuCOO; PhCOO; $\mathrm{PhSO}_{2} \mathrm{COO}$; $p$ - $\mathrm{CH}_{3} \mathrm{PhCOO} ; \mathbf{R}_{2}=\mathrm{Bn}$; 4-F-Bn; bezoyl; $\mathbf{R}_{3}=\mathrm{H} ; \mathrm{Me} ; \mathrm{Et} ; n-\mathrm{Pr} ; \mathrm{CH}_{2} \mathrm{Cl} ; \mathrm{CH}_{2} \mathrm{OH} ; \mathrm{CN} ; \mathrm{COOH} ; \mathbf{R}_{4}=\mathrm{H} ; \mathrm{Cl}$.

\subsection{Chemistry}

The synthetic routes to the 3-benzyl- and 3-benzoyl coumarin derivatives are outlined in Schemes 1-3. All substituents are summarized in Table 1.

Scheme 1. Synthesis of substituted 3-benzylcoumarin derivatives ${ }^{1,2}$.<smiles>[R4]CCC(=O)OCC</smiles><smiles>CC[C+]OC(=O)CCc1ccccc1</smiles><smiles>[R]C(=O)C([R2])C(=O)OCC</smiles><smiles>[R]c1cc2c([R3])c([R])c(=O)oc2cc1O</smiles>

4<smiles>[R]c1cc2oc(=O)c([R])c([R])c2cc1[R]</smiles>

$12-82$

3

1a $R_{3}=\mathrm{Me}$

1b $R_{3}=E t$

1c $R_{3}=n-P r$
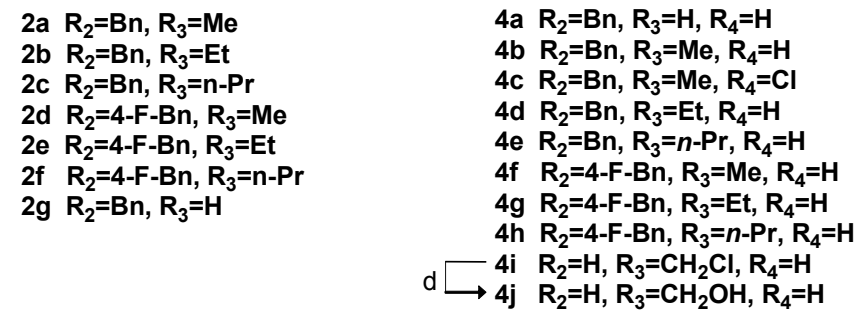

${ }^{1}$ Reagents and Conditions: (a): $\mathrm{NaH}, \mathrm{DMF}, 60{ }^{\circ} \mathrm{C}$; (b): $70 \% \mathrm{H}_{2} \mathrm{SO}_{4}$, r.t.; (c): acyl chloride, NaH, r.t.; (d): $\mathrm{H}_{2} \mathrm{O}$, reflux; (e): NaH, THF, $63.3 \%{ }^{2}$ For $\mathrm{R}_{1}, \mathrm{R}_{2}, \mathrm{R}_{3}$ and $\mathrm{R}_{4}$ of target product, see Table 1 .

Scheme 2. Synthesis of substituted 3-benzylcoumarin derivatives 83-84 ${ }^{1}$.

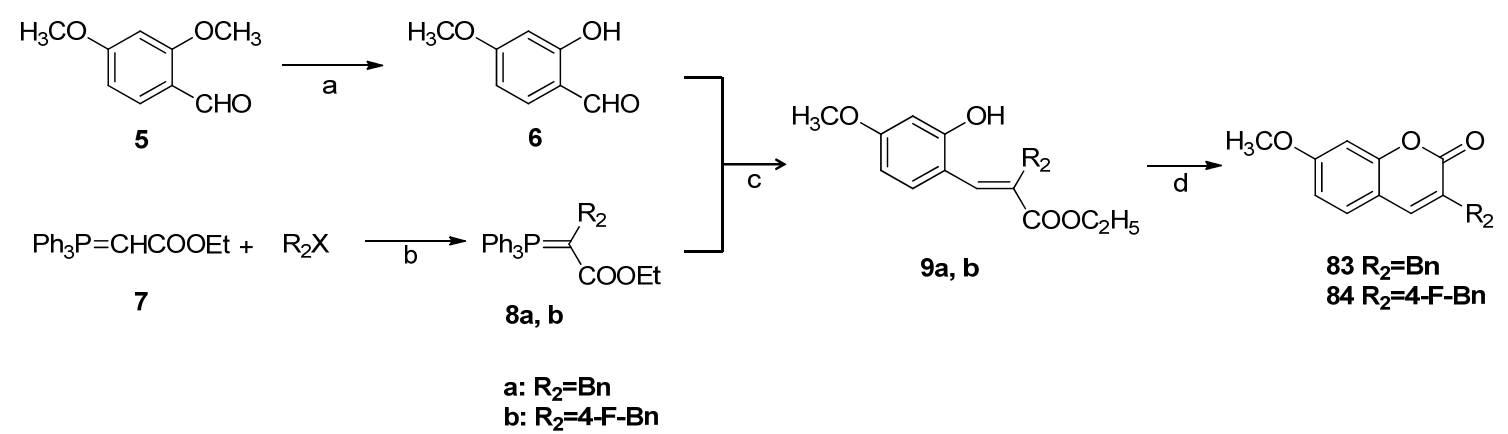

${ }^{1}$ Reagents and Conditions: (a): $\mathrm{AlCl}_{3}, 1$ h, r.t., 86.7\%; (b): $\mathrm{CHCl}_{3}, 15 \mathrm{~h}, 85{ }^{\circ} \mathrm{C}$; (c): toluene, 15 h, $85{ }^{\circ} \mathrm{C}$; (d): $2 \mathrm{~h}, 220^{\circ} \mathrm{C}$, nitrogen atmosphere. 
Scheme 3. Synthesis of substituted 3-benzoyl coumarin derivatives ${ }^{1}$.

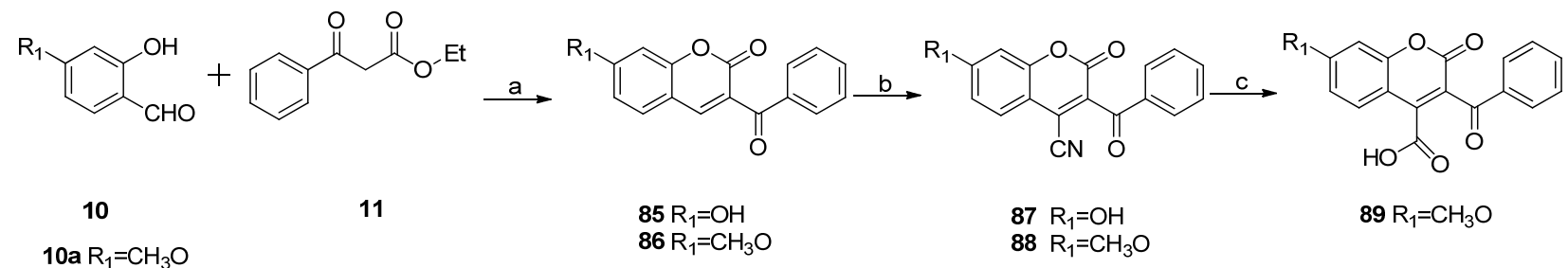

$10 \mathrm{~b} \mathrm{R}=\mathrm{OH}$

${ }^{1}$ Reagents and Conditions: (a): piperidine, $\mathrm{HCl}$; (b): $\mathrm{NaCN}$, r.t. $1 \mathrm{~h} ; \mathrm{I}_{2}, 1 \mathrm{~h}$; (c): $50 \% \mathrm{H}_{2} \mathrm{SO}_{4}, 100{ }^{\circ} \mathrm{C}, 15 \mathrm{~h}$.

Table 1. Potencies in binding affinity assay.<smiles>[R]c1cc2oc(=O)c([R])c([R])c2cc1[R]</smiles>

\begin{tabular}{|c|c|c|c|c|c|c|c|c|c|c|}
\hline Compd. & $\mathbf{R}_{1}$ & $\mathbf{R}_{\mathbf{2}}$ & $\mathbf{R}_{\mathbf{3}}$ & $\mathbf{R}_{4}$ & $\begin{array}{l}\text { \% binding } \\
(20 \mu \mathrm{M})\end{array}$ & Std & $\begin{array}{l}\text { \% binding } \\
(2 \mu \mathrm{M})\end{array}$ & Std & $\begin{array}{l}\mathrm{IC}_{50} \\
(\mathrm{nM})\end{array}$ & $\begin{array}{l}\text { Std } \\
(\mathrm{nM})\end{array}$ \\
\hline $4 b$ & $\mathrm{OH}$ & $\mathrm{Bn}$ & $\mathrm{Me}$ & $\mathrm{H}$ & -6.03 & 0.27 & -0.81 & 0.04 & & \\
\hline $4 c$ & $\mathrm{OH}$ & $\mathrm{Bn}$ & $\mathrm{Me}$ & $\mathrm{Cl}$ & 5.10 & 0.22 & 15.84 & 0.12 & & \\
\hline 4d & $\mathrm{OH}$ & $\mathrm{Bn}$ & Et & $\mathrm{H}$ & 10.39 & 0.47 & 27.04 & 1.38 & & \\
\hline $4 e$ & $\mathrm{OH}$ & $\mathrm{Bn}$ & $n-\operatorname{Pr}$ & $\mathrm{H}$ & 7.06 & 0.16 & 29.06 & 1.28 & & \\
\hline $4 g$ & $\mathrm{OH}$ & 4-F-Bn & Et & $\mathrm{H}$ & 19.62 & 0.92 & 10.90 & 0.48 & & \\
\hline $4 h$ & $\mathrm{OH}$ & 4-F-Bn & $n-\operatorname{Pr}$ & $\mathrm{H}$ & 20.40 & 0.50 & 20.86 & 0.69 & & \\
\hline $4 \mathbf{i}$ & $\mathrm{OH}$ & $\mathrm{H}$ & $\mathrm{CH}_{2} \mathrm{Cl}$ & $\mathrm{H}$ & 22.38 & 0.36 & 33.28 & 1.53 & & \\
\hline $4 \mathbf{j}$ & $\mathrm{OH}$ & $\mathrm{H}$ & $\mathrm{CH}_{2} \mathrm{OH}$ & $\mathrm{H}$ & 33.58 & 1.64 & 36.28 & 0.56 & & \\
\hline 12 & $\mathrm{~N}\left(\mathrm{CH}_{3}\right)_{2} \mathrm{COO}$ & $\mathrm{Bn}$ & $\mathrm{H}$ & $\mathrm{H}$ & 25.62 & 0.46 & 31.63 & 0.62 & & \\
\hline 13 & $\mathrm{~N}\left(\mathrm{CH}_{3}\right)_{2} \mathrm{COO}$ & $\mathrm{Bn}$ & $\mathrm{Me}$ & $\mathrm{H}$ & 95.16 & 0.47 & 75.61 & 3.22 & 222.8 & 7.7 \\
\hline 14 & $\mathrm{~N}\left(\mathrm{CH}_{3}\right)_{2} \mathrm{COO}$ & $\mathrm{Bn}$ & $\mathrm{Me}$ & $\mathrm{Cl}$ & 80.76 & 1.80 & 66.26 & 0.74 & 307.3 & 6.9 \\
\hline 15 & $\mathrm{~N}\left(\mathrm{CH}_{3}\right)_{2} \mathrm{COO}$ & $\mathrm{Bn}$ & Et & $\mathrm{H}$ & 92.78 & 5.95 & 85.01 & 1.92 & 163.5 & 8.2 \\
\hline 16 & $\mathrm{~N}\left(\mathrm{CH}_{3}\right)_{2} \mathrm{COO}$ & $\mathrm{Bn}$ & $n$-Pr & $\mathrm{H}$ & 95.37 & 1.65 & 70.94 & 5.15 & 1035 & 68 \\
\hline 17 & $\mathrm{~N}\left(\mathrm{CH}_{3}\right)_{2} \mathrm{COO}$ & 4-F-Bn & $\mathrm{Me}$ & $\mathrm{H}$ & 82.14 & 0.16 & 71.56 & 1.29 & 407.8 & 3.6 \\
\hline 18 & $\mathrm{~N}\left(\mathrm{CH}_{3}\right)_{2} \mathrm{COO}$ & 4-F-Bn & $\mathrm{Et}$ & $\mathrm{H}$ & 99.40 & 3.30 & 98.24 & 5.62 & 54.57 & 1.4 \\
\hline 19 & $\mathrm{~N}\left(\mathrm{CH}_{3}\right)_{2} \mathrm{COO}$ & 4-F-Bn & $n-\operatorname{Pr}$ & $\mathrm{H}$ & 87.58 & 2.38 & 66.17 & 1.21 & 157.8 & 10.8 \\
\hline 20 & $\mathrm{~N}(\mathrm{Et})_{2} \mathrm{COO}$ & $\mathrm{Bn}$ & $\mathrm{Me}$ & $\mathrm{H}$ & 20.02 & 0.90 & 15.49 & 0.66 & & \\
\hline 21 & $\mathrm{~N}(\mathrm{Et})_{2} \mathrm{COO}$ & $\mathrm{Bn}$ & $\mathrm{Me}$ & $\mathrm{Cl}$ & 48.14 & 2.71 & 27.00 & 2.55 & & \\
\hline 22 & $\mathrm{~N}(\mathrm{Et})_{2} \mathrm{COO}$ & $\mathrm{Bn}$ & Et & $\mathrm{H}$ & 48.09 & 1.63 & 6.63 & 1.59 & 6600 & 210 \\
\hline 23 & $\mathrm{~N}(\mathrm{Et})_{2} \mathrm{COO}$ & $\mathrm{Bn}$ & $n-\operatorname{Pr}$ & $\mathrm{H}$ & 46.11 & 0.43 & 43.14 & 2.78 & & \\
\hline 24 & $\mathrm{~N}(\mathrm{Et})_{2} \mathrm{COO}$ & 4-F-Bn & $\mathrm{Me}$ & $\mathrm{H}$ & 27.76 & 0.15 & 22.26 & 1.10 & & \\
\hline 25 & $\mathrm{~N}(\mathrm{Et})_{2} \mathrm{COO}$ & 4-F-Bn & Et & $\mathrm{H}$ & 59.16 & 2.78 & 25.91 & 3.73 & 2190 & 130 \\
\hline 26 & $\mathrm{~N}(\mathrm{Et})_{2} \mathrm{COO}$ & 4-F-Bn & $n-\operatorname{Pr}$ & $\mathrm{H}$ & 37.50 & 1.25 & 35.17 & 1.46 & & \\
\hline 27 & $\mathrm{CH}_{3} \mathrm{COO}$ & $\mathrm{Bn}$ & $\mathrm{Me}$ & $\mathrm{Cl}$ & 30.83 & 0.66 & 30.55 & 0.77 & & \\
\hline 28 & $\mathrm{CH}_{3} \mathrm{COO}$ & $\mathrm{Bn}$ & $\mathrm{Me}$ & $\mathrm{H}$ & 96.53 & 0.82 & 72.22 & 3.08 & 519.8 & 11.2 \\
\hline 29 & $\mathrm{CH}_{3} \mathrm{COO}$ & $\mathrm{Bn}$ & Et & $\mathrm{H}$ & 102.10 & 3.01 & 88.70 & 4.35 & 175.7 & 11.1 \\
\hline 30 & $\mathrm{CH}_{3} \mathrm{COO}$ & $\mathrm{Bn}$ & $n-\operatorname{Pr}$ & $\mathrm{H}$ & 25.60 & 0.89 & 15.47 & 3.45 & & \\
\hline
\end{tabular}


Table 1. Cont.

\begin{tabular}{|c|c|c|c|c|c|c|c|c|c|c|}
\hline Compd. & $\mathbf{R}_{1}$ & $\mathbf{R}_{\mathbf{2}}$ & $\mathbf{R}_{\mathbf{3}}$ & $\mathbf{R}_{4}$ & $\begin{array}{l}\text { \% binding } \\
(20 \mu \mathrm{M})\end{array}$ & Std & $\begin{array}{l}\text { \% binding } \\
(2 \mu \mathrm{M})\end{array}$ & Std & $\begin{array}{l}\mathrm{IC}_{50} \\
(\mathrm{nM})\end{array}$ & $\begin{array}{l}\text { Std } \\
(\mathrm{nM})\end{array}$ \\
\hline 31 & $\mathrm{CH}_{3} \mathrm{COO}$ & 4-F-Bn & $\mathrm{Me}$ & $\mathrm{H}$ & 78.18 & 0.75 & 72.20 & 3.59 & 247.6 & 10.1 \\
\hline 32 & $\mathrm{CH}_{3} \mathrm{COO}$ & 4-F-Bn & Et & $\mathrm{H}$ & 100.96 & 2.00 & 94.57 & 1.06 & 91.2 & 7.9 \\
\hline 33 & $\mathrm{CH}_{3} \mathrm{COO}$ & 4-F-Bn & $n-\operatorname{Pr}$ & $\mathrm{H}$ & 72.16 & 3.49 & 61.41 & 3.90 & 252.1 & 7.5 \\
\hline 34 & EtCOO & $\mathrm{Bn}$ & $\mathrm{Me}$ & $\mathrm{Cl}$ & 72.37 & 0.30 & 70.05 & 0.30 & 325.5 & 12.6 \\
\hline 35 & EtCOO & $\mathrm{Bn}$ & $\mathrm{Me}$ & $\mathrm{H}$ & 85.02 & 3.73 & 64.55 & 3.93 & 1033 & 79 \\
\hline 36 & EtCOO & $\mathrm{Bn}$ & Et & $\mathrm{H}$ & 87.02 & 3.71 & 81.04 & 0.83 & 391.1 & 8.8 \\
\hline 37 & EtCOO & $\mathrm{Bn}$ & $n-\operatorname{Pr}$ & $\mathrm{H}$ & 38.80 & 1.86 & 19.36 & 2.40 & & \\
\hline 38 & EtCOO & 4-F-Bn & $\mathrm{Me}$ & $\mathrm{H}$ & 90.85 & 1.95 & 75.69 & 4.53 & 189.9 & 12.2 \\
\hline 39 & EtCOO & 4-F-Bn & $\mathrm{Et}$ & $\mathrm{H}$ & 76.31 & 3.28 & 75.42 & 3.13 & 140.4 & 10.7 \\
\hline 40 & EtCOO & 4-F-Bn & $n-\operatorname{Pr}$ & $\mathrm{H}$ & 78.53 & 0.50 & 72.18 & 2.40 & 175.6 & 11.3 \\
\hline 41 & $n$-PrCOO & $\mathrm{Bn}$ & $\mathrm{Me}$ & $\mathrm{Cl}$ & 25.79 & 0.34 & 20.97 & 0.97 & & \\
\hline 42 & $n$-PrCOO & $\mathrm{Bn}$ & $\mathrm{Me}$ & $\mathrm{H}$ & 68.43 & 1.74 & 53.76 & 3.25 & 352.9 & 12.3 \\
\hline 43 & $n$-PrCOO & $\mathrm{Bn}$ & Et & $\mathrm{H}$ & 54.72 & 1.51 & 45.04 & 3.28 & 473.3 & 13.4 \\
\hline 44 & $n$-PrCOO & $\mathrm{Bn}$ & $n-\operatorname{Pr}$ & $\mathrm{H}$ & 38.86 & 2.22 & 13.97 & 0.77 & & \\
\hline 45 & $n-\mathrm{PrCOO}$ & 4-F-Bn & $\mathrm{Me}$ & $\mathrm{H}$ & 72.35 & 4.52 & 45.34 & 0.29 & 824.5 & 10.5 \\
\hline 46 & $n$-PrCOO & 4-F-Bn & Et & $\mathrm{H}$ & 96.49 & 3.67 & 76.94 & 2.67 & 908.6 & 28 \\
\hline 47 & $n-\mathrm{PrCOO}$ & 4-F-Bn & $n-\operatorname{Pr}$ & $\mathrm{H}$ & 70.28 & 6.06 & 56.96 & 2.35 & 944.1 & 10.9 \\
\hline 48 & $\mathrm{BuCOO}$ & $\mathrm{Bn}$ & $\mathrm{Me}$ & $\mathrm{H}$ & 21.23 & 0.83 & 18.83 & 0.37 & & \\
\hline 49 & $\mathrm{BuCOO}$ & $\mathrm{Bn}$ & $\mathrm{Me}$ & $\mathrm{Cl}$ & 20.33 & 0.07 & 8.15 & 0.40 & & \\
\hline 50 & $\mathrm{BuCOO}$ & $\mathrm{Bn}$ & Et & $\mathrm{H}$ & 43.18 & 0.27 & 37.25 & 0.10 & & \\
\hline 51 & $\mathrm{BuCOO}$ & $\mathrm{Bn}$ & $n-\operatorname{Pr}$ & $\mathrm{H}$ & 42.48 & 0.12 & 29.52 & 0.97 & & \\
\hline 52 & $\mathrm{BuCOO}$ & 4-F-Bn & Et & $\mathrm{H}$ & 34.02 & 0.89 & 42.77 & 0.31 & & \\
\hline 53 & $\mathrm{BuCOO}$ & 4-F-Bn & $\mathrm{Me}$ & $\mathrm{H}$ & 38.28 & 1.30 & 34.74 & 1.63 & & \\
\hline 54 & $\mathrm{BuCOO}$ & 4-F-Bn & $n$-Pr & $\mathrm{H}$ & 23.93 & 1.97 & 11.72 & 0.44 & & \\
\hline 55 & $t$-BuCOO & $\mathrm{Bn}$ & $\mathrm{Me}$ & $\mathrm{H}$ & 14.78 & 0.29 & 14.62 & 0.24 & & \\
\hline 56 & $t$-BuCOO & $\mathrm{Bn}$ & $\mathrm{Me}$ & $\mathrm{Cl}$ & 34.11 & 1.82 & 16.56 & 0.57 & & \\
\hline 57 & $t$-BuCOO & $\mathrm{Bn}$ & $\mathrm{Et}$ & $\mathrm{H}$ & 21.02 & 0.90 & 6.61 & 0.82 & & \\
\hline 58 & $t$-BuCOO & $\mathrm{Bn}$ & $n-\operatorname{Pr}$ & $\mathrm{H}$ & 19.05 & 0.83 & 43.16 & 1.78 & & \\
\hline 59 & $t$-BuCOO & 4-F-Bn & $\mathrm{Et}$ & $\mathrm{H}$ & 23.36 & 0.12 & 45.92 & 0.65 & & \\
\hline 60 & $t$-BuCOO & 4-F-Bn & $\mathrm{Me}$ & $\mathrm{H}$ & 20.26 & 0.78 & 23.71 & 0.06 & & \\
\hline 61 & $t$-BuCOO & 4-F-Bn & $n-\operatorname{Pr}$ & $\mathrm{H}$ & 40.92 & 1.79 & 31.62 & 0.48 & & \\
\hline 62 & $\mathrm{PhCOO}$ & $\mathrm{Bn}$ & $\mathrm{Me}$ & $\mathrm{H}$ & 31.11 & 1.73 & 4.07 & 0.06 & & \\
\hline 63 & $\mathrm{PhCOO}$ & $\mathrm{Bn}$ & $\mathrm{Me}$ & $\mathrm{Cl}$ & 27.96 & 0.66 & 33.33 & 1.58 & & \\
\hline 64 & $\mathrm{PhCOO}$ & $\mathrm{Bn}$ & $\mathrm{Et}$ & $\mathrm{H}$ & 21.54 & 0.40 & 10.11 & 1.54 & & \\
\hline 65 & $\mathrm{PhCOO}$ & $\mathrm{Bn}$ & $n-\operatorname{Pr}$ & $\mathrm{H}$ & 37.15 & 0.59 & 32.57 & 0.68 & & \\
\hline 66 & $\mathrm{PhCOO}$ & 4-F-Bn & $\mathrm{Me}$ & $\mathrm{H}$ & 30.96 & 1.14 & 25.78 & 0.02 & & \\
\hline 67 & $\mathrm{PhCOO}$ & 4-F-Bn & $\mathrm{Et}$ & $\mathrm{H}$ & 21.28 & 0.70 & 44.56 & 1.26 & & \\
\hline 68 & $\mathrm{PhCOO}$ & 4-F-Bn & $n-\operatorname{Pr}$ & $\mathrm{H}$ & 45.57 & 0.58 & 26.15 & 0.45 & & \\
\hline 69 & $\mathrm{PhSO}_{3}$ & $\mathrm{Bn}$ & $\mathrm{Me}$ & $\mathrm{H}$ & 2.32 & 0.00 & -11.27 & 0.42 & & \\
\hline 70 & $\mathrm{PhSO}_{3}$ & $\mathrm{Bn}$ & $\mathrm{Me}$ & $\mathrm{Cl}$ & 24.53 & 0.39 & 29.87 & 0.08 & & \\
\hline
\end{tabular}


Table 1. Cont.

\begin{tabular}{|c|c|c|c|c|c|c|c|c|c|c|}
\hline Compd. & $\mathbf{R}_{1}$ & $\mathbf{R}_{\mathbf{2}}$ & $\mathbf{R}_{\mathbf{3}}$ & $\mathbf{R}_{4}$ & $\begin{array}{l}\text { \% binding } \\
(20 \mu \mathrm{M})\end{array}$ & Std & $\begin{array}{l}\text { \% binding } \\
(2 \mu \mathrm{M})\end{array}$ & Std & $\begin{array}{l}\mathrm{IC}_{50} \\
(\mathrm{nM})\end{array}$ & $\begin{array}{l}\text { Std } \\
(\mathrm{nM})\end{array}$ \\
\hline 71 & $\mathrm{PhSO}_{3}$ & $\mathrm{Bn}$ & Et & $\mathrm{H}$ & -2.35 & 0.11 & 31.12 & 1.30 & & \\
\hline 72 & $\mathrm{PhSO}_{3}$ & $\mathrm{Bn}$ & $n-\operatorname{Pr}$ & $\mathrm{H}$ & 14.03 & 0.10 & 26.00 & 1.13 & & \\
\hline 73 & $\mathrm{PhSO}_{3}$ & 4-F-Bn & Et & $\mathrm{H}$ & 7.40 & 0.31 & 16.59 & 0.56 & & \\
\hline 74 & $\mathrm{PhSO}_{3}$ & 4-F-Bn & $\mathrm{Me}$ & $\mathrm{H}$ & 17.00 & 0.95 & 21.39 & 0.43 & & \\
\hline 75 & $\mathrm{PhSO}_{3}$ & 4-F-Bn & $n-\operatorname{Pr}$ & $\mathrm{H}$ & 13.78 & 0.29 & 21.55 & 0.38 & & \\
\hline 76 & $\mathrm{TsO}$ & $\mathrm{Bn}$ & $\mathrm{Me}$ & $\mathrm{H}$ & -2.36 & 0.03 & 2.87 & 0.09 & & \\
\hline 77 & $\mathrm{TsO}$ & $\mathrm{Bn}$ & $\mathrm{Me}$ & $\mathrm{Cl}$ & 29.57 & 1.22 & 31.68 & 1.30 & & \\
\hline 78 & $\mathrm{TsO}$ & $\mathrm{Bn}$ & Et & $\mathrm{H}$ & 4.76 & 0.16 & 33.20 & 1.65 & & \\
\hline 79 & $\mathrm{TsO}$ & $\mathrm{Bn}$ & $n-\operatorname{Pr}$ & $\mathrm{H}$ & 11.73 & 0.53 & 24.60 & 0.18 & & \\
\hline 80 & $\mathrm{TsO}$ & 4-F-Bn & Et & $\mathrm{H}$ & 16.54 & 0.07 & 33.06 & 0.56 & & \\
\hline 81 & $\mathrm{TsO}$ & 4-F-Bn & $\mathrm{Me}$ & $\mathrm{H}$ & 9.55 & 0.20 & 8.05 & 0.10 & & \\
\hline 82 & $\mathrm{TsO}$ & 4-F-Bn & $n-\operatorname{Pr}$ & $\mathrm{H}$ & 45.87 & 1.77 & 37.51 & 0.33 & & \\
\hline 83 & $\mathrm{CH}_{3} \mathrm{O}$ & $\mathrm{Bn}$ & $\mathrm{H}$ & $\mathrm{H}$ & 2.93 & 0.05 & 23.04 & 0.00 & & \\
\hline 84 & $\mathrm{CH}_{3} \mathrm{O}$ & 4-F-Bn & $\mathrm{H}$ & $\mathrm{H}$ & 15.43 & 0.51 & 17.56 & 0.68 & & \\
\hline 85 & $\mathrm{OH}$ & $\mathrm{PhCO}$ & $\mathrm{H}$ & $\mathrm{H}$ & 20.52 & 0.44 & 23.01 & 0.85 & & \\
\hline 86 & $\mathrm{CH}_{3} \mathrm{O}$ & $\mathrm{PhCO}$ & $\mathrm{H}$ & $\mathrm{H}$ & -8.83 & 0.42 & 7.96 & 0.16 & & \\
\hline 87 & $\mathrm{OH}$ & $\mathrm{PhCO}$ & $\mathrm{CN}$ & $\mathrm{H}$ & 30.03 & 1.87 & 31.91 & 1.87 & & \\
\hline 88 & $\mathrm{CH}_{3} \mathrm{O}$ & $\mathrm{PhCO}$ & $\mathrm{CN}$ & $\mathrm{H}$ & 22.90 & 1.50 & 32.41 & 0.21 & & \\
\hline 89 & $\mathrm{CH}_{3} \mathrm{O}$ & $\mathrm{PhCO}$ & $\mathrm{COOH}$ & $\mathrm{H}$ & 6.34 & 0.24 & 16.51 & 0.76 & & \\
\hline
\end{tabular}

The substituted 3-benzylcoumarin derivatives have been synthesized in three steps (Scheme 1) starting from ethyl acylacetate $\mathbf{1}$ and benzyl bromide or 4-fluorobenzyl bromide in the presence of sodium hydride or potassium carbonate in DMF at $60{ }^{\circ} \mathrm{C}$ to afford the corresponding substituted ethyl acylacetates 2. However, 2-formoxyl-ethyl-3-phenyl propionate (2g) can't be obtained by this method since the starting material (ethyl formyl acetate) is not commercially available. In this case, $\mathbf{2 g}$ was obtained by an alternative Claisen condensation of ethyl-3-phenyl propionate (3) and ethyl formate. Next, the condensation of 2 with resorcinol by the Pechmann reaction in the presence of $70 \% \mathrm{H}_{2} \mathrm{SO}_{4}$ led to the formation of the intermediate 7-hydroxycoumarin cyclization products 4 , some of which (compounds $\mathbf{4 b}-\mathbf{e}, \mathbf{4 g}-\mathbf{j}$ ) were also evaluated as target compounds. Esterification of $\mathbf{4}$ with acyl chlorides in the presence of $\mathrm{NaH}$ afforded the target products 12-82 [24].

The Pechmann reaction was not suitable for the synthesis of 3-benzyl-7- $N, N$ dimethylcarbamoyloxyl-2H-chromen-2-one (12) which has no substituent group at the $\mathrm{C} 4$ position, and the overall yield of $\mathbf{1 2}$ was as low as $3.6 \%$. To improve the synthetic yield of this kind of compounds, the Wittig reaction [25] was adopted and a better synthetic route was used, which provided 3-benzyl-7-methoxy-2H-chromen-2-one (83) and 3-(4-fluorobenzyl)-7-methoxy-2Hchromen-2-one (84) in four steps (Scheme 2). First, selective demethylation of 2,4-dimethoxybenzaldehyde (5) was performed in the presence of anhydrous $\mathrm{AlCl}_{3}$ to afford 2-hydroxy-4-methoxybenzaldehyde (6). Ethoxycarbonylmethylene triphenylphosphorane (7) was mixed with benzyl bromide or 4-fluorobenzyl bromide in dry chloroform to form the stable alkylated phosphorane 8 . Next $\mathbf{6}$ was reacted in toluene with phosphorane $\mathbf{8}$, which is a resonance stabilized ylide, to yield the corresponding 
hydroxyesters 9. Only $E$-isomers of 9 were obtained [25]. These were then converted thermally under nitrogen atmosphere to the respective coumarins 83 and 84 in high yields.

The substituted 3-benzoylcoumarins have been synthesized as described in Scheme 3. Condensation of $o$-hydroxybenzaldehyde (10) and ethyl benzoylacetate (11) in the presence of piperidine afforded 3-benzoyl coumarin rings $\mathbf{8 5}, 86$ [26]. Compound 86 could be synthesized without solvent, while acetonitrile was required as solvent for the synthesis of $\mathbf{8 5}$. In addition, it took $24 \mathrm{~h}$ to get $\mathbf{8 5}$ while the synthesis of $\mathbf{8 6}$ was finished almost instantaneously with the product obtained as solid, and by-products would be produced if the reaction time was prolonged. Next, cyanation occured in the presence of $\mathrm{NaCN}$ at room temperature for $1 \mathrm{~h}$, followed by addition of iodine into the mixture and reaction for another hour to give the nitriles 87, 88 [27]. Hydrolysis of the nitriles with $50 \% \mathrm{H}_{2} \mathrm{SO}_{4}$ gave the corresponding 4-carboxylic acids 89 [28]. The products were purified by flash chromatography. The structures were confirmed by ${ }^{1} \mathrm{H}$ and ${ }^{13} \mathrm{C}$-NMR spectroscopy, EI-MS or EI-HRMS spectra (for details, see Experimental).

\subsection{Binding to Phosphorylated MEK1}

All of the newly synthesized compounds were first tested for binding affinity to phosphorylated MEK1 at $20 \mu \mathrm{M} 2 \mu \mathrm{M}$ in a biochemical homogeneous time-resolved fluorescence (HTRF) assay. The $\mathrm{IC}_{50}$ values were determined for the 25 compounds with $>45 \%$ inhibition of the tracer binding at $20 \mu \mathrm{M}$ and the best $\mathrm{IC}_{50}$ value $(54.57 \mathrm{nM})$ was observed for $\mathbf{1 8}$ (Table 1).

Only coumarin derivatives with benzyl- or 4-fluorobenzyl substitutions at the C3 position showed activity (compounds 12-84), while all 3-benzoyl-substituted analogues demonstrated less than 40\% binding affinity at $20 \mu \mathrm{M}$ (compounds 85-89). This might related to the reduced flexibility of the carbonyl group, which can block the phenyl ring from entering into the lipophilic pocket, compared with the $\mathrm{CH}_{2}$ in the benzyl substitution. In addition, 4-fluorobenzyl substitution at the $\mathrm{C} 3$ position seemed to be better than a benzyl group, as observed by comparison of 15, 16, 28-30, 35-37 with their respective analogues $\mathbf{1 8}, \mathbf{1 9}, \mathbf{3 1}-\mathbf{3 3}, \mathbf{3 8}-\mathbf{4 0}$, which suggested that fluorine could enhance the binding affinity between the inhibitor and protein. Fluorine is different from other halogens. As a small atom of high electronegativity, fluorine prefers to orient towards the electropositive guanidinium side chain of Arg234 and undergoes C-F $\cdots \mathrm{H}-\mathrm{N}$ interactions, and therefore strengthens protein-ligand binding affinity, while no other halogen could have such an effect [29-31]. Compounds with alkyl chains, including methyl, ethyl and propyl groups, at the $\mathrm{C} 4$ position displayed good affinity and the ethyl group is the best of them $\left(\mathbf{1 3}, \mathrm{IC}_{50}=222.8 \mathrm{nM} ; \mathbf{1 5}, \mathrm{IC}_{50}=163.5 \mathrm{nM} ; \mathbf{1 6}, \mathrm{IC}_{50}=1,035 \mathrm{nM}\right)$ while compounds without any substitution at this site (e.g., 12) led to the disappearance of affinity. The affinities of most compounds substituted with chlorine at the C6 position $(\mathbf{1 4}, \mathbf{2 1}, \mathbf{2 7}, \mathbf{3 4}, \mathbf{4 1}, \mathbf{4 9}, \mathbf{5 6}$, $63,70,77)$ and the non-substituted analogues $(13,20,28,35,42,48,55,62,69,76)$ displayed no obvious differences. Compounds with a $N, N$-dimethylcarbamoyloxyl at the $\mathrm{C} 7$ position displayed the best activity, and the sequence of the substituents for better binding affinity was $\mathrm{N}\left(\mathrm{CH}_{3}\right)_{2} \mathrm{COO}>$ $\mathrm{MeCOO}$, EtCOO, $n$-PrCOO $>\mathrm{N}(\mathrm{Et})_{2} \mathrm{COO}$, while other substituents such as $t$-BuCOO, BuCOO, $\mathrm{PhCOO}, \mathrm{TsO}, \mathrm{PhSO}_{3}, \mathrm{OH}, \mathrm{OCH}_{3}$ showed no activity (comparing the active 18, 25, 32, 39, 46 and the inactive 52, 59, 67, 73, 80), revealing that the affinity was quite sensitive to modifications at the 7-position. From the structures of these substituent groups at the $\mathrm{C} 7$ position, we speculated that their 
distinct activities may be related to their different steric hindrances and carbon chain lengths. Neither larger nor smaller substituents at the $\mathrm{C} 7$ position were good for activity. The docking results suggested that the coumarin derivatives with $\mathrm{N}\left(\mathrm{CH}_{3}\right)_{2} \mathrm{COO}, \mathrm{MeCOO}$, EtCOO, $n$-PrCOO or $\mathrm{N}(\mathrm{Et})_{2} \mathrm{COO}$ at the $\mathrm{C} 7$ position (compounds 18, 25, 32, 39 and 46) could occupy the lipophilic pocket suitably. Moreover, $\mathrm{N}\left(\mathrm{CH}_{3}\right)_{2} \mathrm{COO}$ could just occupy the pocket completely. Substituent groups whose steric hindrances and carbon chain lengths are larger than $n$-PrCOO, such as $t$-BuCOO, $n$-BuCOO, PhCOO, TsO, $\mathrm{PhSO}_{3}$ (compounds 52, 59, 67, 73 and 80), would extend beyond the pocket. That's the reason why compounds with different substituents at the $\mathrm{C} 7$ position showed different binding affinities.

\subsection{Inhibition of ERK Pathway}

The effects of the inhibitors on the activation of ERK pathway were determined in TPA (12-Otetradecanoylphorbol-13-acetate)-stimulated cells using the AP-1 luciferase reporter gene assay system. Activating protein-1 (AP-1) is the nuclear transcription factor which is a heterodimeric protein downstream of MAPK composed of dimers of the Fos and Jun proteins. The stable AP-1 dimers bind to DNA recognition elements (AP-1 response elements) and mediate transcriptional induction. AP-1 controls a number of cellular events including differentiation, proliferation and apoptosis [32,33]. Simultaneously, the expression of AP-1 can be regulated in response to different extracellular stimuli, such as cytokines, growth factors, stress, and bacterial and viral infections. ERK pathway is the most important mediator which is closely related to these responses. Activation of ERK pathway causes induction of fos gene, and then the product heterodimerizes with the Jun protein to form the AP-1 dimers. These newly formed heterodimers can enhance the expression of c-jun through AP-1 binding sites in the c-jun promoter. TPA can increase levels of AP-1 proteins through activation of the ERK pathway. U0126, a specific MEK inhibitor, can suppress the activation of the ERK pathway through inhibition of MEK1/2. It is reported that U0126 was an inhibitor of AP-1 transactivation [34]. As a cellular AP-1 antagonist, U0126 did not prevent AP-1 from DNA binding rather it inhibited the upregulation of c-Fos and c-Jun and protein levels in activated cells. These effects resulted from inhibition of the ERK pathway. The AP-1 luciferase reporter assay system was constructed according to the effect of U0126 on AP-1 levels in TPA-activated cells as described above. This system was used to screen synthesized compounds which may have the same effect as U0126.

Twenty compounds which had excellent binding affinity with phosphorylated MEK1 were selected for further testing in intracellular assays. U0126 was taken as a positive control. In HEK 293 cells treated with TPA, $30 \mu \mathrm{M}$ U0126 could suppress the up-regulation of AP-1 by $50 \%$, as detected by the reporter gene assay. The AP-1 $\mathrm{IC}_{50} \mathrm{~s}$ for inhibition of ERK pathway activation are shown in Table 2. Fifteen of 20 compounds exhibited inhibition effects on activation of the ERK pathway. Among them, six compounds $(\mathbf{1 3}, \mathbf{1 7}, \mathbf{1 8}, \mathbf{1 9}, \mathbf{3 1}, \mathbf{3 3})$ acted more efficiently than U0126 at the same concentration. All of them were 3-(4-fluorobenzyl)- or 3-benzylcoumarins with methyl, ethyl or propyl substitutions at the $\mathrm{C} 4$ position and $N, N$-dimethylcarbamoyloxyl or acetoxyl substitution at the $\mathrm{C} 7$ position. Compounds with other substituent groups at these positions showed less inhibition in this assay. 
Table 2. Inhibition of ERK pathway in AP-1 luciferase reporter assay.

\begin{tabular}{cccc}
\hline & $\mathbf{I C}_{\mathbf{5 0}}(\boldsymbol{\mu M})$ & & $\mathbf{I C}_{\mathbf{5 0}}(\boldsymbol{\mu M})$ \\
\hline $\mathrm{U} 0126$ & $27.50 \pm 1.16$ & $\mathbf{3 2}$ & $\mathrm{N} / \mathrm{A}$ \\
$\mathbf{1 3}$ & $5.40 \pm 1.26$ & $\mathbf{3 3}$ & $11.63 \pm 1.20$ \\
$\mathbf{1 4}$ & $30.80 \pm 1.40$ & $\mathbf{3 4}$ & $\mathrm{N} / \mathrm{A}$ \\
$\mathbf{1 5}$ & $\mathrm{N} / \mathrm{A}$ & $\mathbf{3 6}$ & $49.82 \pm 1.24$ \\
$\mathbf{1 7}$ & $4.06 \pm 3.26$ & $\mathbf{3 8}$ & $38.1 \pm 1.26$ \\
$\mathbf{1 8}$ & $23.37 \pm 1.11$ & $\mathbf{3 9}$ & $\mathrm{N} / \mathrm{A}$ \\
$\mathbf{1 9}$ & $4.31 \pm 2.14$ & $\mathbf{4 0}$ & $87.45 \pm 1.98$ \\
$\mathbf{2 0}$ & $\mathrm{N} / \mathrm{A}$ & $\mathbf{4 2}$ & $88.68 \pm 2.52$ \\
$\mathbf{2 8}$ & $37.56 \pm 1.10$ & $\mathbf{4 3}$ & $85.86 \pm 1.46$ \\
$\mathbf{2 9}$ & $90.49 \pm 1.83$ & $\mathbf{6 7}$ & $64.61 \pm 1.74$ \\
$\mathbf{3 1}$ & $15.70 \pm 1.18$ & & \\
\hline
\end{tabular}

\subsection{Inhibition of Virus Replication}

To further examine the functional effects, we selected EV71 to perform the antiviral analysis. It is established that inhibition of the ERK pathway with U0126 can suppress EV71 replication in HEK 293 and $\mathrm{RD}$ cells [10], so the antiviral activity of six compounds $(13,17,18,19,31,33)$ was determined by measuring the inhibition of virus-induced cytopathic effects in cells. $\mathrm{EC}_{50} \mathrm{~S}$ of inhibition of EV71 replication for the six compounds are summarized in Table $3 . \mathrm{CC}_{50}$ is the median cytotoxic concentration measured with the MTT assay. Therapeutic index (TI) was calculated as a comparison of a compound that caused the therapeutic effect $\left(\mathrm{EC}_{50}\right)$ to the amount that caused cytotoxicity $\left(\mathrm{CC}_{50}\right)$, whereby the higher the value of TI, the safer the compound was. The results in Table 3 showed four compounds but not $\mathbf{1 7}$ and $\mathbf{3 1}$ had inhibition effects on EV71 replication in both HEK293 and RD cells, but according to the values of TI, compounds $\mathbf{1 3}$ and $\mathbf{1 9}$ not only had a better anti-viral activity, but could also be used more safely. Examining the structures of compounds, all of them had benzyl or substituted benzyl at the $\mathrm{C} 3$ position, an alkyl group at the $\mathrm{C} 4$ position and $N, N$-dimethylcarbamoyloxyl or acetoxyl substitution at the $\mathrm{C} 7$ position, suggesting that these substituent groups were beneficial to the antiviral effects.

Table 3. Antiviral effects in HEK293 cells and RD cells.

\begin{tabular}{cccccccc}
\hline & \multicolumn{3}{c}{ HEK293 cells } & & \multicolumn{3}{c}{ RD cells } \\
\cline { 2 - 4 } \cline { 6 - 8 } & $\mathbf{E C}_{\mathbf{5 0}}(\boldsymbol{\mu M})$ & $\mathbf{C C}_{\mathbf{5 0}}(\boldsymbol{\mu M})$ & $\mathbf{T I}\left(\mathbf{C C}_{\mathbf{5 0}} / \mathbf{I C}_{\mathbf{5 0}}\right)$ & & $\mathbf{E C}_{\mathbf{5 0}}(\boldsymbol{\mu M})$ & $\mathbf{C C}_{\mathbf{5 0}}(\boldsymbol{\mu M})$ & $\mathbf{T I}\left(\mathbf{C C}_{\mathbf{5 0}} / \mathbf{I C}_{\mathbf{5 0}}\right)$ \\
\hline $\mathbf{1 3}$ & 3.29 & 98.22 & 29.85 & & 2.5 & 152 & 60.8 \\
$\mathbf{1 7}$ & $\mathrm{N} / \mathrm{A}$ & 42.38 & $\mathrm{~N} / \mathrm{A}$ & & 5.25 & 85.91 & 16.36 \\
$\mathbf{1 8}$ & 19.38 & 65.31 & 3.37 & & 10 & 72.92 & 7.29 \\
$\mathbf{1 9}$ & 4.85 & 316.43 & 65.24 & & 3.98 & 756.06 & 190 \\
$\mathbf{3 1}$ & $\mathrm{N} / \mathrm{A}$ & 119.3 & $\mathrm{~N} / \mathrm{A}$ & & $\mathrm{N} / \mathrm{A}$ & $\mathrm{N} / \mathrm{A}$ & $\mathrm{N} / \mathrm{A}$ \\
$\mathbf{3 3}$ & 12.77 & 27.88 & 2.18 & & 18.5 & 41.46 & 2.24 \\
\hline
\end{tabular}

For compounds 13, 19 and 33, we did further experiments by western blots which were processed as previously described [22] to verify their inhibition to ERK pathway and EV71 replication in RD cells (Figure 5). 
Figure 5. Verification of the inhibition to ERK pathway and EV71 replication in RD cells by western blots.

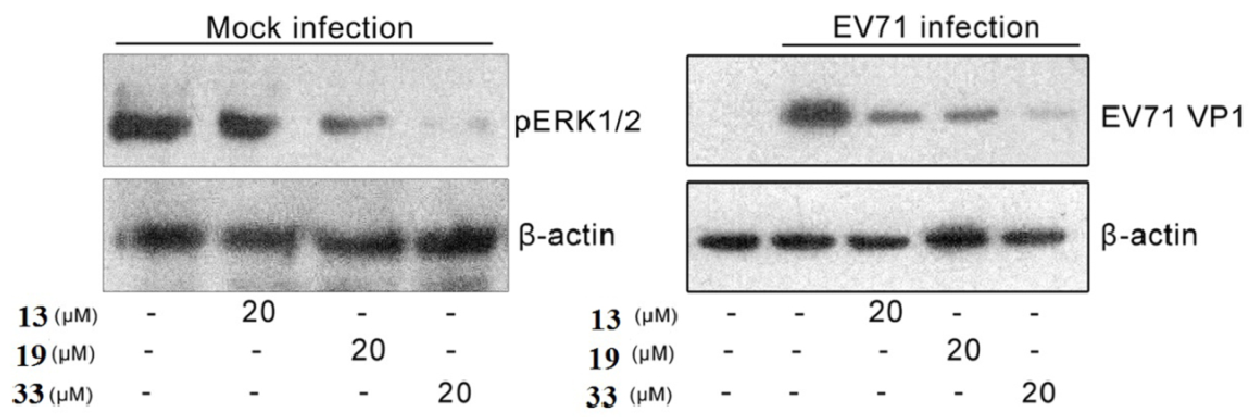

The results showed that the expression of pERK and virus capsid protein VP1 can be inhibited significantly and dramatically by compounds at $20 \mu \mathrm{M}$. These results intuitively verified the compound inhibition of the ERK pathway and EV71 replication in RD cells.

\section{Experimental}

\subsection{General Conditions}

All solvents and reagents were used as obtained. Melting points were taken with an XT4A apparatus and are uncorrected. ${ }^{1} \mathrm{H}-\mathrm{NMR}$ and ${ }^{13} \mathrm{C}$-NMR spectra were recorded at ambient temperature using a $400 \mathrm{MHz}$ Bruker Avance III spectrometer or $300 \mathrm{MHz}$ JEOL JNM-AL300 spectrometer. Chemical shifts are expressed in ppm relative to tetramethylsilane. MS data were obtained with Bruker Apex IV FTMS or MDS SCIEX QSTAR systems. TLC analysises were performed on silica gel GF254 purchased from Qingdao Haiyang Chemical Co. (Qingdao, China) or Merck (Darmstadt, Germany).

\subsection{Chemistry}

3.2.1. General Procedure for the Preparation of Ethyl 2-Benzylacylacetate or Ethyl 2-( $p$-Fluorobenzyl) Acylacetates 2a-f

$\mathrm{NaH}$ (1.2 equiv.) was added to a solution of ethyl acylacetate (1, 1.0 equiv.) in THF ( $3 \mathrm{~mL} / \mathrm{mmol}$ ethyl acylacetate) at $0{ }^{\circ} \mathrm{C}$ under a nitrogen atmosphere. The reaction mixture was stirred for 15 minutes and benzyl bromide or 4-fluorobenzyl bromide (1.1 equiv.) was added dropwise. The reaction mixture was then heated to $60{ }^{\circ} \mathrm{C}$ for $12 \mathrm{~h}$. The reaction mixture was poured into ice-cold saturated $\mathrm{NH}_{4} \mathrm{Cl}$ and extracted with EtOAc three times. The combined organic extract was washed with brine, dried over $\mathrm{MgSO}_{4}$ and the solvent was removed under reduced pressure. The products were purified by flash column chromatography.

Ethyl 2-benzyl-3-oxobutanoate (2a). Yield: $7.17 \mathrm{~g}, 65.1 \%$, yellow oil. ${ }^{1} \mathrm{H}-\mathrm{NMR}\left(300 \mathrm{MHz}, \mathrm{CDCl}_{3}\right): \delta$ $1.18\left(\mathrm{t}, J=7.1 \mathrm{~Hz}, 3 \mathrm{H}, \mathrm{CH}_{3}\right), 2.17\left(\mathrm{~s}, 3 \mathrm{H}, \mathrm{CH}_{3}\right), 3.15$ (d, $\left.J=7.5 \mathrm{~Hz}, 2 \mathrm{H}, \mathrm{PhCH}_{2}\right), 3.78$ (t, $J=7.5 \mathrm{~Hz}$, $1 \mathrm{H}, \mathrm{CH}), 4.13$ (q, $\left.J=7.2 \mathrm{~Hz}, 2 \mathrm{H}, \mathrm{C}_{2} \mathrm{CH}_{3}\right), 7.16-7.28(\mathrm{~m}, 5 \mathrm{H}, \mathrm{PhH})$.

Ethyl 2-benzyl-3-oxopentanoate (2b). Yield: 0.799 g, 68.11\%, colorless oil. ${ }^{1} \mathrm{H}-\mathrm{NMR}\left(\mathrm{CDCl}_{3}\right): \delta 1.00$ (t, $\left.J=7.2 \mathrm{~Hz}, 3 \mathrm{H}, \mathrm{COCH}_{2} \underline{\mathrm{CH}}_{3}\right), 1.19$ (t, $\left.J=7.2 \mathrm{~Hz}, 3 \mathrm{H}, \mathrm{OCH}_{2} \mathrm{C}_{3}\right), 1.49-1.59$ (m, $\left.1 \mathrm{H}, \mathrm{CH}_{2} \mathrm{Ph}\right), 2.53-2.60$ 
(m, $1 \mathrm{H}, \mathrm{CH}_{2} \mathrm{Ph}$ ), 3.16 (q, $\left.J=7.6 \mathrm{~Hz}, 2 \mathrm{H}, \mathrm{COCH}_{2} \mathrm{CH}_{3}\right), 3.76-3.81$ (dt, $J=2.4,5.2 \mathrm{~Hz}, 1 \mathrm{H}, \mathrm{CHCH}_{2} \mathrm{Ph}$ ), 4.13 (q, $\left.J=7.2 \mathrm{~Hz}, 2 \mathrm{H}, \mathrm{OC}_{2} \mathrm{CH}_{3}\right), 7.15-7.28$ (m, 5H, PhH). MS (ESI): $m / z 235.1\left(\mathrm{M}^{+} \mathrm{H}^{+}\right), 257.1$ $\left(\mathrm{M}+\mathrm{Na}^{+}\right), 273.1\left(\mathrm{M}+\mathrm{K}^{+}\right)$.

Ethyl 2-benzyl-3-oxohexanoate (2c). Yield: $0.949 \mathrm{~g}, 76.4 \%$, colorless oil. ${ }^{1} \mathrm{H}-\mathrm{NMR}\left(\mathrm{CDCl}_{3}\right): \delta 0.84(\mathrm{t}$, $J=7.2 \mathrm{~Hz}, 3 \mathrm{H}, \mathrm{CH}_{2} \mathrm{CH}_{2} \mathrm{CH}_{3}$ ), 1.19 (t, $J=7.2 \mathrm{~Hz}, 3 \mathrm{H}, \mathrm{OCH}_{2} \underline{\mathrm{CH}}_{3}$ ), 1.54 (sext, $J=7.2 \mathrm{~Hz}, 2 \mathrm{H}$, $\mathrm{CH}_{2} \underline{\mathrm{C}}_{2} \mathrm{CH}_{3}$ ), 2.27-2.35 (dt, $J=7.2 \mathrm{~Hz}, 1 \mathrm{H}, \mathrm{CH}_{2} \mathrm{Ph}$ ), 2.47-2.55 (dt, J=7.2 Hz, 1H, $\mathrm{CH}_{2} \mathrm{Ph}$ ), 3.15 (t, $\left.J=7.2 \mathrm{~Hz}, 2 \mathrm{H}, \mathrm{C}_{2} \mathrm{C}_{2} \mathrm{H}_{5}\right), 3.78\left(\mathrm{t}, J=7.6 \mathrm{~Hz}, 1 \mathrm{H}, \mathrm{CHCH}_{2} \mathrm{Ph}\right), 4.13$ (q, $J=7.2 \mathrm{~Hz}, 2 \mathrm{H}, \mathrm{OC}_{2} \mathrm{CH}_{3}$ ), 7.16-7.28 (m, 5H, PhH). MS (ESI): $m / z 249.1\left(\mathrm{M}+\mathrm{H}^{+}\right), 271.1\left(\mathrm{M}+\mathrm{Na}^{+}\right), 287.1\left(\mathrm{M}+\mathrm{K}^{+}\right)$.

Ethyl 2-(4-fluorobenzyl)-3-oxobutanoate (2d). Yield: $1.41 \mathrm{~g}, 59 \%$, yellow oil. ${ }^{1} \mathrm{H}-\mathrm{NMR}\left(\mathrm{CDCl}_{3}\right): \delta$ 1.21 (t, $J=7.2 \mathrm{~Hz}, 3 \mathrm{H}, \mathrm{CH}_{2} \underline{\mathrm{CH}}_{3}$ ), 2.19 (s, 3H, $\underline{\mathrm{C}}_{3} \mathrm{CO}$ ), 3.13 (dd, $J=1.2,7.2 \mathrm{~Hz}, 2 \mathrm{H}, \mathrm{CH}_{2} \mathrm{Ph}$ ), 3.73 (t, $J=7.6 \mathrm{~Hz}, 1 \mathrm{H}, \mathrm{CH}), 4.14\left(\mathrm{ddd}, J=1.2,7.2,11.6 \mathrm{~Hz}, 2 \mathrm{H}, \mathrm{C}_{2} \mathrm{CH}_{3}\right), 6.93-6.98(\mathrm{~m}, 2 \mathrm{H}, \mathrm{PhH}), 7.12-7.16$ (m, 2H, $\mathrm{PhH})$.

Ethyl 2-(4-fluorobenzyl)-3-oxopentanoate (2e). Yield: $0.52 \mathrm{~g}, 21 \%$, colorless oil. ${ }^{1} \mathrm{H}-\mathrm{NMR}\left(\mathrm{CDCl}_{3}\right): \delta$ 1.00 (t, $\left.J=7.2 \mathrm{~Hz}, 3 \mathrm{H}, \mathrm{CH}_{2} \mathrm{CH}_{3}\right), 1.20$ (t, $\left.J=7.2 \mathrm{~Hz}, 3 \mathrm{H}, \mathrm{OCH}_{2} \underline{\mathrm{C}}_{3}\right), 2.31-2.39$ (dt, $J=7.2 \mathrm{~Hz}, 1 \mathrm{H}$, $\mathrm{CH}_{2} \mathrm{Ph}$ ), 2.53-2.61 (dt, $\left.J=7.2 \mathrm{~Hz}, 1 \mathrm{H}, \mathrm{CH}_{2} \mathrm{Ph}\right), 3.12$ (q, $\left.J=4.8 \mathrm{~Hz}, 2 \mathrm{H}, \mathrm{C}_{2} \mathrm{CH}_{3}\right), 3.74$ (t, $J=7.6 \mathrm{~Hz}$, $\left.1 \mathrm{H}, \mathrm{CHCH}_{2} \mathrm{Ph}\right), 4.14\left(\mathrm{dd}, J=7.2 \mathrm{~Hz}, 2 \mathrm{H}, \mathrm{OC}_{2} \mathrm{CH}_{3}\right), 6.93-6.97(\mathrm{~m}, 2 \mathrm{H}, \mathrm{PhH}), 7.11-7.15(\mathrm{~m}, 2 \mathrm{H}$, $\mathrm{PhH})$. MS (ESI): $m / z 253.1\left(\mathrm{M}+\mathrm{H}^{+}\right), 275.1\left(\mathrm{M}+\mathrm{Na}^{+}\right), 291.1\left(\mathrm{M}+\mathrm{K}^{+}\right)$.

Ethyl 2-(4-fluorobenzyl)-3-oxohexanoate (2f). Yield: 2.086 g, 78.3\%, colorless oil. ${ }^{1} \mathrm{H}-\mathrm{NMR}\left(\mathrm{CDCl}_{3}\right)$ : $\delta 0.85\left(\mathrm{t}, J=7.2 \mathrm{~Hz}, 3 \mathrm{H}, \mathrm{CH}_{2} \mathrm{CH}_{2} \mathrm{C}_{3}\right), 1.21\left(\mathrm{t}, J=7.2 \mathrm{~Hz}, 3 \mathrm{H}, \mathrm{OCH}_{2} \underline{\mathrm{C}}_{3}\right), 1.55$ (sext, $J=7.2 \mathrm{~Hz}, 2 \mathrm{H}$, $\mathrm{CH}_{2} \mathrm{CH}_{2} \mathrm{CH}_{3}$ ), 2.28-2.36 (dt, $J=7.2 \mathrm{~Hz}, 1 \mathrm{H}, \mathrm{CH}_{2} \mathrm{Ph}$ ), 2.48-2.56 (dt, $J=7.2 \mathrm{~Hz}, 1 \mathrm{H}, \mathrm{CH}_{2} \mathrm{Ph}$ ), 3.07-3.17 $\left(\mathrm{m}, 2 \mathrm{H}, \underline{\mathrm{C}}_{2} \mathrm{C}_{2} \mathrm{H}_{5}\right), 3.73$ (t, $\left.J=7.6 \mathrm{~Hz}, 1 \mathrm{H}, \mathrm{C}_{\underline{H C H}} \mathrm{Ph}\right), 4.11-4.17$ (dd, $J=7.2 \mathrm{~Hz}, 2 \mathrm{H}, \mathrm{OC}_{2} \mathrm{CH}_{3}$ ), 6.93-6.97 (m, 2H, PhH), 7.11-7.15 (m, 2H, PhH). MS (ESI): $m / z 267.1\left(\mathrm{M}+\mathrm{H}^{+}\right), 289.1\left(\mathrm{M}^{+} \mathrm{Na}^{+}\right)$, $305.1\left(\mathrm{M}+\mathrm{K}^{+}\right)$.

\subsubsection{General Procedure for the Preparation of 7-Hydroxy-2H-chromen-2-one derivatives $\mathbf{4 b}-\mathbf{i}$}

The compounds 2 obtained above (1.0 equiv.) and resorcinol (1.0 equiv.) were suspended in 70\% sulfuric acid ( $2 \mathrm{~mL} / \mathrm{mmol}$ resorcinol) at room temperature. The reaction mixture was stirred for $12 \mathrm{~h}$ and poured into ice water and extracted with EtOAc three times. The combined organic extract was washed with brine, dried over $\mathrm{MgSO}_{4}$ and the solvent was removed under reduced pressure. The crude products were recrystalized from ethanol to afford the products.

3-Benzyl-7-hydroxy-4-methyl-2H-chromen-2-one (4b). Yield: 0.84 g, 63.2\%, yellow solid, m.p.: 228-230 ${ }^{\circ} \mathrm{C} .{ }^{1} \mathrm{H}-\mathrm{NMR}$ (DMSO-d6): $\delta 2.40\left(\mathrm{~s}, 3 \mathrm{H}, \mathrm{CH}_{3}\right), 3.93\left(\mathrm{~s}, 2 \mathrm{H}, \mathrm{CH}_{2}\right), 6.72(\mathrm{~d}, J=2.4 \mathrm{~Hz}, 1 \mathrm{H}$, $\mathrm{PhH}), 6.82(\mathrm{dd}, J=2.4,8.8 \mathrm{~Hz}, 1 \mathrm{H}, \mathrm{PhH}), 7.16-7.30$ (m, 5H, PhH), 7.64 (d, $J=8.8 \mathrm{~Hz}, 1 \mathrm{H}, \mathrm{PhH})$.

3-Benzyl-6-chloro-7-hydroxy-4-methyl-2H-chromen-2-one (4c). Yield: 0.652 g, 43.5\%, white powder, m.p.: $261-263{ }^{\circ} \mathrm{C} .{ }^{1} \mathrm{H}-\mathrm{NMR}$ (DMSO-d6): $\delta 2.40$ (s, 3H, $\mathrm{CH}_{3}$ ), 3.93 (s, 2H, $\mathrm{CH}_{2}$ ), 6.89 (s, 1H, $\mathrm{PhH}$ ), 7.15-7.28 (m, 5H, PhH), 7.79 (s, 1H, PhH), 11.26 (s, 1H, OH). 
3-Benzyl-4-ethyl-7-hydroxy-2H-chromen-2-one (4d). Yield: 0.251 g, 56.3\%, yellow solid, m.p.: 140-141 ${ }^{\circ} \mathrm{C} .{ }^{1} \mathrm{H}-\mathrm{NMR}$ (DMSO-d6): $\delta 1.02$ (t, $J=7.6 \mathrm{~Hz}, 3 \mathrm{H}, \mathrm{CH}_{3}$ ), 2.82 (q, $J=7.6 \mathrm{~Hz}, 2 \mathrm{H}, \mathrm{CH}_{2} \mathrm{CH}_{3}$ ), 3.91 (s, 2H, $\mathrm{CH}_{2} \mathrm{Ph}$ ), 6.72 (d, $\left.J=2.8 \mathrm{~Hz}, 1 \mathrm{H}, \mathrm{H}-8\right), 6.80-6.83$ (dd, $\left.J=2.4,8.8 \mathrm{~Hz}, 1 \mathrm{H}, \mathrm{H}-6\right), 7.17-7.29$

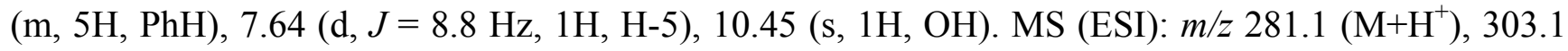
$\left(\mathrm{M}+\mathrm{Na}^{+}\right), 319.1\left(\mathrm{M}+\mathrm{K}^{+}\right)$.

3-Benzyl-7-hydroxy-4-propyl-2H-chromen-2-one (4e). Yield: 0.185 g, 46\%, white solid, m.p.: 139-140 ${ }^{\circ} \mathrm{C}$. ${ }^{1} \mathrm{H}-\mathrm{NMR}$ (DMSO-d6): $\delta 0.95\left(\mathrm{t}, J=7.2 \mathrm{~Hz}, 3 \mathrm{H}, \mathrm{CH}_{3}\right), 1.35-1.42\left(\mathrm{~m}, J=7.6 \mathrm{~Hz}, 2 \mathrm{H}, \mathrm{CH}_{2} \mathrm{C}_{2} \mathrm{CH}_{3}\right)$, $2.77\left(\mathrm{t}, J=8.0 \mathrm{~Hz}, 2 \mathrm{H}, \mathrm{CH}_{2} \mathrm{C}_{2} \mathrm{H}_{5}\right), 3.91$ (s, 2H, $\left.\mathrm{CH}_{2} \mathrm{Ph}\right), 6.71$ (d, $\left.J=2.4 \mathrm{~Hz}, 1 \mathrm{H}, \mathrm{H}-8\right), 6.80-6.83$ (dd, $J=2.0,8.8 \mathrm{~Hz}, 1 \mathrm{H}, \mathrm{H}-6), 7.15-7.28$ (m, 5H, PhH), 7.63 (d, $J=8.8 \mathrm{~Hz}, 1 \mathrm{H}, \mathrm{H}-5), 10.44$ (s, 1H, OH).

${ }^{13} \mathrm{C}-\mathrm{NMR}$ (DMSO- $d 6$ ): $\delta 14.57,22.82,30.77,32.33,102.60,111.89,113.54,120.11,126.48,127.13$, $128.35,128.83,140.22,152.80,154.37,160.84,162.10$. HRMS (ESI): $m / z 295.13330\left(\mathrm{M}^{+} \mathrm{H}^{+}\right)$, $317.11525\left(\mathrm{M}+\mathrm{Na}^{+}\right), 333.08918\left(\mathrm{M}+\mathrm{K}^{+}\right)$.

3-(4-Fluorobenzyl)-7-hydroxy-4-methyl-2H-chromen-2-one (4f). Yield: 0.762 g, 78\%, white powder, m.p.: $243-244{ }^{\circ} \mathrm{C} .{ }^{1} \mathrm{H}-\mathrm{NMR}$ (DMSO-d6): $\delta 2.40\left(\mathrm{~s}, 3 \mathrm{H}, \mathrm{CH}_{3}\right), 3.90\left(\mathrm{~s}, 2 \mathrm{H}, \mathrm{CH}_{2}\right), 6.71(\mathrm{~s}, 1 \mathrm{H}, \mathrm{PhH})$, $6.81(\mathrm{~d}, J=8.4 \mathrm{~Hz}, 1 \mathrm{H}, \mathrm{PhH}), 7.01-7.10(\mathrm{~m}, 2 \mathrm{H}, \mathrm{PhH}), 7.23-7.27$ (m, 2H, PhH), 7.63-7.66 (d, J=8.8 Hz, $1 \mathrm{H}, \mathrm{PhH}), 10.46(\mathrm{~s}, 1 \mathrm{H}, \mathrm{OH}) .{ }^{13} \mathrm{C}-\mathrm{NMR}\left(\mathrm{CDCl}_{3}\right): \delta 15.06,31.26,101.89,112.38,112.92,114.92$, $115.13,120.01,126.77,129.72,129.80,135.53,148.58,153.43,160.46,161.29,161.86$.

4-Ethyl-3-(4-fluorobenzyl)-7-hydroxy-2H-chromen-2-one (4g). Yield: 0.183 g, yield 31\%. M.p.: 131-132 ${ }^{\circ} \mathrm{C}$. Light yellow solid. ${ }^{1} \mathrm{H}-\mathrm{NMR}$ (DMSO- $\left.d 6\right): \delta 1.03\left(\mathrm{t}, J=7.6 \mathrm{~Hz}, 3 \mathrm{H}, \mathrm{CH}_{3}\right.$ ), 2.83 (q, $\left.J=7.6 \mathrm{~Hz}, 2 \mathrm{H}, \mathrm{C}_{2} \mathrm{CH}_{3}\right), 3.90$ (s, $\left.2 \mathrm{H}, \mathrm{CH}_{2} \mathrm{Ph}\right), 6.73$ (s, 1H, H-8), 6.82 (d, J=8.8 Hz, 1H, H-6), 7.09 $(\mathrm{t}, J=8.8 \mathrm{~Hz}, 2 \mathrm{H}, \mathrm{PhH}), 7.25$ (t, 2H, PhH), 7.65 (d, $J=8.8 \mathrm{~Hz}, 1 \mathrm{H}, \mathrm{H}-5), 10.47(\mathrm{~s}, 1 \mathrm{H}, \mathrm{OH}) .{ }^{13} \mathrm{C}-\mathrm{NMR}$ (DMSO-d6): $\delta 13.47,21.52,30.87,102.18,111.01,113.11,114.91,115.12,119.12,126.55,129.62$, $129.70,135.76,153.85,153.99,159.45,160.41,161.61$. HRMS (ESI): $m / z 299.10780\left(\mathrm{M}^{+} \mathrm{H}^{+}\right)$, $321.09033\left(\mathrm{M}+\mathrm{Na}^{+}\right), 337.06455\left(\mathrm{M}+\mathrm{K}^{+}\right)$.

3-(4-Fluorobenzyl)-7-hydroxy-4-propyl-2H-chromen-2-one (4h). Yield: 0.631 g, 67.4\%, white solid, m.p.: $130-131{ }^{\circ} \mathrm{C} .{ }^{1} \mathrm{H}-\mathrm{NMR}\left(\mathrm{CDCl}_{3}\right): \delta 1.04$ (t, $\left.J=7.2 \mathrm{~Hz}, 3 \mathrm{H}, \mathrm{CH}_{2} \mathrm{CH}_{2} \mathrm{C}_{3}\right), 1.52$ (sext, $J=7.2 \mathrm{~Hz}, 2 \mathrm{H}$, $\mathrm{CH}_{2} \underline{\mathrm{C}}_{2} \mathrm{CH}_{3}$ ), 2.75-2.90 (t, $J=8.0 \mathrm{~Hz}, 2 \mathrm{H}, \mathrm{C}_{2} \mathrm{C}_{2} \mathrm{H}_{5}$ ), 3.97 (s, $2 \mathrm{H}, \mathrm{CH}_{2} \mathrm{Ph}$ ), 6.80-6.83 (dd, $J=2.4$, $8.8 \mathrm{~Hz}, 1 \mathrm{H}, \mathrm{H}-6), 6.92-7.00$ (m, 3H, PhH, H-8), 7.19-7.23 (m, 2H, PhH), 7.48 (d, J=8.8 Hz, 1H, H-5). MS (ESI): $m / z 313.1\left(\mathrm{M}+\mathrm{H}^{+}\right), 335.1\left(\mathrm{M}+\mathrm{Na}^{+}\right), 351.1\left(\mathrm{M}+\mathrm{K}^{+}\right)$.

4-(Chloromethyl)-7-hydroxy-2H-chromen-2-one (4i). Yield: 1.518 g, 72\%, grey solid, m.p.: $166-167{ }^{\circ} \mathrm{C}$. ${ }^{1} \mathrm{H}-\mathrm{NMR}$ (DMSO-d6): $\delta 4.96$ (s, 2H, $\underline{\mathrm{C}}_{2}$ ), 6.42 (s, 1H, H-3), 6.76 (s, 1H, H-8), 6.85 (d, $J=8.8 \mathrm{~Hz}, 1 \mathrm{H}$, $\mathrm{H}-6), 7.68$ (d, $J=8.8 \mathrm{~Hz}, 1 \mathrm{H}, \mathrm{H}-5), 10.66$ (s, 1H, O$) .{ }^{13} \mathrm{C}-\mathrm{NMR}$ (DMSO-d6): $\delta$ 41.33, 102.49, $109.32,111.03,113.05,126.52,150.95,155.27,160.11,161.43$. HRMS (ESI): $\mathrm{m} / z 211.01561$ $\left(\mathrm{M}+\mathrm{H}^{+}\right), 232.99758\left(\mathrm{M}+\mathrm{Na}^{+}\right)$.

\subsubsection{Procedure for the Preparation of 7-Hydroxy-4-(hydroxymethyl)-2H-chromen-2-one (4j)}

Compound 4i (1 mmol, $0.21 \mathrm{~g})$ was suspended in water $(20 \mathrm{~mL})$ and refluxed for four days. After extraction with EtOAc three times the organic extracts were combined, washed with brine and dried 
over $\mathrm{MgSO}_{4}$. The products were purified by flash column chromatography to afford a yellow solid. Yield: $78 \mathrm{mg}$, yield 41\%, m.p.: $148-149{ }^{\circ} \mathrm{C} .{ }^{1} \mathrm{H}-\mathrm{NMR}$ (DMSO-d6): $\delta 4.71$ (s, 2H, $\underline{\mathrm{C}}_{2}$ ), 5.59 (br s, $1 \mathrm{H}$, ArOH), 6.24 (s, 1H, H-3), 6.73 (s, 1H, H-8), 6.78 (d, $J=8.4$ Hz, 1H, H-6), 7.53 (d, $J=8.4$ Hz, 1H, H-5), $10.52\left(\mathrm{~s}, 1 \mathrm{H}, \mathrm{CH}_{2} \mathrm{OH}\right) .{ }^{13} \mathrm{C}-\mathrm{NMR}$ (DMSO-d6): $\delta 59.04,102.26,106.51,109.53,112.79,125.45$, 154.83, 156.77, 160.60, 160.95. HRMS (ESI): $m / z 193.04956\left(\mathrm{M}+\mathrm{H}^{+}\right), 215.03145\left(\mathrm{M}+\mathrm{Na}^{+}\right), 231.00538$ $\left(\mathrm{M}+\mathrm{K}^{+}\right)$.

\subsubsection{Procedure for the Preparation of 3-benzyl-7- $N, N$-Dimethylcarbamate- $2 H$-chromen-2-one (12)}

To the solution of ethyl-3-phenylpropionate (3, $0.98 \mathrm{~g}, 5.5 \mathrm{mmol}, 1$ equiv.,) in DMF (4 mL), was added $\mathrm{NaH}$ ( $0.25 \mathrm{~g}, 8.25 \mathrm{mmol}, 1.5$ equiv. $)$ at $0{ }^{\circ} \mathrm{C}$ under a nitrogen atmosphere. The reaction mixture was stirred for $1 \mathrm{~h}$ and ethyl formate $(0.68 \mathrm{~mL}, 8.25 \mathrm{mmol}, 1.5$ equiv. $)$ was added. The reaction mixture was stirred for another hour at $0{ }^{\circ} \mathrm{C}$ and then $24 \mathrm{~h}$ at r.t. Then the $\mathrm{pH}$ was adjusted to $2-3$ with $3 \mathrm{M} \mathrm{HCl}$, followed by routine workup. Purification of the residue by flash column chromatography $(\mathrm{PE}-\mathrm{EA}=30: 1)$ afforded 2-formoxylethyl-3-phenylpropionate (2g) as a yellow oil (0.718 g, 63.3\%).

Compound $2 \mathrm{~g}$ (0.206 g, $1 \mathrm{mmol}, 1$ equiv.) and resorcinol (0.110 g, $1 \mathrm{mmol}, 1$ equiv.) were suspended in $70 \%$ sulfuric acid $(4 \mathrm{~mL})$, and heated at $100{ }^{\circ} \mathrm{C}$ for $1 \mathrm{~h}$. The mixture was processed by routine procedures. Purification of the residue by flash column chromatography (PE-EA $=5: 1$ ) afforded 3-benzyl-7-hydroxylcoumarin (4a) as a thick white solid (0.074 g, 29.2\%).

To the solution of compound $4 \mathbf{a}(0.25 \mathrm{~g}, 1 \mathrm{mmol}, 1$ equiv. $)$ in DMF $(12 \mathrm{~mL})$ was added $\mathrm{NaH}(0.045 \mathrm{~g}$, $1.5 \mathrm{mmol}, 1.5$ equiv.) at room temperature under a nitrogen atmosphere. The reaction mixture was stirred for $1 \mathrm{~h}$ and dimethycarbamoyl chloride $(0.14 \mathrm{~mL}, 1.5 \mathrm{mmol}, 1.5$ equiv.) was added. The reaction mixture was stirred for another $4 \mathrm{~h}$. The mixture was processed by routine procedures, then the crude product was recrystallised from ethanol as a white solid $(0.063 \mathrm{~g}, 19.5 \%)$, m.p.: $151-153{ }^{\circ} \mathrm{C}$. ${ }^{1} \mathrm{H}-\mathrm{NMR}\left(\mathrm{CDCl}_{3}\right): \delta 3.02\left(\mathrm{~s}, 3 \mathrm{H}, \mathrm{NCH}_{3}\right), 3.11\left(\mathrm{~s}, 3 \mathrm{H}, \mathrm{NCH}_{3}\right), 3.88\left(\mathrm{~s}, 2 \mathrm{H}, \mathrm{CH}_{2}\right), 7.01-7.04(\mathrm{dd}, J=2$, 8.4 Hz, 1H, PhH), 7.10 (d, $J=6 \mathrm{~Hz}, 1 \mathrm{H}, \mathrm{PhH}), 7.24-7.37$ (m, 7H, PhH). HRMS (ESI): $m / z$ 324.12341 $\left(\mathrm{M}+\mathrm{H}^{+}\right), 346.10524\left(\mathrm{M}+\mathrm{Na}^{+}\right)$.

\subsubsection{General Procedure for the Preparation of 7-Carboxylate- $2 H$-chromen-2-one derivatives 13-82 [24]}

To the solution of the 7-hydroxycoumarin derivatives 4 obtained above (1.0 equiv.) in DMF ( $5.5 \mathrm{~mL} / \mathrm{mmol})$ was added $\mathrm{NaH}$ (2.0 equiv.) at room temperature under a nitrogen atmosphere. The reaction mixture was stirred for 30 minutes and acylchloride (2.0 equiv.) was added. The reaction mixture was stirred for another hour and poured into saturated $\mathrm{NaHCO}_{3}$. After extraction with EtOAc three times the organic extract was combined washed with brine and dried over $\mathrm{MgSO}_{4}$. The products were purified by flash column chromatography.

3-Benzyl-4-methyl-2-oxo-2H-chromen-7-yl dimethylcarbamate (13). Yield: 0.44 g, 86.8\%, white solid, m.p.: $130-133{ }^{\circ} \mathrm{C} .{ }^{1} \mathrm{H}-\mathrm{NMR}\left(\mathrm{CDCl}_{3}\right): \delta 2.43\left(\mathrm{~s}, 3 \mathrm{H}, \mathrm{CH}_{3}\right), 3.03\left(\mathrm{~s}, 3 \mathrm{H}, \mathrm{NCH}_{3}\right), 3.12\left(\mathrm{~s}, 3 \mathrm{H}, \mathrm{NCH}_{3}\right)$, $4.06\left(\mathrm{~s}, 2 \mathrm{H}, \mathrm{CH}_{2}\right), 7.08-7.29(\mathrm{~m}, 5 \mathrm{H}, \mathrm{PhH}), 7.58(\mathrm{~d}, J=8.8 \mathrm{~Hz}, 1 \mathrm{H}, \mathrm{PhH}) .{ }^{13} \mathrm{C}-\mathrm{NMR}\left(\mathrm{CDCl}_{3}\right): \delta 15.48$, $32.95,36.56,36.82,110.10,117.88,118.22,124.38,125.15,126.34,128.26,128.57,138.82,147.13$, 152.91, 153.41, 153.99, 161.79. HRMS (ESI): $m / z 338.13939\left(\mathrm{M}+\mathrm{H}^{+}\right)$. 
3-Benzyl-6-chloro-4-methyl-2-oxo-2H-chromen-7-yl dimethylcarbamate (14). Yield: $0.193 \mathrm{~g}, 52 \%$, white solid, m.p.: $156-157{ }^{\circ} \mathrm{C} .{ }^{1} \mathrm{H}-\mathrm{NMR}\left(\mathrm{CDCl}_{3}\right): \delta 2.42\left(\mathrm{~s}, 3 \mathrm{H}, \mathrm{CH}_{3}\right), 3.05\left(\mathrm{~s}, 3 \mathrm{H}, \mathrm{NCH}_{3}\right), 3.17$ (s, $\left.3 \mathrm{H}, \mathrm{NCH}_{3}\right), 4.06\left(\mathrm{~s}, 2 \mathrm{H}, \mathrm{CH}_{2}\right), 7.19-7.29(\mathrm{~m}, 6 \mathrm{H}, \mathrm{PhH}), 7.64(\mathrm{~s}, 1 \mathrm{H}, \mathrm{PhH}) .{ }^{13} \mathrm{C}-\mathrm{NMR}\left(\mathrm{CDCl}_{3}\right): \delta$ 15.53, 33.04, 36.64, 36.98, 112.58, 119.13, 123.18, 125.36, 125.64, 126.47, 128.24, 128.64, 138.44, 146.02, 149.19, 151.16, 152.99, 161.22. HRMS (ESI): $m / z 372.10060\left(\mathrm{M}+\mathrm{H}^{+}\right)$.

3-Benzyl-4-ethyl-2-oxo-2H-chromen-7-yl dimethylcarbamate (15). Yield: $0.147 \mathrm{~g}, 94.6 \%$, white solid, m.p.: 85-86 ${ }^{\circ} \mathrm{C} .{ }^{1} \mathrm{H}-\mathrm{NMR}\left(\mathrm{CDCl}_{3}\right): \delta 1.14\left(\mathrm{t}, J=7.6 \mathrm{~Hz}, 3 \mathrm{H}, \mathrm{CH}_{3}\right), 2.86\left(\mathrm{q}, J=7.6 \mathrm{~Hz}, 2 \mathrm{H}, \mathrm{CH}_{2} \mathrm{CH}_{3}\right)$, 3.03 (s, 3H, NCH 3$), 3.12$ (s, 3H, $\left.\mathrm{NCH}_{3}\right), 4.04$ (s, 2H, $\left.\mathrm{CH}_{2} \mathrm{Ph}\right), 7.08$ (d, J=2.4 Hz, 1H, H-8), 7.11-7.13 $(\mathrm{dd}, J=2.4,7.6 \mathrm{~Hz}, 1 \mathrm{H}, \mathrm{H}-6), 7.17-7.27(\mathrm{~m}, 5 \mathrm{H}, \mathrm{ArH}), 7.60(\mathrm{~d}, J=8.8 \mathrm{~Hz}, 1 \mathrm{H}, \mathrm{H}-5) .{ }^{13} \mathrm{C}-\mathrm{NMR}$ $\left(\mathrm{CDCl}_{3}\right): \delta 13.20,22.27,32.54,36.56,36.82,110.38,116.66,118.28,123.42,125.12,126.33,128.19$,

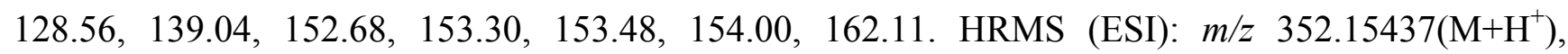
$374.13662\left(\mathrm{M}+\mathrm{Na}^{+}\right)$.

3-Benzyl-2-oxo-4-propyl-2H-chromen-7-yl dimethylcarbamate (16). Yield: $0.44 \mathrm{~g}, 86.8 \%$, white solid, m.p.: $117-118{ }^{\circ} \mathrm{C} .{ }^{1} \mathrm{H}-\mathrm{NMR}$ (DMSO-d6): $\delta 0.97$ (t, $J=7.2 \mathrm{~Hz}, 3 \mathrm{H}, \mathrm{CH}_{2} \mathrm{CH}_{2} \mathrm{C}_{3}$ ), $1.38-1.45$ (m, $\left.J=7.6 \mathrm{~Hz}, 2 \mathrm{H}, \mathrm{CH}_{2} \mathrm{C}_{2} \mathrm{CH}_{3}\right), 2.84\left(\mathrm{t}, J=8.0 \mathrm{~Hz}, 2 \mathrm{H}, \mathrm{C}_{2} \mathrm{C}_{2} \mathrm{H}_{5}\right), 2.93\left(\mathrm{~s}, 3 \mathrm{H}, \mathrm{NCH}_{3}\right), 3.06(\mathrm{~s}, 3 \mathrm{H}$, $\mathrm{NCH}_{3}$ ), 3.97 (s, 2H, CH $\left.2 \mathrm{Ph}\right), 7.15-7.27(\mathrm{~m}, 7 \mathrm{H}, \mathrm{ArH}), 7.83(\mathrm{~d}, J=8.8 \mathrm{~Hz}, 1 \mathrm{H}, \mathrm{H}-5) .{ }^{13} \mathrm{C}-\mathrm{NMR}$ $\left(\mathrm{CDCl}_{3}\right): \delta 14.46,22.46,31.15,32.73,36.56,36.82,110.33,116.99,118.21,123.80,125.22,126.34$,

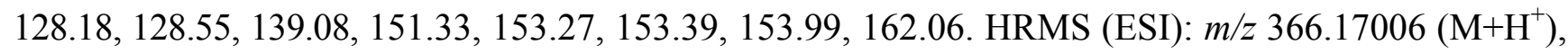
$388.15222\left(\mathrm{M}+\mathrm{Na}^{+}\right)$.

3-(4-Fluorobenzyl)-4-methyl-2-oxo-2H-chromen-7-yl dimethylcarbamate (17). Yield: $0.173 \mathrm{~g}, 65.3 \%$, white powder, m.p.: $149-150{ }^{\circ} \mathrm{C} .{ }^{1} \mathrm{H}-\mathrm{NMR}\left(\mathrm{CDCl}_{3}\right): \delta 2.44\left(\mathrm{~s}, 3 \mathrm{H}, \mathrm{CH}_{3}\right), 3.03\left(\mathrm{~s}, 3 \mathrm{H}, \mathrm{NCH}_{3}\right), 3.12$ (s, $\left.3 \mathrm{H}, \mathrm{NCH}_{3}\right), 4.02\left(\mathrm{~s}, 2 \mathrm{H}, \mathrm{CH}_{2}\right), 6.93-6.97$ (m, 2H, PhH), 7.09-7.11 (m, 2H, PhH), 7.20-7.23 (m, 2H, $\mathrm{PhH}), 7.59(\mathrm{~d}, J=8.6 \mathrm{~Hz}, 1 \mathrm{H}, \mathrm{PhH}) .{ }^{13} \mathrm{C}-\mathrm{NMR}\left(\mathrm{CDCl}_{3}\right): \delta 15.44,32.20,36.56,36.82,110.15,115.24$, $115.45,117.78,118.30,124.25,125.19,129.65,129.73,134.42,134.45,147.11,152.91,153.50$, 153.96, 160.32, 161.71, 162.74. HRMS (ESI): $m / z 356.12960\left(\mathrm{M}+\mathrm{H}^{+}\right)$.

4-Ethyl-3-(4-fluorobenzyl)-2-oxo-2H-chromen-7-yl dimethylcarbamate (18). Yield: $0.090 \mathrm{~g}$, yield 68\%. M.p.: $75{ }^{\circ} \mathrm{C}$. White solid. ${ }^{1} \mathrm{H}-\mathrm{NMR}\left(\mathrm{CDCl}_{3}\right): \delta 1.14\left(\mathrm{t}, J=7.6 \mathrm{~Hz}, 3 \mathrm{H}, \mathrm{CH}_{3}\right), 2.85$ (q, $J=7.6 \mathrm{~Hz}$, $\left.2 \mathrm{H}, \mathrm{C}_{2} \mathrm{CH}_{3}\right), 3.02\left(\mathrm{~s}, 3 \mathrm{H}, \mathrm{NCH}_{3}\right), 3.12\left(\mathrm{~s}, 3 \mathrm{H}, \mathrm{NCH}_{3}\right), 3.99\left(\mathrm{~s}, 2 \mathrm{H}, \mathrm{CH}_{2} \mathrm{Ph}\right), 6.94(\mathrm{t}, J=8.0 \mathrm{~Hz}, 2 \mathrm{H}$, $\mathrm{PhH}$ ), 7.09-7.14 (m, 2H, H-6, H-8), 7.20-7.23 (m, J=6.4 Hz, 2H, PhH), 7.60 (d, J=8.8 Hz, 1H, H-5). ${ }^{13} \mathrm{C}-\mathrm{NMR}\left(\mathrm{CDCl}_{3}\right): \delta 13.28,22.25,31.77,36.54,36.79,110.37,115.17,115.39,116.51,118.38$, 123.16, 125.23, 129.60, 129.68, 134.72, 152.83, 153.40, 153.96, 160.27, 162.04, 162.70. HRMS (ESI): $\mathrm{m} / \mathrm{z} 370.14511\left(\mathrm{M}+\mathrm{H}^{+}\right), 392.12716\left(\mathrm{M}+\mathrm{Na}^{+}\right)$.

3-(4-Fluorobenzyl)-2-oxo-4-propyl-2H-chromen-7-yl dimethylcarbamate (19). Yield: $0.175 \mathrm{~g}, 91.6 \%$, white solid, m.p.: $82-84{ }^{\circ} \mathrm{C} .{ }^{1} \mathrm{H}-\mathrm{NMR}\left(\mathrm{CDCl}_{3}\right): \delta 1.03\left(\mathrm{t}, J=7.6 \mathrm{~Hz}, 3 \mathrm{H}, \mathrm{CH}_{2} \mathrm{CH}_{2} \mathrm{CH}_{3}\right.$ ), 1.52 (sext, $\left.J=7.6 \mathrm{~Hz}, 2 \mathrm{H}, \mathrm{CH}_{2} \mathrm{C}_{2} \mathrm{CH}_{3}\right), 2.80\left(\mathrm{t}, J=7.6 \mathrm{~Hz}, 2 \mathrm{H}, \mathrm{C}_{2} \mathrm{C}_{2} \mathrm{H}_{5}\right), 3.03\left(\mathrm{~s}, 3 \mathrm{H}, \mathrm{NCH}_{3}\right), 3.12(\mathrm{~s}, 3 \mathrm{H}$, $\mathrm{NCH}_{3}$ ), 3.99 (s, 2H, $\left.\mathrm{CH}_{2} \mathrm{Ph}\right), 6.92-6.97$ (m, 2H, ArH), 7.08-7.13 (m, 2H, ArH), 7.19-7.23 (m, 2H, $\mathrm{ArH}), 7.58$ (d, $J=8.8 \mathrm{~Hz}, 1 \mathrm{H}, \mathrm{H}-5) .{ }^{13} \mathrm{C}-\mathrm{NMR}\left(\mathrm{CDCl}_{3}\right): \delta 14.45,22.52,31.12,31.97,36.55,36.81$, 
$110.35,115.19,115.40,116.86,118.32,123.58,125.31,129.57,129.65,134.72,151.43,153.36$, 153.96, 160.30, 161.99, 162.73. HRMS (ESI): $m / z 384.16069\left(\mathrm{M}+\mathrm{H}^{+}\right), 406.14275\left(\mathrm{M}+\mathrm{Na}^{+}\right)$.

3-Benzyl-4-methyl-2-oxo-2H-chromen-7-yl diethylcarbamate (20). Yield: $0.05 \mathrm{~g}, 27 \%$, white solid, m.p.: $109^{\circ} \mathrm{C} .{ }^{1} \mathrm{H}-\mathrm{NMR}\left(\mathrm{CDCl}_{3}\right): \delta 1.20-1.29\left(\mathrm{dt}, J=6.8 \mathrm{~Hz}, 6 \mathrm{H}, \mathrm{CH}_{2} \underline{\mathrm{C}}_{3}\right), 2.44$ (s, 3H, $\left.\underline{\mathrm{CH}}_{3}\right), 3.39-3.46$ (m, $\left.J=6.8 \mathrm{~Hz}, 4 \mathrm{H}, \mathrm{C}_{2} \mathrm{CH}_{3}\right), 4.06$ (s, 2H, $\left.\underline{\mathrm{H}}_{2} \mathrm{Ph}\right), 7.09-7.12$ (m, 2H, ArH), 7.19-7.26 (m, 5H, ArH), $7.59(\mathrm{~d}, J=8.4 \mathrm{~Hz}, 1 \mathrm{H}, \mathrm{ArH}) .{ }^{13} \mathrm{C}-\mathrm{NMR}\left(\mathrm{CDCl}_{3}\right): \delta 13.33,14.26,15.50,32.96,42.01,42.40,110.05$, $117.78,118.22,124.30,125.12,126.34,128.27,128.58,138.84,147.16,152.93,153.33,153.48$, 161.82. HRMS (ESI): $m / z 366.16971\left(\mathrm{M}+\mathrm{H}^{+}\right), 388.15157\left(\mathrm{M}+\mathrm{Na}^{+}\right), 404.12558\left(\mathrm{M}+\mathrm{K}^{+}\right)$.

3-Benzyl-6-chloro-4-methyl-2-oxo-2H-chromen-7-yl diethylcarbamate (21). Yield: $0.069 \mathrm{~g}, 58 \%$, white solid, m.p.: $83-84{ }^{\circ} \mathrm{C} .{ }^{1} \mathrm{H}-\mathrm{NMR}\left(\mathrm{CDCl}_{3}\right): \delta 1.21-1.32\left(\mathrm{dt}, J=6.4 \mathrm{~Hz}, 6 \mathrm{H}, \mathrm{CH}_{2} \mathrm{CH}_{3}\right), 2.41(\mathrm{~s}, 3 \mathrm{H}$, $\mathrm{C}_{3}$ ), 3.39-3.51 (m, $\left.J=6.8 \mathrm{~Hz}, 4 \mathrm{H}, \mathrm{C}_{2} \mathrm{CH}_{3}\right), 4.05$ (s, 2H, $\left.\underline{\mathrm{CH}}_{2} \mathrm{Ph}\right), 7.18-7.27$ (m, 6H, ArH), 7.64 (s, $1 \mathrm{H}, \mathrm{H}-5) .{ }^{13} \mathrm{C}-\mathrm{NMR}\left(\mathrm{CDCl}_{3}\right): \delta 13.27,14.15,15.53,33.05,42.21,42.59,112.54,119.01,123.30$, $125.38,125.55,126.47,128.25,128.64,138.48,146.07,149.28,151.16,152.34,161.25$. HRMS (ESI): $m / z 400.13113\left(\mathrm{M}+\mathrm{H}^{+}\right), 422.11302\left(\mathrm{M}+\mathrm{Na}^{+}\right), 438.08702\left(\mathrm{M}+\mathrm{K}^{+}\right)$.

3-Benzyl-4-ethyl-2-oxo-2H-chromen-7-yl diethylcarbamate (22). Yield: $0.118 \mathrm{~g}, 62.4 \%$, milk white solid, m.p.: $64-65{ }^{\circ} \mathrm{C} .{ }^{1} \mathrm{H}-\mathrm{NMR}\left(\mathrm{CDCl}_{3}\right): \delta 1.15$ (t, $\left.J=7.6 \mathrm{~Hz}, 3 \mathrm{H}, \underline{\mathrm{C}}_{3}\right), 1.21-1.29$ (dt, $J=6.8 \mathrm{~Hz}$, $\left.6 \mathrm{H}, \mathrm{N}\left(\mathrm{CH}_{2} \mathrm{CH}_{3}\right)_{2}\right), 2.87$ (q, $\left.J=7.6 \mathrm{~Hz}, 2 \mathrm{H}, \underline{\mathrm{C}}_{2} \mathrm{CH}_{3}\right), 3.38-3.49$ (m, $\left.J=6.8 \mathrm{~Hz}, 4 \mathrm{H}, \mathrm{N}\left(\mathrm{CH}_{2} \mathrm{CH}_{3}\right)_{2}\right)$, 4.05 (s, 2H, $\left.\underline{\mathrm{C}}_{2} \mathrm{Ph}\right), 7.11-7.13(\mathrm{~m}, 2 \mathrm{H}, \mathrm{H}-6$ and $\mathrm{H}-8), 7.20-7.30\left(\mathrm{~m}, 5 \mathrm{H}, \mathrm{CH}_{2} \mathrm{Ph}\right), 7.61(\mathrm{~d}, J=8.4 \mathrm{~Hz}$, 1H, H-5). ${ }^{13} \mathrm{C}-\mathrm{NMR}\left(\mathrm{CDCl}_{3}\right): \delta 13.26,13.35,14.30,22.30,32.54,42.06,43.43,110.33,116.54$, $118.34,123.28,125.17,126.34,128.20,128.57,139.08,152.81,153.37,153.45,162.17$. HRMS (ESI): $m / z 380.18545\left(\mathrm{M}+\mathrm{H}^{+}\right), 402.16736\left(\mathrm{M}+\mathrm{Na}^{+}\right), 418.14141\left(\mathrm{M}+\mathrm{K}^{+}\right)$.

3-Benzyl-2-oxo-4-propyl-2H-chromen-7-yl diethylcarbamate (23). Yield: 0.099 g, 50\%, white solid, m.p.: $112-113{ }^{\circ} \mathrm{C} .{ }^{1} \mathrm{H}-\mathrm{NMR}\left(\mathrm{CDCl}_{3}\right): \delta 1.02\left(3 \mathrm{H}, \mathrm{CH}_{2} \mathrm{CH}_{2} \mathrm{CH}_{3}\right), 1.21-1.23\left(6 \mathrm{H}, \mathrm{CH}_{2} \mathrm{CH}_{3}\right), 1.50(2 \mathrm{H}$, $\left.\mathrm{CH}_{2} \underline{\mathrm{C}}_{2} \mathrm{CH}_{3}\right), 2.79\left(2 \mathrm{H}, \mathrm{CH}_{2} \mathrm{CH}_{2} \mathrm{CH}_{3}\right), 3.41\left(4 \mathrm{H}, \underline{\mathrm{CH}}_{2} \mathrm{CH}_{3}\right), 4.03$ (s, 2H, $\left.\underline{\mathrm{C}}_{2} \mathrm{Ph}\right), 7.08-7.24$ (m, 7H, $\mathrm{ArH}), 7.56(\mathrm{~d}, J=7.2 \mathrm{~Hz}, 1 \mathrm{H}, \mathrm{ArH}) .{ }^{13} \mathrm{C}-\mathrm{NMR}\left(\mathrm{CDCl}_{3}\right): \delta 18.30,19.25,19.42,27.45,36.11,37.73$, 47.04, 47.42, 115.22, 121.85, 123.17, 128.71, 130.20, 131.31, 133.18, 133.52, 144.13, 156.34, 158.30, 158.39, 167.03. HRMS (ESI): $m / z$ 394.20179 $\left(\mathrm{M}+\mathrm{H}^{+}\right), 416.18395\left(\mathrm{M}+\mathrm{Na}^{+}\right), 432.15778\left(\mathrm{M}+\mathrm{K}^{+}\right)$.

3-(4-Fluorobenzyl)-4-methyl-2-oxo-2H-chromen-7-yl diethylcarbamate (24). Yield: $0.02 \mathrm{~g}, 10 \%$, white solid, m.p.: $101-102{ }^{\circ} \mathrm{C} .{ }^{1} \mathrm{H}-\mathrm{NMR}\left(\mathrm{CDCl}_{3}\right): \delta 1.22-1.27\left(\mathrm{~m}, 6 \mathrm{H}, \mathrm{CH}_{2} \mathrm{CH}_{3}\right), 2.44$ (s, 3H, $\left.\underline{\mathrm{C}}_{3}\right), 3.39-3.45$ (m, 4H, $\underline{\mathrm{C}}_{2} \mathrm{CH}_{3}$ ), 4.02 (s, 2H, $\left.\underline{\mathrm{H}}_{2} \mathrm{Ph}\right), 6.95$ (t, $\left.J=8.0 \mathrm{~Hz}, 2 \mathrm{H}, \mathrm{ArH}\right), 7.10-7.12$ (m, 2H, H-6 and $\mathrm{H}-8), 7.22(\mathrm{~m}, 2 \mathrm{H}, \mathrm{ArH}), 7.60(\mathrm{~d}, J=8.0 \mathrm{~Hz}, 1 \mathrm{H}, \mathrm{H}-5) .{ }^{13} \mathrm{C}-\mathrm{NMR}\left(\mathrm{CDCl}_{3}\right): \delta 13.33,14.27,15.48$, $32.20,42.03,42.42,110.09,115.24,115.45,117.67,118.32,124.15,125.18,129.66,129.74,134.48$, $147.18,152.91,153.30,153.57,160.30,161.75,162.73$. HRMS (ESI): $m / z 384.16108\left(\mathrm{M}^{+} \mathrm{H}^{+}\right)$, $406.14280\left(\mathrm{M}+\mathrm{Na}^{+}\right), 422.11691\left(\mathrm{M}+\mathrm{K}^{+}\right)$.

4-Ethyl-3-(4-fluorobenzyl)-2-oxo-2H-chromen-7-yl diethylcarbamate (25). Yield: $0.125 \mathrm{~g}, 63 \%$, white solid, m.p.: $74-75{ }^{\circ} \mathrm{C} .{ }^{1} \mathrm{H}-\mathrm{NMR}\left(\mathrm{CDCl}_{3}\right): \delta 1.15$ (t, $\left.J=7.6 \mathrm{~Hz}, 3 \mathrm{H}, \underline{\mathrm{C}}_{3}\right), 1.20-1.29$ (dt, $J=6.8 \mathrm{~Hz}$, $\left.6 \mathrm{H}, \mathrm{N}\left(\mathrm{CH}_{2} \mathrm{CH}_{3}\right)_{2}\right), 2.86$ (q, $\left.J=7.6 \mathrm{~Hz}, 2 \mathrm{H}, \underline{\mathrm{CH}}_{2} \mathrm{CH}_{3}\right), 3.38-3.48\left(\mathrm{~m}, J=6.8 \mathrm{~Hz}, 4 \mathrm{H}, \mathrm{N}\left(\mathrm{CH}_{2} \mathrm{CH}_{3}\right)_{2}\right)$, 
$4.00\left(\mathrm{~s}, 2 \mathrm{H}, \mathrm{CH}_{2} \mathrm{Ph}\right), 6.96$ (t, $\left.J=8.4 \mathrm{~Hz}, 2 \mathrm{H}, \mathrm{ArH}\right), 7.10$ (d, 1H, H-6), 7.13 (s, 1H, H-8), 7.22 (m, 2H, $\mathrm{ArH}), 7.60(\mathrm{~d}, J=8.4 \mathrm{~Hz}, 1 \mathrm{H}, \mathrm{H}-5) .{ }^{13} \mathrm{C}-\mathrm{NMR}\left(\mathrm{CDCl}_{3}\right): \delta 18.27,19.24,27.24,36.79,47.03,47.42$, $115.34,120.20,120.41,121.42,123.34,128.16,130.12,134.58,134.66,139.67,139.70,157.73$, 158.30, 158.47, 165.30, 167.03, 167.73. HRMS (ESI): $m / z 398.17617\left(\mathrm{M}^{+} \mathrm{H}^{+}\right), 420.15785\left(\mathrm{M}^{+} \mathrm{Na}^{+}\right)$, $436.13206\left(\mathrm{M}+\mathrm{K}^{+}\right)$.

3-(4-Fluorobenzyl)-2-oxo-4-propyl-2H-chromen-7-yl diethylcarbamate (26). Yield: $0.134 \mathrm{~g}, 65 \%$, white solid, mp: $51-52{ }^{\circ} \mathrm{C} .{ }^{1} \mathrm{H}-\mathrm{NMR}\left(\mathrm{CDCl}_{3}\right): \delta 1.04$ (t, $\left.J=7.2 \mathrm{~Hz}, 3 \mathrm{H}, \mathrm{CH}_{2} \mathrm{CH}_{2} \mathrm{CH}_{3}\right), 1.20-1.29$ (m, $6 \mathrm{H}, \mathrm{CH}_{2} \mathrm{CH}_{3}$ ), 1.52-1.53 (m, 2H, $\mathrm{CH}_{2} \underline{\mathrm{C}}_{2} \mathrm{CH}_{3}$ ), 2.80 (br s, 2H, $\underline{\mathrm{C}}_{2} \mathrm{CH}_{2} \mathrm{CH}_{3}$ ), 3.40-3.46 (m, 4H, $\left.\mathrm{CH}_{2} \mathrm{CH}_{3}\right), 4.00$ (s, 2H, $\left.\underline{\mathrm{H}}_{2} \mathrm{Ph}\right), 6.95$ (t, $\left.J=8.4 \mathrm{~Hz}, 2 \mathrm{H}, \mathrm{ArH}\right), 7.10-7.14$ (m, 2H, H-6 and H-8), 7.20-7.23 $(\mathrm{m}, 2 \mathrm{H}, \mathrm{ArH}), 7.58(\mathrm{~d}, J=8.4 \mathrm{~Hz}, 1 \mathrm{H}, \mathrm{H}-5) .{ }^{13} \mathrm{C}-\mathrm{NMR}\left(\mathrm{CDCl}_{3}\right): \delta 13.35,14.29,14.50,22.57,31.15$, $32.00,42.09,42.45,110.31,115.22$, 115.44, 116.79, 118.35, 123.54, 125.32, 129.64, 134.79, 151.49, 153.35, 160.34, 162.04, 162.75. HRMS (ESI): $m / z 412.19179\left(\mathrm{M}+\mathrm{H}^{+}\right), 434.17324\left(\mathrm{M}+\mathrm{Na}^{+}\right)$.

3-Benzyl-6-chloro-4-methyl-2-oxo-2H-chromen-7-yl acetate (27). Yield: $0.05 \mathrm{~g}, 29 \%$, white solid, m.p.: $190{ }^{\circ} \mathrm{C} .{ }^{1} \mathrm{H}-\mathrm{NMR}\left(\mathrm{CDCl}_{3}\right): \delta 2.39$ (s, 3H, $\left.\underline{\mathrm{C}}_{3} \mathrm{CO}\right), 2.43$ (s, 3H, $\left.\underline{\mathrm{C}}_{3}\right), 4.06\left(\mathrm{~s}, 2 \mathrm{H}, \mathrm{C}_{2} \mathrm{Ph}\right), 7.15$ (s, 1H, H-8), 7.20-7.27 (m, 5H, $\left.\mathrm{CH}_{2} \mathrm{Ph}\right), 7.68(\mathrm{~s}, 1 \mathrm{H}, \mathrm{H}-5) .{ }^{13} \mathrm{C}-\mathrm{NMR}\left(\mathrm{CDCl}_{3}\right): \delta 15.56,20.60,33.07$, $112.32,119.73,122.97,125.69,126.08,126.53,128.24,128.67,138.31,145.88,148.40,151.16$, 161.01, 167.94. HRMS (ESI): $m / z$ 343.07294 $\left(\mathrm{M}+\mathrm{H}^{+}\right), 365.05485\left(\mathrm{M}+\mathrm{Na}^{+}\right)$.

3-Benzyl-4-methyl-2-oxo-2H-chromen-7-yl acetate (28). Yield: 0.082 g, 55\%, white solid, m.p.: 165-166 ${ }^{\circ} \mathrm{C} .{ }^{1} \mathrm{H}-\mathrm{NMR}\left(\mathrm{CDCl}_{3}\right): \delta 2.33$ (s, 3H, $\left.\underline{\mathrm{H}}_{3} \mathrm{CO}\right), 2.44$ (s, 3H, $\left.\underline{\mathrm{C}}_{3}\right), 4.06$ (s, 2H, $\left.\underline{\mathrm{H}}_{2} \mathrm{Ph}\right), 7.05$ (dd, $J=8.8,2.0 \mathrm{~Hz}, 1 \mathrm{H}, \mathrm{H}-6), 7.10$ (d, $J=2.0 \mathrm{~Hz}, 1 \mathrm{H}, \mathrm{H}-8), 7.18-7.29$ (m, 5H, $\left.\mathrm{CH}_{2} \mathrm{Ph}\right), 7.62(\mathrm{~d}$, $J=8.8 \mathrm{~Hz}, 1 \mathrm{H}, \mathrm{H}-5) .{ }^{13} \mathrm{C}-\mathrm{NMR}\left(\mathrm{CDCl}_{3}\right): \delta 15.51,21.11,32.97,110.16,118.00,118.47,124.85$, $125.43,126.40,128.25,128.60,138.69,146.98,152.34,152.90,161.61,168.82$. HRMS (ESI): $\mathrm{m} / z$ $309.11175\left(\mathrm{M}+\mathrm{H}^{+}\right), 331.09374\left(\mathrm{M}+\mathrm{Na}^{+}\right), 347.06770\left(\mathrm{M}+\mathrm{K}^{+}\right)$.

3-Benzyl-4-ethyl-2-oxo-2H-chromen-7-yl acetate (29). Yield: $0.11 \mathrm{~g}, 66 \%$, white solid, m.p.: $123-125{ }^{\circ} \mathrm{C}$. ${ }^{1} \mathrm{H}-\mathrm{NMR}\left(\mathrm{CDCl}_{3}\right): \delta 1.14\left(\mathrm{t}, J=7.6 \mathrm{~Hz}, 3 \mathrm{H}, \mathrm{CH}_{2} \mathrm{C}_{3}\right), 2.34\left(\mathrm{~s}, 3 \mathrm{H}, \mathrm{CH}_{3} \mathrm{CO}\right), 2.86(\mathrm{q}, J=7.6 \mathrm{~Hz}, 2 \mathrm{H}$, $\left.\mathrm{C}_{2} \mathrm{CH}_{3}\right), 4.04\left(\mathrm{~s}, 2 \mathrm{H}, \underline{\mathrm{C}}_{2} \mathrm{Ph}\right), 7.06$ (d, $\left.J=8.8 \mathrm{~Hz}, 1 \mathrm{H}, \mathrm{H}-6\right), 7.12$ (s, 1H, H-8), 7.19-7.29 (m, 5H, $\left.\mathrm{CH}_{2} \mathrm{Ph}\right), 7.62(\mathrm{~d}, J=8.8 \mathrm{~Hz}, 1 \mathrm{H}, \mathrm{H}-5) .{ }^{13} \mathrm{C}-\mathrm{NMR}\left(\mathrm{CDCl}_{3}\right): \delta 13.20,21.12,22.28,32.56,110.43$, $117.26,118.05,123.90,125.39,126.40,128.19,128.59,138.91,152.24,152.52,153.46,161.91$, 168.84. HRMS (ESI): $m / z 323.12751\left(\mathrm{M}+\mathrm{H}^{+}\right), 345.10923\left(\mathrm{M}+\mathrm{Na}^{+}\right), 361.08309\left(\mathrm{M}+\mathrm{K}^{+}\right)$.

3-Benzyl-2-oxo-4-propyl-2H-chromen-7-yl acetate (30). Yield: 0.105 g, 63\%, white solid, m.p.: 139-140 ${ }^{\circ} \mathrm{C} .{ }^{1} \mathrm{H}-\mathrm{NMR}\left(\mathrm{CDCl}_{3}\right): \delta 1.04\left(\mathrm{t}, J=7.2 \mathrm{~Hz}, 3 \mathrm{H}, \mathrm{CH}_{2} \mathrm{CH}_{2} \underline{\mathrm{C}}_{3}\right), 1.49-1.55(\mathrm{~m}, J=7.6 \mathrm{~Hz}, 2 \mathrm{H}$, $\mathrm{CH}_{2} \underline{\mathrm{C}}_{2} \mathrm{CH}_{3}$ ), 2.34 (s, 3H, $\left.\underline{\mathrm{C}}_{3} \mathrm{CO}\right), 2.81$ (t, $J=7.2 \mathrm{~Hz}, 2 \mathrm{H}, \mathrm{C}_{2} \mathrm{CH}_{2} \mathrm{CH}_{3}$ ), 4.04 (s, 2H, $\underline{\mathrm{H}}_{2} \mathrm{Ph}$ ), 7.05 (d, $J=8.4 \mathrm{~Hz}, 1 \mathrm{H}, \mathrm{H}-6), 7.11$ (s, 1H, H-8), 7.19-7.29 (m, 5H, $\left.\mathrm{CH}_{2} \mathrm{Ph}\right), 7.60$ (d, $\left.J=8.8 \mathrm{~Hz}, 1 \mathrm{H}, \mathrm{H}-5\right)$. ${ }^{13} \mathrm{C}-\mathrm{NMR}\left(\mathrm{CDCl}_{3}\right): \delta 14.48,21.12,22.46,31.15,32.75,110.38,117.58,117.99,124.28,125.48$, 126.40, 128.17, 128.58, 138.95, 151.17, 152.21, 153.38, 161.86, 168.83. HRMS (ESI): $\mathrm{m} / \mathrm{z} 337.14307$ $\left(\mathrm{M}+\mathrm{H}^{+}\right), 359.12512\left(\mathrm{M}+\mathrm{Na}^{+}\right), 375.09918\left(\mathrm{M}+\mathrm{K}^{+}\right)$. 
3-(4-Fluorobenzyl)-4-methyl-2-oxo-2H-chromen-7-yl acetate (31). Yield: $0.100 \mathrm{~g}, 61 \%$, white solid, m.p.: $119-120{ }^{\circ} \mathrm{C} .{ }^{1} \mathrm{H}-\mathrm{NMR}\left(\mathrm{CDCl}_{3}\right): \delta 2.34$ (s, 3H, $\left.\underline{\mathrm{C}}_{3} \mathrm{CO}\right), 2.44$ (s, 3H, $\left.\underline{\mathrm{H}}_{3}\right), 4.02\left(\mathrm{~s}, 2 \mathrm{H}, \mathrm{C}_{2} \mathrm{Ph}\right)$, $6.95(\mathrm{t}, J=8.4 \mathrm{~Hz}, 2 \mathrm{H}, \mathrm{ArH}), 7.06-7.11(\mathrm{~m}, 2 \mathrm{H}, \mathrm{H}-6$ and H-8), 7.12 (s, 1H, H-8), 7.21-7.26 (m, 2H, $\mathrm{ArH}), 7.62(\mathrm{~d}, J=8.8 \mathrm{~Hz}, 1 \mathrm{H}, \mathrm{H}-5) .{ }^{13} \mathrm{C}-\mathrm{NMR}\left(\mathrm{CDCl}_{3}\right): \delta 15.47,21.11,32.21,110.19,115.26,115.47$, $118.09,118.36,124.69,125.49,129.66,129.74,134.31,134.34,146.97,152.43,152.88,160.32$, 161.52, 162.75, 168.80. HRMS (ESI): $m / z 327.10315\left(\mathrm{M}+\mathrm{H}^{+}\right), 349.08500\left(\mathrm{M}+\mathrm{Na}^{+}\right), 365.05920\left(\mathrm{M}^{+} \mathrm{K}^{+}\right)$.

4-Ethyl-3-(4-fluorobenzyl)-2-oxo-2H-chromen-7-yl acetate (32). Yield: $0.12 \mathrm{~g}, 70 \%$, white solid, m.p.: 122-123 ${ }^{\circ} \mathrm{C} .{ }^{1} \mathrm{H}-\mathrm{NMR}\left(\mathrm{CDCl}_{3}\right): \delta 1.16\left(\mathrm{t}, J=7.6 \mathrm{~Hz}, 3 \mathrm{H}, \mathrm{CH}_{2} \underline{\mathrm{C}}_{3}\right), 2.34\left(\mathrm{~s}, 3 \mathrm{H}, \mathrm{C}_{3} \mathrm{CO}\right), 2.86$ (q, $\left.J=7.6 \mathrm{~Hz}, 2 \mathrm{H}, \mathrm{CH}_{2} \mathrm{CH}_{3}\right), 4.00\left(\mathrm{~s}, 2 \mathrm{H}, \underline{\mathrm{CH}}_{2} \mathrm{Ph}\right), 6.95$ (t, $\left.J=8.4 \mathrm{~Hz}, 2 \mathrm{H}, \mathrm{ArH}\right), 7.07$ (d, $J=8.8 \mathrm{~Hz}, 1 \mathrm{H}$, H-6), 7.12 (s, 1H, H-8), 7.20-7.26 (m, 2H, ArH), 7.63 (d, J=8.8 Hz, 1H, H-5). ${ }^{13} \mathrm{C}-\mathrm{NMR}\left(\mathrm{CDCl}_{3}\right): \delta$ 13.27, 21.11, 22.26, 31.82, 110.47, 115.25, 115.46, 117.15, 118.14, 123.72, 125.43, 129.59, 129.67, 134.52, 134.55, 152.33, 152.56, 153.45, 160.33, 161.83, 162.76, 168.83. HRMS (ESI): $m / z ~ 341.11816$ $\left(\mathrm{M}+\mathrm{H}^{+}\right), 363.10008\left(\mathrm{M}+\mathrm{Na}^{+}\right)$.

3-(4-Fluorobenzyl)-2-oxo-4-propyl-2H-chromen-7-yl acetate (33). Yield: $0.127 \mathrm{~g}, 72 \%$, white solid, m.p.: $150-151{ }^{\circ} \mathrm{C} .{ }^{1} \mathrm{H}-\mathrm{NMR}\left(\mathrm{CDCl}_{3}\right): \delta 1.07\left(\mathrm{t}, J=7.6 \mathrm{~Hz}, 3 \mathrm{H}, \mathrm{CH}_{2} \mathrm{CH}_{2} \mathrm{CH}_{3}\right), 1.52-1.58(\mathrm{~m}, J=7.6 \mathrm{~Hz}$, $2 \mathrm{H}, \mathrm{CH}_{2} \mathrm{CH}_{2} \mathrm{CH}_{3}$ ), 2.36 (s, 3H, $\underline{\mathrm{C}}_{3} \mathrm{CO}$ ), 2.80-2.85 (m, 2H, $\left.\mathrm{C}_{2} \mathrm{CH}_{2} \mathrm{CH}_{3}\right), 4.02$ (s, 2H, $\underline{\mathrm{H}}_{2} \mathrm{Ph}$ ), 6.98 (t, $J=8.4 \mathrm{~Hz}, 2 \mathrm{H}, \mathrm{ArH}), 7.07-7.10$ (dd, $J=2.0,8.4 \mathrm{~Hz}, 1 \mathrm{H}, \mathrm{H}-6), 7.13$ (d, $J=2.0 \mathrm{~Hz}, 1 \mathrm{H}, \mathrm{H}-8), 7.21-7.25$ $(\mathrm{m}, 2 \mathrm{H}, \mathrm{ArH}), 7.63(\mathrm{~d}, J=8.8 \mathrm{~Hz}, 1 \mathrm{H}, \mathrm{H}-5) .{ }^{13} \mathrm{C}-\mathrm{NMR}\left(\mathrm{CDCl}_{3}\right): \delta 14.49,21.12,22.52,31.14,32.01$, $110.43,115.25,115.46,117.47,118.08,124.11,125.54,129.57,129.65,134.58,151.20,152.30$,

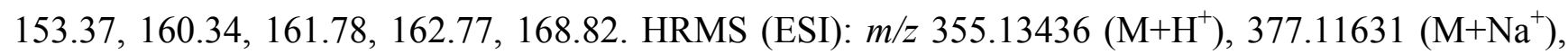
$393.09050\left(\mathrm{M}+\mathrm{K}^{+}\right)$.

3-Benzyl-6-chloro-4-methyl-2-oxo-2H-chromen-7-yl propionate (34). Yield: $0.047 \mathrm{~g}, 44 \%$, white solid, m.p.: $124-126{ }^{\circ} \mathrm{C} .{ }^{1} \mathrm{H}-\mathrm{NMR}\left(\mathrm{CDCl}_{3}\right): \delta 1.32\left(\mathrm{t}, J=7.2 \mathrm{~Hz}, 3 \mathrm{H}, \mathrm{CH}_{2} \mathrm{C}_{3}\right), 2.43\left(\mathrm{~s}, 3 \mathrm{H}, \mathrm{C}_{3}\right), 2.69$ (q, $\left.J=7.2 \mathrm{~Hz}, 2 \mathrm{H}, \mathrm{C}_{2} \mathrm{CH}_{3}\right), 4.06\left(\mathrm{~s}, 2 \mathrm{H}, \mathrm{C}_{2} \mathrm{Ph}\right), 7.15(\mathrm{~s}, 1 \mathrm{H}, \mathrm{H}-8), 7.19-7.28\left(\mathrm{~m}, 5 \mathrm{H}, \mathrm{CH}_{2} \mathrm{Ph}\right), 7.67$ (s, $1 \mathrm{H}, \mathrm{H}-5) .{ }^{13} \mathrm{C}-\mathrm{NMR}\left(\mathrm{CDCl}_{3}\right): \delta 8.99,15.56,27.45,33.07,112.33,119.63,123.00,125.66,126.01$, 126.52, 128.25, 128.67, 138.34, 145.92, 148.51, 151.18, 161.05, 171.48. HRMS (ESI): $\mathrm{m} / \mathrm{z} 357.08905$ $\left(\mathrm{M}+\mathrm{H}^{+}\right), 379.07086\left(\mathrm{M}+\mathrm{Na}^{+}\right), 395.04497\left(\mathrm{M}+\mathrm{K}^{+}\right)$.

3-Benzyl-4-methyl-2-oxo-2H-chromen-7-yl propionate (35). Yield: 0.14 g, 87\%, white solid, m.p.: 118-119 ${ }^{\circ} \mathrm{C} .{ }^{1} \mathrm{H}-\mathrm{NMR}\left(\mathrm{CDCl}_{3}\right): \delta 1.28\left(\mathrm{t}, J=7.6 \mathrm{~Hz}, 3 \mathrm{H}, \mathrm{CH}_{2} \mathrm{C}_{3}\right), 2.45$ (s, 3H, $\left.\mathrm{C}_{3}\right), 2.63$ (q, J=7.6 Hz, $\left.2 \mathrm{H}, \underline{\mathrm{C}}_{2} \mathrm{CH}_{3}\right), 4.07$ (s, 2H, $\left.\underline{\mathrm{H}}_{2} \mathrm{Ph}\right), 7.06$ (d, J=8.4 Hz, 1H, H-6), 7.10 (s, 1H, H-8), 7.19-7.29 (m, 5H, $\left.\mathrm{CH}_{2} \mathrm{Ph}\right), 7.61(\mathrm{~d}, J=8.8 \mathrm{~Hz}, 1 \mathrm{H}, \mathrm{H}-5) .{ }^{13} \mathrm{C}-\mathrm{NMR}\left(\mathrm{CDCl}_{3}\right): \delta 8.93,15.50,27.74,32.97,110.12,118.00$, $118.38,124.78,125.38,126.39,128.26,128.60,138.71,147.00,152.50,152.92,161.64,172.35$. HRMS (ESI): $m / z 323.12765\left(\mathrm{M}+\mathrm{H}^{+}\right), 345.10937\left(\mathrm{M}+\mathrm{Na}^{+}\right), 361.08330\left(\mathrm{M}+\mathrm{K}^{+}\right)$.

3-Benzyl-4-ethyl-2-oxo-2H-chromen-7-yl propionate (36). Yield: 0.143 g, 85\%, white solid, m.p.: $124{ }^{\circ} \mathrm{C}$. ${ }^{1} \mathrm{H}-\mathrm{NMR}\left(\mathrm{CDCl}_{3}\right): \delta 1.15\left(\mathrm{t}, J=7.6 \mathrm{~Hz}, 3 \mathrm{H}, \mathrm{CH}_{2} \underline{\mathrm{C}}_{3}\right), 1.28\left(\mathrm{t}, J=7.6 \mathrm{~Hz}, 3 \mathrm{H}, \mathrm{COCH}_{2} \mathrm{C}_{3}\right), 2.63(\mathrm{q}$, $\left.J=7.6 \mathrm{~Hz}, 2 \mathrm{H}, \mathrm{CH}_{2} \mathrm{CH}_{3}\right), 2.87$ (q, $\left.J=7.6 \mathrm{~Hz}, 2 \mathrm{H}, \mathrm{COCH}_{2} \mathrm{CH}_{3}\right), 4.05\left(\mathrm{~s}, 2 \mathrm{H}, \underline{\mathrm{C}}_{2} \mathrm{Ph}\right), 7.06$ (d, J=8.8 Hz, 1H, H-6), 7.12 (s, 1H, H-8), 7.19-7.29 (m, 5H, $\left.\mathrm{CH}_{2} \mathrm{Ph}\right), 7.62$ (d, $\left.J=8.8 \mathrm{~Hz}, 1 \mathrm{H}, \mathrm{H}-5\right) .{ }^{13} \mathrm{C}-\mathrm{NMR}$ $\left(\mathrm{CDCl}_{3}\right): \delta 8.94,13.21,22.28,27.74,32.56,110.39,117.16,118.06,123.82,125.34,126.39,128.20$, 


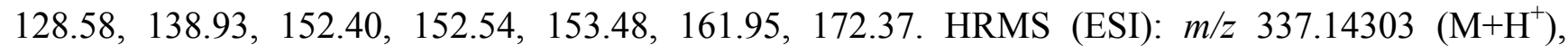
$359.12504\left(\mathrm{M}+\mathrm{Na}^{+}\right)$.

3-Benzyl-2-oxo-4-propyl-2H-chromen-7-yl propionate (37). Yield: 0.121 g, 69\%, white solid, m.p.: 120-121 ${ }^{\circ} \mathrm{C} .{ }^{1} \mathrm{H}-\mathrm{NMR}\left(\mathrm{CDCl}_{3}\right): \delta 1.04\left(\mathrm{t}, J=7.2 \mathrm{~Hz}, 3 \mathrm{H}, \mathrm{CH}_{2} \mathrm{CH}_{2} \mathrm{CH}_{3}\right), 1.28(\mathrm{t}, J=7.6 \mathrm{~Hz}, 3 \mathrm{H}$, $\mathrm{COCH}_{2} \underline{\mathrm{CH}}_{3}$ ), $1.49-1.57$ (m, $\left.J=7.6 \mathrm{~Hz}, 2 \mathrm{H}, \mathrm{CH}_{2} \underline{\mathrm{CH}}_{2} \mathrm{CH}_{3}\right), 2.63$ (q, J=7.6 Hz, 2H, $\left.\mathrm{COCH}_{2} \mathrm{CH}_{3}\right), 2.81$ (t, $\left.J=8.0 \mathrm{~Hz}, 2 \mathrm{H}, \underline{\mathrm{C}}_{2} \mathrm{CH}_{2} \mathrm{CH}_{3}\right), 4.04$ (s, 2H, $\left.\underline{\mathrm{C}}_{2} \mathrm{Ph}\right), 7.05$ (d, $\left.J=8.8 \mathrm{~Hz}, 1 \mathrm{H}, \mathrm{H}-6\right), 7.11$ (s, 1H, H-8), 7.19-7.29 (m, 5H, $\left.\mathrm{CH}_{2} \mathrm{Ph}\right), 7.59$ (d, $\left.J=8.4 \mathrm{~Hz}, 1 \mathrm{H}, \mathrm{H}-5\right) .{ }^{13} \mathrm{C}-\mathrm{NMR}\left(\mathrm{CDCl}_{3}\right): \delta 8.94,14.48,22.47$, 27.74, 31.16, 32.75, 110.34, 117.48, 117.99, 124.19, 125.44, 126.40, 128.18, 128.57, 138.97, 151.20, 152.37, 153.39, 161.90, 172.35. HRMS (ESI): $m / z \quad 351.15891\left(\mathrm{M}+\mathrm{H}^{+}\right), 373.14083\left(\mathrm{M}^{+} \mathrm{Na}^{+}\right)$, $389.11452\left(\mathrm{M}+\mathrm{K}^{+}\right)$.

3-(4-Fluorobenzyl)-4-methyl-2-oxo-2H-chromen-7-yl propionate (38). Yield: $0.082 \mathrm{~g}$, 48\%, white solid, m.p.: $115-116{ }^{\circ} \mathrm{C} .{ }^{1} \mathrm{H}-\mathrm{NMR}\left(\mathrm{CDCl}_{3}\right): \delta 1.28\left(\mathrm{t}, J=7.6 \mathrm{~Hz}, 3 \mathrm{H}, \mathrm{CH}_{2} \mathrm{C}_{3}\right), 2.45\left(\mathrm{~s}, 3 \mathrm{H}, \mathrm{C}_{3}\right)$, 2.63 (q, $\left.J=7.6 \mathrm{~Hz}, 2 \mathrm{H}, \underline{\mathrm{C}}_{2} \mathrm{CH}_{3}\right), 4.02$ (s, 2H, $\left.\underline{\mathrm{C}}_{2} \mathrm{Ph}\right), 6.95$ (t, $\left.J=8.0 \mathrm{~Hz}, 2 \mathrm{H}, \mathrm{ArH}\right), 7.06-7.10$ (m, 2H, H-6 and H-8), 7.20-7.26 (m, 2H, ArH), 7.62 (d, $J=8.8 \mathrm{~Hz}, 1 \mathrm{H}, \mathrm{H}-5) .{ }^{13} \mathrm{C}-\mathrm{NMR}\left(\mathrm{CDCl}_{3}\right): \delta 8.93$, $15.47,27.73,32.22,110.16,115.26,115.48,118.09,118.27,124.63,125.43,129.67,129.75,134.33$, 134.36, 146.98, 152.59, 152.91, 160.33, 161.56, 162.76, 172.33. HRMS (ESI): $\mathrm{m} / z$ 341.11829 $\left(\mathrm{M}+\mathrm{H}^{+}\right), 363.10044\left(\mathrm{M}+\mathrm{Na}^{+}\right), 379.07431\left(\mathrm{M}+\mathrm{K}^{+}\right)$.

4-Ethyl-3-(4-fluorobenzyl)-2-oxo-2H-chromen-7-yl propionate (39). Yield: 0.14 g, 81\%, white solid, m.p.: 97-98 ${ }^{\circ} \mathrm{C} .{ }^{1} \mathrm{H}-\mathrm{NMR}\left(\mathrm{CDCl}_{3}\right): \delta 1.16\left(\mathrm{t}, J=7.6 \mathrm{~Hz}, 3 \mathrm{H}, \mathrm{CH}_{2} \mathrm{C}_{3}\right), 1.28(\mathrm{t}, J=7.6 \mathrm{~Hz}, 3 \mathrm{H}$, $\mathrm{COCH}_{2} \underline{\mathrm{C}}_{3}$ ), 2.63 (q, $\left.J=7.6 \mathrm{~Hz}, 2 \mathrm{H}, \mathrm{C}_{2} \mathrm{CH}_{3}\right), 2.87$ (q, $\left.J=7.6 \mathrm{~Hz}, 2 \mathrm{H}, \mathrm{COC}_{2} \mathrm{CH}_{3}\right), 4.00$ (s, 2H, $\left.\mathrm{C}_{2} \mathrm{Ph}\right), 6.95$ (t, $\left.J=8.4 \mathrm{~Hz}, 2 \mathrm{H}, \mathrm{ArH}\right), 7.07$ (d, $\left.J=8.8 \mathrm{~Hz}, 1 \mathrm{H}, \mathrm{H}-6\right), 7.12$ (s, 1H, H-8), 7.20-7.24 (m, 2H, ArH), $7.62(\mathrm{~d}, J=8.8 \mathrm{~Hz}, 1 \mathrm{H}, \mathrm{H}-5) .{ }^{13} \mathrm{C}-\mathrm{NMR}\left(\mathrm{CDCl}_{3}\right): \delta 8.93,13.27,22.26,27.74,31.82$, $110.43,115.25,115.46,117.04,118.14,123.65,125.38,129.60,129.68,134.54,134.57,152.49,152.57$, 153.47, 160.33, 161.87, 162.76, 172.35. HRMS (ESI): $m / z 355.13383\left(\mathrm{M}+\mathrm{H}^{+}\right), 377.11579\left(\mathrm{M}^{+} \mathrm{Na}^{+}\right)$.

3-(4-Fluorobenzyl)-2-oxo-4-propyl-2H-chromen-7-yl propionate (40). Yield: $0.113 \mathrm{~g}$, 61\%, white solid, m.p.: $94-95{ }^{\circ} \mathrm{C} .{ }^{1} \mathrm{H}-\mathrm{NMR}\left(\mathrm{CDCl}_{3}\right): \delta 1.05\left(\mathrm{t}, J=7.2 \mathrm{~Hz}, 3 \mathrm{H}, \mathrm{CH}_{2} \mathrm{CH}_{2} \mathrm{C}_{3}\right), 1.28(\mathrm{t}, J=7.6 \mathrm{~Hz}$, $3 \mathrm{H}, \mathrm{COCH}_{2} \underline{\mathrm{C}}_{3}$ ), $1.50-1.56\left(\mathrm{~m}, J=7.6 \mathrm{~Hz}, 2 \mathrm{H}, \mathrm{CH}_{2} \mathrm{CH}_{2} \mathrm{CH}_{3}\right), 2.63$ (q, $J=7.6 \mathrm{~Hz}, 2 \mathrm{H}, \mathrm{COC}_{2} \mathrm{CH}_{3}$ ), $2.81\left(\mathrm{t}, J=7.6 \mathrm{~Hz}, 2 \mathrm{H}, \mathrm{CH}_{2} \mathrm{CH}_{2} \mathrm{CH}_{3}\right), 4.00\left(\mathrm{~s}, 2 \mathrm{H}, \mathrm{C}_{2} \mathrm{Ph}\right), 6.95$ (t, $\left.J=8.4 \mathrm{~Hz}, 2 \mathrm{H}, \mathrm{ArH}\right), 7.06$ (d, $J=8.8 \mathrm{~Hz}, 1 \mathrm{H}, \mathrm{H}-6), 7.11(\mathrm{~s}, 1 \mathrm{H}, \mathrm{H}-8), 7.19-7.23(\mathrm{~m}, 2 \mathrm{H}, \mathrm{ArH}), 7.60(\mathrm{~d}, J=8.8 \mathrm{~Hz}, 1 \mathrm{H}, \mathrm{H}-5)$. ${ }^{13} \mathrm{C}-\mathrm{NMR}\left(\mathrm{CDCl}_{3}\right): \delta 8.93,14.49,22.53,27.74,31.14,32.01,110.39,115.24,115.45,117.37,118.09$, $124.03,125.49,129.58,129.66,134.58,134.61,151.23,152.46,153.38,160.34,161.82,162.77$, 172.35. HRMS (ESI): $m / z$ 369.15020 $\left(\mathrm{M}+\mathrm{H}^{+}\right), 391.13211\left(\mathrm{M}+\mathrm{Na}^{+}\right), 407.10587\left(\mathrm{M}+\mathrm{K}^{+}\right)$.

3-Benzyl-6-chloro-4-methyl-2-oxo-2H-chromen-7-yl butyrate (41). Yield: $0.076 \mathrm{~g}, 68.5 \%$, white solid, m.p.: 107-108 ${ }^{\circ} \mathrm{C} .{ }^{1} \mathrm{H}-\mathrm{NMR}\left(\mathrm{CDCl}_{3}\right): \delta 1.07\left(\mathrm{t}, J=7.2 \mathrm{~Hz}, 3 \mathrm{H}, \mathrm{CH}_{2} \mathrm{CH}_{2} \mathrm{CH}_{3}\right), 1.83(\mathrm{~m}, 2 \mathrm{H}$, $\mathrm{CH}_{2} \underline{\mathrm{C}}_{2} \mathrm{CH}_{3}$ ), 2.42 (s, $\left.2 \mathrm{H}, \mathrm{C}_{3}\right), 2.63$ (t, J= $\left.7.2 \mathrm{~Hz}, 2 \mathrm{H}, \underline{\mathrm{C}}_{2} \mathrm{CH}_{2} \mathrm{CH}_{3}\right), 4.05$ (s, 2H, $\underline{\mathrm{H}}_{2} \mathrm{Ph}$ ), 7.13 (s, $1 \mathrm{H}, \mathrm{H}-8), 7.18-7.28(\mathrm{~m}, 5 \mathrm{H}, \mathrm{ArH}), 7.66(\mathrm{~s}, 1 \mathrm{H}, \mathrm{H}-5) .{ }^{13} \mathrm{C}-\mathrm{NMR}\left(\mathrm{CDCl}_{3}\right): \delta 13.65,15.55,18.34,33.07$, $35.84,112.34,119.62,123.00,125.67,125.99,126.52,128.25,128.66,138.35,145.93,148.50,151.16$, 161.03, 170.64. HRMS (ESI): $m / z 371.10463\left(\mathrm{M}+\mathrm{H}^{+}\right), 393.08669\left(\mathrm{M}+\mathrm{Na}^{+}\right), 409.06073\left(\mathrm{M}^{+} \mathrm{K}^{+}\right)$. 
3-Benzyl-4-methyl-2-oxo-2H-chromen-7-yl butyrate (42). Yield: $0.15 \mathrm{~g}$, 89\%, white solid, m.p.: 139-140 ${ }^{\circ} \mathrm{C} .{ }^{1} \mathrm{H}-\mathrm{NMR}\left(\mathrm{CDCl}_{3}\right): \delta 1.05\left(\mathrm{t}, J=7.6 \mathrm{~Hz}, 3 \mathrm{H}, \mathrm{CH}_{2} \underline{\mathrm{CH}}_{3}\right), 1.80(\mathrm{q}, J=7.6 \mathrm{~Hz}, 2 \mathrm{H}$, $\left.\mathrm{C}_{2} \mathrm{CH}_{3}\right), 2.44\left(\mathrm{~s}, 3 \mathrm{H}, \mathrm{CH}_{3}\right), 2.57\left(\mathrm{t}, J=7.6 \mathrm{~Hz}, 2 \mathrm{H}, \mathrm{CH}_{2} \mathrm{CH}_{2} \mathrm{CH}_{3}\right), 4.06\left(\mathrm{~s}, 2 \mathrm{H}, \mathrm{CH}_{2} \mathrm{Ph}\right), 7.05(\mathrm{~d}$, $J=8.8 \mathrm{~Hz}, 1 \mathrm{H}, \mathrm{H}-6), 7.09$ (s, 1H, H-8), 7.19-7.26 (m, 5H, $\left.\mathrm{CH}_{2} \mathrm{Ph}\right), 7.61$ (d, $\left.J=8.8 \mathrm{~Hz}, 1 \mathrm{H}, \mathrm{H}-5\right)$.

${ }^{13} \mathrm{C}-\mathrm{NMR}\left(\mathrm{CDCl}_{3}\right): \delta 13.61,15.51,18.34,32.97,36.17,110.14,118.04,118.37,124.77,125.39$, $126.39,128.26,128.60,138.72,147.00,152.48,152.91,161.63,171.52$. HRMS (ESI): $m / z ~ 337.14308$ $\left(\mathrm{M}+\mathrm{H}^{+}\right), 359.12508\left(\mathrm{M}+\mathrm{Na}^{+}\right)$.

3-Benzyl-4-ethyl-2-oxo-2H-chromen-7-yl butyrateen-7-yl propionate (43). Yield: $0.18 \mathrm{~g}, 100 \%$, white solid, m.p.: $102{ }^{\circ} \mathrm{C} .{ }^{1} \mathrm{H}-\mathrm{NMR}\left(\mathrm{CDCl}_{3}\right): \delta 1.06\left(\mathrm{t}, J=7.2 \mathrm{~Hz}, 3 \mathrm{H}, \mathrm{COCH}_{2} \mathrm{CH}_{2} \mathrm{CH}_{3}\right), 1.14(\mathrm{t}, J=7.6 \mathrm{~Hz}$, $\left.3 \mathrm{H}, \mathrm{CH}_{2} \underline{\mathrm{C}}_{3}\right), 1.78-1.83\left(\mathrm{~m}, J=7.2 \mathrm{~Hz}, 2 \mathrm{H}, \mathrm{COCH}_{2} \mathrm{C}_{2} \mathrm{CH}_{3}\right), 2.58\left(\mathrm{t}, J=7.2 \mathrm{~Hz}, 2 \mathrm{H}, \mathrm{COCH}_{2} \mathrm{CH}_{2} \mathrm{CH}_{3}\right)$, 2.87 (q, $\left.J=7.6 \mathrm{~Hz}, 2 \mathrm{H}, \underline{\mathrm{C}}_{2} \mathrm{CH}_{3}\right), 4.04$ (s, 2H, $\left.\underline{\mathrm{C}}_{2} \mathrm{Ph}\right), 7.05$ (d, J=8.8 Hz, 1H, H-6), 7.11 (s, 1H, H-8), 7.19-7.29 (m, 5H, $\left.\mathrm{CH}_{2} \mathrm{Ph}\right), 7.62(\mathrm{~d}, J=8.8 \mathrm{~Hz}, 1 \mathrm{H}, \mathrm{H}-5) .{ }^{13} \mathrm{C}-\mathrm{NMR}\left(\mathrm{CDCl}_{3}\right): \delta 13.20,13.61,22.28$, 29.71, 32.57, 36.17, 110.42, 117.15, 118.08, 123.82, 125.34, 126.38, 128.19, 128.58, 138.94, 152.38, 152.53, 153.48, 161.93, 171.55. HRMS (ESI): $m / z$ 351.15891 $\left(\mathrm{M}+\mathrm{H}^{+}\right), 373.14081\left(\mathrm{M}^{+} \mathrm{Na}^{+}\right)$, $389.11448\left(\mathrm{M}+\mathrm{K}^{+}\right)$.

3-Benzyl-2-oxo-4-propyl-2H-chromen-7-yl butyrate (44). Yield: 0.167 g, 92\%, white solid, m.p.: 105-106 ${ }^{\circ} \mathrm{C} .{ }^{1} \mathrm{H}-\mathrm{NMR}\left(\mathrm{CDCl}_{3}\right): \delta 1.02-1.07\left(\mathrm{~m}, J=7.6 \mathrm{~Hz}, 6 \mathrm{H}, \mathrm{CH}_{3}\right), 1.49-1.55(\mathrm{~m}, J=7.6 \mathrm{~Hz}$, $\left.2 \mathrm{H}, \mathrm{CH}_{2} \underline{\mathrm{C}}_{2} \mathrm{CH}_{3}\right), 1.77-1.83\left(\mathrm{~m}, J=7.6 \mathrm{~Hz}, 2 \mathrm{H}, \mathrm{COCH}_{2} \underline{\mathrm{C}}_{2} \mathrm{CH}_{3}\right), 2.58(\mathrm{t}, J=7.2 \mathrm{~Hz}, 2 \mathrm{H}$, $\left.\mathrm{COC}_{2} \mathrm{CH}_{2} \mathrm{CH}_{3}\right), 2.81\left(\mathrm{t}, J=8.0 \mathrm{~Hz}, 2 \mathrm{H}, \mathrm{CH}_{2} \mathrm{CH}_{2} \mathrm{CH}_{3}\right), 4.04\left(\mathrm{~s}, 2 \mathrm{H}, \underline{\mathrm{C}}_{2} \mathrm{Ph}\right), 7.04(\mathrm{~d}, J=8.8 \mathrm{~Hz}, 1 \mathrm{H}$, H-6), 7.10 (s, 1H, H-8), 7.19-7.29 (m, 5H, $\left.\mathrm{CH}_{2} \mathrm{Ph}\right), 7.59$ (d, J=8.4 Hz, 1H, H-5). ${ }^{13} \mathrm{C}-\mathrm{NMR}\left(\mathrm{CDCl}_{3}\right)$ : $\delta 13.60,14.48,18.35,22.47,31.15,32.76,36.17,110.37,117.48,118.03,124.19,125.45,126.40$, $128.18,128.57,138.98,151.20,152.36,153.39,161.89$, 171.54. HRMS (ESI): $\mathrm{m} / z \quad 365.17454$ $\left(\mathrm{M}+\mathrm{H}^{+}\right), 387.15649\left(\mathrm{M}+\mathrm{Na}^{+}\right), 403.13042\left(\mathrm{M}+\mathrm{K}^{+}\right)$.

3-(4-Fluorobenzyl)-4-methyl-2-oxo-2H-chromen-7-yl butyrate (45). Yield: $0.122 \mathrm{~g}, 69 \%$, white solid, m.p.: 85-86 ${ }^{\circ} \mathrm{C} .{ }^{1} \mathrm{H}-\mathrm{NMR}\left(\mathrm{CDCl}_{3}\right): \delta 1.05\left(\mathrm{t}, J=7.2 \mathrm{~Hz}, 3 \mathrm{H}, \mathrm{CH}_{2} \mathrm{CH}_{2} \mathrm{C}_{3}\right), 1.77-1.83(\mathrm{~m}, J=7.2 \mathrm{~Hz}$, $\left.2 \mathrm{H}, \mathrm{CH}_{2} \underline{\mathrm{C}}_{2} \mathrm{CH}_{3}\right), 2.45\left(\mathrm{~s}, 3 \mathrm{H}, \mathrm{CH}_{3}\right), 2.58\left(\mathrm{t}, J=7.2 \mathrm{~Hz}, 2 \mathrm{H}, \underline{\mathrm{C}}_{2} \mathrm{CH}_{2} \mathrm{CH}_{3}\right), 4.02\left(\mathrm{~s}, 2 \mathrm{H}, \mathrm{C}_{2} \mathrm{Ph}\right), 6.95$ (t, $J=8.0 \mathrm{~Hz}, 2 \mathrm{H}, \mathrm{ArH}), 7.05-7.10(\mathrm{~m}, 2 \mathrm{H}, \mathrm{H}-6$ and H-8), 7.20-7.26 (m, 2H, ArH), 7.62 (d, $J=8.8 \mathrm{~Hz}$, $1 \mathrm{H}, \mathrm{H}-5) .{ }^{13} \mathrm{C}-\mathrm{NMR}\left(\mathrm{CDCl}_{3}\right): \delta 13.61,15.47,18.34,32.22,36.16,110.18,115.26,115.47,118.13$, $118.27,124.63,125.43,129.67,129.75,134.33,134.36,146.99,152.57,152.90,160.32,161.54$, 162.75, 171.51. HRMS (ESI): $m / z$ 355.13422 $\left(\mathrm{M}+\mathrm{H}^{+}\right), 377.11617\left(\mathrm{M}+\mathrm{Na}^{+}\right), 393.09024\left(\mathrm{M}^{+} \mathrm{K}^{+}\right)$.

4-Ethyl-3-(4-fluorobenzyl)-2-oxo-2H-chromen-7-yl butyrate (46). Yield: $0.155 \mathrm{~g}, 84 \%$, white solid, m.p.: $79{ }^{\circ} \mathrm{C}$. ${ }^{1} \mathrm{H}-\mathrm{NMR}\left(\mathrm{CDCl}_{3}\right): \delta 1.06\left(\mathrm{t}, J=7.6 \mathrm{~Hz}, 3 \mathrm{H}, \mathrm{CH}_{2} \mathrm{CH}_{2} \mathrm{CH}_{3}\right), 1.16(\mathrm{t}, J=7.6 \mathrm{~Hz}, 3 \mathrm{H}$, $\left.\mathrm{CH}_{2} \underline{\mathrm{C}}_{3}\right), 1.78-1.83\left(\mathrm{~m}, J=7.6 \mathrm{~Hz}, 2 \mathrm{H}, \mathrm{CH}_{2} \underline{\mathrm{C}}_{2} \mathrm{CH}_{3}\right), 2.58$ (t, $\left.J=7.6 \mathrm{~Hz}, 2 \mathrm{H}, \mathrm{CH}_{2} \mathrm{CH}_{2} \mathrm{CH}_{3}\right), 2.87$ (q, $\left.J=7.6 \mathrm{~Hz}, 2 \mathrm{H}, \underline{\mathrm{CH}}_{2} \mathrm{CH}_{3}\right), 4.00\left(\mathrm{~s}, 2 \mathrm{H}, \underline{\mathrm{CH}}_{2} \mathrm{Ph}\right), 6.95$ (t, $\left.J=8.4 \mathrm{~Hz}, 2 \mathrm{H}, \mathrm{ArH}\right), 7.06(\mathrm{~d}, J=8.4 \mathrm{~Hz}, 1 \mathrm{H}$, $\mathrm{H}-6), 7.11(\mathrm{~s}, 1 \mathrm{H}, \mathrm{H}-8), 7.20-7.24(\mathrm{~m}, 2 \mathrm{H}, \mathrm{ArH}), 7.62$ (d, $J=8.4 \mathrm{~Hz}, 1 \mathrm{H}, \mathrm{H}-5) .{ }^{13} \mathrm{C}-\mathrm{NMR}\left(\mathrm{CDCl}_{3}\right): \delta$ $13.27,13.60,18.34,22.26,31.82,36.17,110.46,115.25,115.46,117.04,118.17,123.66,125.37$, $129.59,129.67,134.53,134.57,152.47,152.56,153.47,160.34,161.85,162.77,171.54$. HRMS (ESI): $m / z 369.14937\left(\mathrm{M}+\mathrm{H}^{+}\right), 391.13124\left(\mathrm{M}+\mathrm{Na}^{+}\right)$. 
3-(4-Fluorobenzyl)-2-oxo-4-propyl-2H-chromen-7-yl butyrate (47). Yield: $0.122 \mathrm{~g}, 64 \%$, white solid, m.p.: 88-90 ${ }^{\circ} \mathrm{C} .{ }^{1} \mathrm{H}-\mathrm{NMR}\left(\mathrm{CDCl}_{3}\right): \delta 1.05-1.07\left(\mathrm{~m}, 6 \mathrm{H}, \mathrm{CH}_{3}\right), 1.50-1.56(\mathrm{~m}, J=7.6 \mathrm{~Hz}, 2 \mathrm{H}$, $\left.\mathrm{CH}_{2} \underline{\mathrm{C}}_{2} \mathrm{CH}_{3}\right), 1.77-1.83\left(\mathrm{~m}, J=7.2 \mathrm{~Hz}, 2 \mathrm{H}, \mathrm{COCH}_{2} \mathrm{CH}_{2} \mathrm{CH}_{3}\right), 2.58\left(\mathrm{t}, J=7.2 \mathrm{~Hz}, 2 \mathrm{H}, \mathrm{COCH}_{2} \mathrm{CH}_{2} \mathrm{CH}_{3}\right)$, $2.80\left(\mathrm{t}, J=7.6 \mathrm{~Hz}, 2 \mathrm{H}, \underline{\mathrm{C}}_{2} \mathrm{CH}_{2} \mathrm{CH}_{3}\right), 4.00\left(\mathrm{~s}, 2 \mathrm{H}, \mathrm{CH}_{2} \mathrm{Ph}\right), 6.95$ (t, $\left.J=8.4 \mathrm{~Hz}, 2 \mathrm{H}, \mathrm{ArH}\right), 7.05$ (d, $J=8.8 \mathrm{~Hz}, 1 \mathrm{H}, \mathrm{H}-6), 7.10$ (s, 1H, H-8), 7.21-7.22 (m, 2H, ArH), 7.60 (d, $J=8.8 \mathrm{~Hz}, 1 \mathrm{H}, \mathrm{H}-5)$.

${ }^{13} \mathrm{C}-\mathrm{NMR}\left(\mathrm{CDCl}_{3}\right): \delta 13.60,14.49,18.35,22.53,31.14,32.01,36.17,110.42,115.24,115.45,117.37$, 118.12 , 124.03, 125.48, 129.58, 129.65, 134.58, 151.22, 152.44, 153.38, 160.34, 161.81, 162.77, 171.53. HRMS (ESI): $m / z 383.16575\left(\mathrm{M}+\mathrm{H}^{+}\right), 405.14765\left(\mathrm{M}+\mathrm{Na}^{+}\right), 421.12162\left(\mathrm{M}+\mathrm{K}^{+}\right)$.

3-Benzyl-4-methyl-2-oxo-2H-chromen-7-yl pentanoate (48). Yield: 0.151 g, 86\%, white solid, m.p.: 110-111 ${ }^{\circ} \mathrm{C} .{ }^{1} \mathrm{H}-\mathrm{NMR}\left(\mathrm{CDCl}_{3}\right): \delta 0.98\left(\mathrm{t}, J=7.6 \mathrm{~Hz}, 3 \mathrm{H}, \mathrm{CH}_{2} \mathrm{C}_{3}\right), 1.43-1.48(\mathrm{~m}, J=7.6 \mathrm{~Hz}, 2 \mathrm{H}$, $\left.\mathrm{C}_{2} \mathrm{CH}_{3}\right), 1.73-1.77\left(\mathrm{~m}, J=7.6 \mathrm{~Hz}, 2 \mathrm{H}, \mathrm{C}_{2} \mathrm{CH}_{2} \mathrm{CH}_{3}\right), 2.44$ (s, 3H, $\left.\underline{\mathrm{C}}_{3}\right), 2.59$ (t, $J=7.6 \mathrm{~Hz}, 2 \mathrm{H}$, $\left.\mathrm{COCH}_{2}\right), 4.06\left(\mathrm{~s}, 2 \mathrm{H}, \mathrm{CH}_{2} \mathrm{Ph}\right), 7.05$ (d, $\left.J=8.8 \mathrm{~Hz}, 1 \mathrm{H}, \mathrm{H}-6\right), 7.09$ (s, 1H, H-8), 7.18-7.25 (m, 5H, $\left.\mathrm{CH}_{2} \mathrm{Ph}\right), 7.61$ (d, $\left.J=8.8 \mathrm{~Hz}, 1 \mathrm{H}, \mathrm{H}-5\right) .{ }^{13} \mathrm{C}-\mathrm{NMR}\left(\mathrm{CDCl}_{3}\right): \delta 13.71,15.50,22.23,26.86,32.97,34.07$, $110.13,118.03,118.37,124.76,125.39,126.38,128.27,128.60,138.73,147.00,152.50,152.91$, 161.62, 171.70. HRMS (ESI): $m / z 351.15892\left(\mathrm{M}+\mathrm{H}^{+}\right), 373.14081\left(\mathrm{M}+\mathrm{Na}^{+}\right), 389.11455\left(\mathrm{M}^{+} \mathrm{K}^{+}\right)$.

3-Benzyl-6-chloro-4-methyl-2-oxo-2H-chromen-7-yl pentanoate (49). Yield: $0.099 \mathrm{~g}, 86 \%$, white solid, m.p.: $108-109{ }^{\circ} \mathrm{C} .{ }^{1} \mathrm{H}-\mathrm{NMR}\left(\mathrm{CDCl}_{3}\right): \delta 0.98\left(\mathrm{t}, J=7.2 \mathrm{~Hz}, 3 \mathrm{H}, \mathrm{CH}_{2} \mathrm{CH}_{3}\right), 1.45-1.50(\mathrm{~m}, J=7.2 \mathrm{~Hz}$, $\left.2 \mathrm{H}, \mathrm{CH}_{2} \mathrm{CH}_{2} \mathrm{CH}_{2} \mathrm{CH}_{3}\right), 1.74-1.80\left(\mathrm{~m}, J=7.2 \mathrm{~Hz}, 2 \mathrm{H}, \mathrm{CH}_{2} \mathrm{CH}_{2} \mathrm{CH}_{2} \mathrm{CH}_{3}\right), 2.42\left(\mathrm{~s}, 3 \mathrm{H}, \mathrm{CH}_{3}\right), 2.65$ (t, $\left.J=7.2 \mathrm{~Hz}, 2 \mathrm{H}, \mathrm{CH}_{2} \mathrm{CH}_{2} \mathrm{CH}_{2} \mathrm{CH}_{3}\right), 4.05$ (s, 2H, $\left.\underline{\mathrm{C}}_{2} \mathrm{Ph}\right), 7.13$ (s, 1H, H-8), 7.19-7.29 (m, 5H, $\left.\mathrm{CH}_{2} \mathrm{Ph} \underline{\mathrm{H}}\right), 7.66(\mathrm{~s}, 1 \mathrm{H}, \mathrm{H}-5) .{ }^{13} \mathrm{C}-\mathrm{NMR}\left(\mathrm{CDCl}_{3}\right): \delta 13.70,15.55,22.23,26.82,33.07,33.72,112.34$, $119.62,123.00,125.67,125.99,126.52,128.25,128.66,138.35,145.93,148.51,151.16,161.03$, 170.81. HRMS (ESI): $m / z 385.12011\left(\mathrm{M}+\mathrm{H}^{+}\right), 407.10215\left(\mathrm{M}+\mathrm{Na}^{+}\right), 423.07623\left(\mathrm{M}+\mathrm{K}^{+}\right)$.

3-Benzyl-4-ethyl-2-oxo-2H-chromen-7-yl pentanoate (50). Yield: $0.112 \mathrm{~g}$, 62\%, white solid, m.p.: $72-73{ }^{\circ} \mathrm{C} .{ }^{1} \mathrm{H}-\mathrm{NMR}\left(\mathrm{CDCl}_{3}\right): \delta 0.98\left(\mathrm{t}, J=7.2 \mathrm{~Hz}, 3 \mathrm{H}, \mathrm{CH}_{2} \mathrm{CH}_{2} \mathrm{CH}_{2} \mathrm{CH}_{3}\right), 1.14(\mathrm{t}, J=6.8 \mathrm{~Hz}, 3 \mathrm{H}$, $\left.\mathrm{CH}_{2} \underline{\mathrm{C}}_{3}\right), 1.43-1.48\left(\mathrm{~m}, J=6.8 \mathrm{~Hz}, 2 \mathrm{H}, \mathrm{CH}_{2} \mathrm{CH}_{2} \underline{\mathrm{C}}_{2} \mathrm{CH}_{3}\right), 1.74-1.77(\mathrm{~m}, J=6.8 \mathrm{~Hz}, 2 \mathrm{H}$, $\left.\mathrm{CH}_{2} \underline{\mathrm{C}}_{2} \mathrm{CH}_{2} \mathrm{CH}_{3}\right), 2.59$ (t, $\left.J=6.8 \mathrm{~Hz}, 2 \mathrm{H}, \mathrm{COC}_{2}\right), 2.86-2.87\left(\mathrm{~m}, J=6.0 \mathrm{~Hz}, 2 \mathrm{H}, \mathrm{C}_{2} \mathrm{CH}_{3}\right), 4.04(\mathrm{~s}$, $\left.2 \mathrm{H}, \underline{\mathrm{C}}_{2} \mathrm{Ph}\right), 7.04-7.10$ (m, 2H, H-6 and H-8), 7.18-7.25 (m, 5H, $\left.\mathrm{CH}_{2} \mathrm{Ph} \underline{\mathrm{H}}\right), 7.61(\mathrm{~d}, J=6.0 \mathrm{~Hz}, 1 \mathrm{H}$, $\mathrm{H}-5) .{ }^{13} \mathrm{C}-\mathrm{NMR}\left(\mathrm{CDCl}_{3}\right): \delta 18.17,18.70,27.21,27.26,31.85,37.56,39.06,115.40,122.14,123.06$, $128.81,130.32,131.37,133.18,133.57,143.93,157.39,157.51,158.47,166.92,176.71$. HRMS (ESI): $m / z 365.17447\left(\mathrm{M}+\mathrm{H}^{+}\right), 387.15629\left(\mathrm{M}+\mathrm{Na}^{+}\right), 403.13036\left(\mathrm{M}+\mathrm{K}^{+}\right)$.

3-Benzyl-2-oxo-4-propyl-2H-chromen-7-yl pentanoate (51). Yield: 0.166 g, 88\%, white solid, m.p.: 78-79 ${ }^{\circ} \mathrm{C} .{ }^{1} \mathrm{H}-\mathrm{NMR}\left(\mathrm{CDCl}_{3}\right): \delta 0.95-1.05\left(\mathrm{~m}, 6 \mathrm{H}, \mathrm{CH}_{3}\right), 1.43-1.53\left(\mathrm{~m}, 4 \mathrm{H}, \mathrm{CH}_{2} \mathrm{CH}_{2} \mathrm{CH}_{2} \mathrm{CH}_{3}\right.$ and $\mathrm{CH}_{2} \underline{\mathrm{C}}_{2} \mathrm{CH}_{3}$ ), 1.74-1.79 (m, 2H, $\mathrm{CH}_{2} \underline{\mathrm{C}}_{2} \mathrm{CH}_{2} \mathrm{CH}_{3}$ ), 2.57-2.61 (m, 2H, $\underline{\mathrm{C}}_{2} \mathrm{CH}_{2} \mathrm{CH}_{3}$ ), 2.78-2.82 (m, $\left.2 \mathrm{H}, \mathrm{COCH}_{2}\right), 4.04$ (s, 2H, $\left.\underline{\mathrm{H}}_{2} \mathrm{Ph}\right), 7.03-7.09$ (m, 2H, H-6 and H-8), 7.18-7.25 (m, 5H, $\mathrm{CH}_{2} \mathrm{Ph} \underline{\mathrm{H}}$ ), 7.57-7.59 (m, 1H, H-5). ${ }^{13} \mathrm{C}-\mathrm{NMR}\left(\mathrm{CDCl}_{3}\right): \delta 13.71,14.48,22.22,22.47,26.86,31.15,32.75,34.07$, $110.36,117.47,118.03,124.19,125.44,126.40,128.18,128.57,138.98,151.20,152.37,153.39$, 161.89, 171.73. HRMS (ESI): $m / z$ 379.19074 $\left(\mathrm{M}+\mathrm{H}^{+}\right), 401.17263\left(\mathrm{M}+\mathrm{Na}^{+}\right), 417.14655\left(\mathrm{M}+\mathrm{K}^{+}\right)$. 
4-Ethyl-3-(4-fluorobenzyl)-2-oxo-2H-chromen-7-yl pentanoate (52). Yield: $0.153 \mathrm{~g}, 80 \%$, white solid, m.p.: $70-71{ }^{\circ} \mathrm{C} .{ }^{1} \mathrm{H}-\mathrm{NMR}\left(\mathrm{CDCl}_{3}\right): \delta 0.98\left(\mathrm{t}, J=7.6 \mathrm{~Hz}, 3 \mathrm{H}, \mathrm{CH}_{2} \mathrm{CH}_{2} \mathrm{CH}_{2} \mathrm{CH}_{3}\right), 1.16(\mathrm{t}, J=7.6 \mathrm{~Hz}$, $\left.3 \mathrm{H}, \mathrm{CH}_{2} \mathrm{CH}_{3}\right), 1.43-1.49\left(\mathrm{~m}, J=7.6 \mathrm{~Hz}, 2 \mathrm{H}, \mathrm{CH}_{2} \mathrm{CH}_{2} \underline{\mathrm{C}}_{2} \mathrm{CH}_{3}\right), 1.72-1.80(\mathrm{~m}, J=7.6 \mathrm{~Hz}, 2 \mathrm{H}$, $\mathrm{CH}_{2} \underline{\mathrm{C}}_{2} \mathrm{CH}_{2} \mathrm{CH}_{3}$ ), 2.60 (t, $J=7.6 \mathrm{~Hz}, 2 \mathrm{H}, \mathrm{COC}_{2}$ ), 2.87 (q, $\left.J=7.6 \mathrm{~Hz}, 2 \mathrm{H}, \underline{\mathrm{CH}}_{2} \mathrm{CH}_{3}\right), 4.00(\mathrm{~s}, 2 \mathrm{H}$, $\left.\mathrm{C}_{2} \mathrm{Ph}\right), 6.95$ (t, $\left.J=8.4 \mathrm{~Hz}, 2 \mathrm{H}, \mathrm{ArH}\right), 7.06$ (d, $\left.J=8.8 \mathrm{~Hz}, 1 \mathrm{H}, \mathrm{H}-6\right), 7.11$ (s, 1H, H-8), 7.20-7.23 (m, 2H, $\mathrm{ArH}), 7.62(\mathrm{~d}, J=8.4 \mathrm{~Hz}, 1 \mathrm{H}, \mathrm{H}-5) .{ }^{13} \mathrm{C}-\mathrm{NMR}\left(\mathrm{CDCl}_{3}\right): \delta 13.27,13.70,22.22,22.26,26.86$, $31.82,34.06,110.46,115.25,115.46,117.04,118.17,123.65,125.37,129.60,129.67,134.54,134.57$, $152.49,152.57,153.47,160.34,161.85,162.76,171.72$. HRMS (ESI): $m / z 383.16509\left(\mathrm{M}^{+} \mathrm{H}^{+}\right)$, $405.14697\left(\mathrm{M}+\mathrm{Na}^{+}\right)$.

3-(4-Fluorobenzyl)-4-methyl-2-oxo-2H-chromen-7-yl pentanoate (53). Yield: $0.122 \mathrm{~g}$, 66\%, white solid, m.p.: 83-84 ${ }^{\circ} \mathrm{C} .{ }^{1} \mathrm{H}-\mathrm{NMR}\left(\mathrm{CDCl}_{3}\right): \delta 0.98\left(\mathrm{t}, J=7.2 \mathrm{~Hz}, 3 \mathrm{H}, \mathrm{CH}_{2} \mathrm{CH}_{3}\right), 1.43-1.48(\mathrm{~m}, J=7.2 \mathrm{~Hz}$, $2 \mathrm{H}, \mathrm{CH}_{2} \mathrm{CH}_{2} \mathrm{CH}_{2} \mathrm{CH}_{3}$ ), 1.72-1.79 (m, J = 7.2 Hz, 2H, $\left.\mathrm{CH}_{2} \mathrm{CH}_{2} \mathrm{CH}_{2} \mathrm{CH}_{3}\right), 2.44$ (s, 3H, $\left.\mathrm{CH}_{3}\right), 2.59$ (t, $\left.J=7.2 \mathrm{~Hz}, 2 \mathrm{H}, \mathrm{CH}_{2} \mathrm{CH}_{2} \mathrm{CH}_{2} \mathrm{CH}_{3}\right), 4.02\left(\mathrm{~s}, 2 \mathrm{H}, \mathrm{CH}_{2} \mathrm{Ph}\right), 6.95$ (t, $\left.J=8.0 \mathrm{~Hz}, 2 \mathrm{H}, \mathrm{ArH}\right), 7.05-7.09$ (m, 2H, H-6 and H-8), 7.20-7.26 (m, 2H, ArH), $7.62(\mathrm{~d}, J=8.8 \mathrm{~Hz}, 1 \mathrm{H}, \mathrm{H}-5) .{ }^{13} \mathrm{C}-\mathrm{NMR}\left(\mathrm{CDCl}_{3}\right): \delta 13.70$, $15.47,22.22,26.85,32.22,34.06,110.17,115.26,115.47,118.12,118.26,124.62,125.43,129.67$, $129.75,134.33,134.36,146.98,152.59,152.90,160.32,161.54,162.75,171.69$. HRMS (ESI): $m / z$ $369.15012\left(\mathrm{M}+\mathrm{H}^{+}\right), 391.13209\left(\mathrm{M}+\mathrm{Na}^{+}\right), 407.10611\left(\mathrm{M}+\mathrm{K}^{+}\right)$.

3-(4-Fluorobenzyl)-2-oxo-4-propyl-2H-chromen-7-yl pentanoate (54). Yield: $0.122 \mathrm{~g}$, 62\%, white solid, m.p.: $68-70{ }^{\circ} \mathrm{C} .{ }^{1} \mathrm{H}-\mathrm{NMR}\left(\mathrm{CDCl}_{3}\right): \delta 0.98\left(\mathrm{t}, J=7.2 \mathrm{~Hz}, 3 \mathrm{H}, \mathrm{CH}_{2} \mathrm{CH}_{2} \mathrm{CH}_{2} \mathrm{CH}_{3}\right), 1.05(\mathrm{t}, J=7.2 \mathrm{~Hz}$, $\left.3 \mathrm{H}, \mathrm{CH}_{2} \mathrm{CH}_{2} \underline{\mathrm{C}}_{3}\right), 1.43-1.56\left(\mathrm{~m}, 4 \mathrm{H}, \mathrm{CH}_{2} \mathrm{CH}_{2} \mathrm{CH}_{2} \mathrm{CH}_{3}\right.$ and $\left.\mathrm{CH}_{2} \underline{\mathrm{C}}_{2} \mathrm{CH}_{3}\right), 1.72-1.79$ (m, J=7.2 Hz, $\left.2 \mathrm{H}, \mathrm{CH}_{2} \underline{\mathrm{C}}_{2} \mathrm{CH}_{2} \mathrm{CH}_{3}\right), 2.60\left(\mathrm{t}, J=7.2 \mathrm{~Hz}, 2 \mathrm{H}, \mathrm{COC}_{2}\right), 2.78-2.82\left(\mathrm{~m}, J=7.6 \mathrm{~Hz}, 2 \mathrm{H}, \mathrm{C}_{2} \mathrm{CH}_{2} \mathrm{CH}_{3}\right)$, 4.00 (s, 2H, $\left.\underline{\mathrm{H}}_{2} \mathrm{Ph}\right), 6.94-6.98$ (m, 2H, $\left.\mathrm{CH}_{2} \mathrm{Ph} \underline{\mathrm{H}}\right), 7.05$ (d, J=8.8Hz, 1H, H-6), 7.10 (s, 1H, H-8), $7.20-7.23\left(\mathrm{~m}, 2 \mathrm{H}, \mathrm{CH}_{2} \mathrm{PhH}\right), 7.60(\mathrm{~d}, J=8.4 \mathrm{~Hz}, 1 \mathrm{H}, \mathrm{H}-5) .{ }^{13} \mathrm{C}-\mathrm{NMR}\left(\mathrm{CDCl}_{3}\right): \delta 13.70,14.48,22.22$, $22.53,26.86,31.14,32.01,34.07,110.41,115.24,115.45,117.36,118.11,124.02,125.48,129.58$, $129.66,134.58,134.61,151.22,152.46,153.38,160.34,161.81,162.77,171.71$. HRMS (ESI): $\mathrm{m} / \mathrm{z}$ $397.18122\left(\mathrm{M}+\mathrm{H}^{+}\right), 419.16309\left(\mathrm{M}+\mathrm{Na}^{+}\right)$.

3-Benzyl-4-methyl-2-oxo-2H-chromen-7-yl pivalate (55). Yield: 0.157 g, 90\%, white solid, m.p.: 157-158 ${ }^{\circ} \mathrm{C} .{ }^{1} \mathrm{H}-\mathrm{NMR}\left(\mathrm{CDCl}_{3}\right): \delta 1.37\left(\mathrm{~s}, 9 \mathrm{H}, \mathrm{C}\left(\mathrm{CH}_{3}\right)_{3}\right), 2.44\left(\mathrm{~s}, 3 \mathrm{H}, \mathrm{C}_{3}\right), 4.06\left(\mathrm{~s}, 2 \mathrm{H}, \underline{\mathrm{C}}_{2} \mathrm{Ph}\right), 7.01$ (d, $J=8.8 \mathrm{~Hz}, 1 \mathrm{H}, \mathrm{H}-6), 7.06$ (s, 1H, H-8), 7.19-7.26 (m, 5H, $\left.\mathrm{CH}_{2} \mathrm{Ph}\right), 7.61$ (d, $\left.J=8.8 \mathrm{~Hz}, 1 \mathrm{H}, \mathrm{H}-5\right)$. ${ }^{13} \mathrm{C}-\mathrm{NMR}\left(\mathrm{CDCl}_{3}\right): \delta 15.51,27.08,32.99,39.24,110.06,117.98,118.29,124.72,125.33,126.38$, $128.28,128.60,138.75,147.00,152.94,161.63,176.52$. HRMS (ESI): $m / z 351.15890\left(\mathrm{M}^{+} \mathrm{H}^{+}\right)$, $373.14087\left(\mathrm{M}+\mathrm{Na}^{+}\right), 389.11450\left(\mathrm{M}+\mathrm{K}^{+}\right)$.

3-Benzyl-6-chloro-4-methyl-2-oxo-2H-chromen-7-yl pivalate (56). Yield: $0.1 \mathrm{~g}, 87 \%$, white solid, m.p.: $113{ }^{\circ} \mathrm{C} .{ }^{1} \mathrm{H}-\mathrm{NMR}\left(\mathrm{CDCl}_{3}\right): \delta 1.41\left(\mathrm{~s}, 9 \mathrm{H}, \mathrm{C}\left(\mathrm{C}_{3}\right)_{3}\right), 2.43\left(\mathrm{~s}, 3 \mathrm{H}, \mathrm{CH}_{3}\right), 4.06\left(\mathrm{~s}, 2 \mathrm{H}, \mathrm{C}_{2} \mathrm{Ph}\right), 7.11$ (s, 1H, H-8), 7.20-7.28 (m, 5H, $\left.\mathrm{CH}_{2} \mathrm{Ph} \underline{\mathrm{H}}\right), 7.66$ (s, 1H, H-5). ${ }^{13} \mathrm{C}-\mathrm{NMR}\left(\mathrm{CDCl}_{3}\right): \delta 15.55,27.14$, $33.08,39.43,112.26,119.52,123.06,125.64,125.94,126.51,128.27,128.66,138.38,145.92,148.81$, 151.19, 161.06, 175.56. HRMS (ESI): $m / z 385.12023\left(\mathrm{M}+\mathrm{H}^{+}\right), 407.10224\left(\mathrm{M}+\mathrm{Na}^{+}\right), 423.07644\left(\mathrm{M}^{+} \mathrm{K}^{+}\right)$. 
3-Benzyl-4-ethyl-2-oxo-2H-chromen-7-yl pivalate (57). Yield: 0.180 g, 99\%, white solid, m.p.: 105-106 ${ }^{\circ} \mathrm{C} .{ }^{1} \mathrm{H}-\mathrm{NMR}\left(\mathrm{CDCl}_{3}\right): \delta 1.15$ (t, $\left.J=7.6 \mathrm{~Hz}, 3 \mathrm{H}, \mathrm{CH}_{2} \mathrm{C}_{3}\right), 1.38$ (s, 9H, $\left.\mathrm{C}\left(\mathrm{CH}_{3}\right)_{3}\right), 2.87$ (q, $\left.J=7.6 \mathrm{~Hz}, 2 \mathrm{H}, \underline{\mathrm{C}}_{2} \mathrm{CH}_{3}\right), 4.05\left(\mathrm{~s}, 2 \mathrm{H}, \underline{\mathrm{CH}}_{2} \mathrm{Ph}\right), 7.01-7.03$ (dd, $\left.J=1.6,8.4 \mathrm{~Hz}, 1 \mathrm{H}, \mathrm{H}-6\right), 7.07$ (d, $J=2.0 \mathrm{~Hz}, 1 \mathrm{H}, \mathrm{H}-8), 7.19-7.30\left(\mathrm{~m}, 5 \mathrm{H}, \mathrm{CH}_{2} \mathrm{Ph}\right), 7.61(\mathrm{~d}, J=8.8 \mathrm{~Hz}, 1 \mathrm{H}, \mathrm{H}-5) .{ }^{13} \mathrm{C}-\mathrm{NMR}\left(\mathrm{CDCl}_{3}\right): \delta$ $13.23,22.29,27.08,32.57,39.25,110.34,117.06,118.04,123.76,125.30,126.39,128.21,128.59$, $138.95,152.57,152.83,153.50,161.97,176.58$. HRMS (ESI): $m / z 365.17453\left(\mathrm{M}+\mathrm{H}^{+}\right), 387.15631$ $\left(\mathrm{M}+\mathrm{Na}^{+}\right), 403.13040\left(\mathrm{M}+\mathrm{K}^{+}\right)$.

3-Benzyl-2-oxo-4-propyl-2H-chromen-7-yl pivalate (58). Yield: 0.184 g, 97\%, white solid, m.p.: 138-139 ${ }^{\circ} \mathrm{C} .{ }^{1} \mathrm{H}-\mathrm{NMR}\left(\mathrm{CDCl}_{3}\right): \delta 1.04\left(\mathrm{t}, J=6.4 \mathrm{~Hz}, 3 \mathrm{H}, \mathrm{CH}_{2} \mathrm{CH}_{3}\right), 1.38\left(\mathrm{~s}, 9 \mathrm{H}, \mathrm{C}\left(\mathrm{CH}_{3}\right)_{3}\right), 1.52$ (q, $\left.J=7.2 \mathrm{~Hz}, 2 \mathrm{H}, \mathrm{CH}_{2} \mathrm{C}_{2} \mathrm{CH}_{3}\right), 2.81\left(\mathrm{~m}, 2 \mathrm{H}, \underline{\mathrm{C}}_{2} \mathrm{CH}_{2} \mathrm{CH}_{3}\right), 4.04\left(\mathrm{~s}, 2 \mathrm{H}, \mathrm{C}_{2} \mathrm{Ph}\right), 7.01(\mathrm{~d}, J=8.4 \mathrm{~Hz}$, $1 \mathrm{H}, \mathrm{H}-6), 7.07$ (s, 1H, H-8), 7.19-7.26 (m, 5H, $\left.\mathrm{CH}_{2} \mathrm{Ph}\right), 7.58$ (d, $\left.J=8.4 \mathrm{~Hz}, 1 \mathrm{H}, \mathrm{H}-5\right) .{ }^{13} \mathrm{C}-\mathrm{NMR}$ $\left(\mathrm{CDCl}_{3}\right): \delta 14.48,22.48,27.08,31.15,32.77,39.25,110.28,117.39,117.96,124.14,125.39,126.39$, $128.20,128.57,139.00,151.21,152.82,153.42,161.90,176.54$. HRMS (ESI): $\mathrm{m} / z \quad 379.19072$ $\left(\mathrm{M}+\mathrm{H}^{+}\right), 401.17258\left(\mathrm{M}+\mathrm{Na}^{+}\right), 417.14652\left(\mathrm{M}+\mathrm{K}^{+}\right)$.

4-Ethyl-3-(4-fluorobenzyl)-2-oxo-2H-chromen-7-yl pivalate (59). Yield: $0.16 \mathrm{~g}, 84 \%$, white solid, m.p.: $103-104{ }^{\circ} \mathrm{C} .{ }^{1} \mathrm{H}-\mathrm{NMR}\left(\mathrm{CDCl}_{3}\right): \delta 1.16\left(\mathrm{t}, J=7.6 \mathrm{~Hz}, 3 \mathrm{H}, \mathrm{CH}_{2} \mathrm{CH}_{3}\right), 1.38\left(\mathrm{~s}, 9 \mathrm{H}, \mathrm{C}\left(\mathrm{C}_{3}\right)_{3}\right), 2.87$ (q, $\left.J=7.6 \mathrm{~Hz}, 2 \mathrm{H}, \mathrm{C}_{2} \mathrm{CH}_{3}\right), 4.00\left(\mathrm{~s}, 2 \mathrm{H}, \mathrm{C}_{2} \mathrm{Ph}\right), 6.95(\mathrm{t}, J=8.4 \mathrm{~Hz}, 2 \mathrm{H}, \mathrm{ArH}), 7.03(\mathrm{~d}, J=8.8 \mathrm{~Hz}$, 1H, H-6), 7.08 (s, 1H, H-8), 7.21-7.26 (m, 2H, ArH), 7.62 (d, J = 8.4 Hz, 1H, H-5). ${ }^{13} \mathrm{C}-\mathrm{NMR}$ $\left(\mathrm{CDCl}_{3}\right): \delta 13.28,22.27,27.07,31.83,39.25,110.37,115.24,115.45,116.95,118.11,123.59,125.34$, $129.62,129.69,134.57,134.60,152.58,152.94,153.50,160.33,161.86,162.76,176.53$. HRMS (ESI): $m / z 383.16508\left(\mathrm{M}+\mathrm{H}^{+}\right), 405.14694\left(\mathrm{M}+\mathrm{Na}^{+}\right), 421.11022\left(\mathrm{M}+\mathrm{K}^{+}\right)$.

3-(4-Fluorobenzyl)-4-methyl-2-oxo-2H-chromen-7-yl pivalate (60). Yield: $0.096 \mathrm{~g}, 52 \%$, white solid, m.p.: $136-138{ }^{\circ} \mathrm{C} .{ }^{1} \mathrm{H}-\mathrm{NMR}\left(\mathrm{CDCl}_{3}\right): \delta 1.38\left(\mathrm{~s}, 9 \mathrm{H}, \mathrm{C}\left(\mathrm{CH}_{3}\right)_{3}\right), 2.45\left(\mathrm{~s}, 3 \mathrm{H}, \mathrm{CH}_{3}\right), 4.02\left(\mathrm{~s}, 2 \mathrm{H}, \mathrm{CH}_{2} \mathrm{Ph}\right)$, $6.96(\mathrm{t}, J=8.0 \mathrm{~Hz}, 2 \mathrm{H}, \mathrm{ArH}), 7.01-7.06(\mathrm{~m}, 2 \mathrm{H}, \mathrm{H}-6$ and H-8), 7.21-7.26 (m, 2H, ArH), 7.60 (d, $J=8.8 \mathrm{~Hz}, 1 \mathrm{H}, \mathrm{H}-5) .{ }^{13} \mathrm{C}-\mathrm{NMR}\left(\mathrm{CDCl}_{3}\right): \delta 15.48,27.07,32.24,39.25,110.11,115.27,115.48,118.06$, $118.19,124.59,125.37,129.68,129.76,134.35,134.38,146.98,152.94,153.04,160.33,161.55$, 162.76, 176.52. HRMS (ESI): $m / z$ 369.15012 (M+H' $), 391.13212\left(\mathrm{M}+\mathrm{Na}^{+}\right), 407.10589\left(\mathrm{M}^{+} \mathrm{K}^{+}\right)$.

3-(4-Fluorobenzyl)-2-oxo-4-propyl-2H-chromen-7-yl pivalate (61). Yield: $0.160 \mathrm{~g}, 81 \%$, white solid, m.p.: ${ }^{138-140}{ }^{\circ} \mathrm{C} .{ }^{1} \mathrm{H}-\mathrm{NMR}\left(\mathrm{CDCl}_{3}\right): \delta 1.05\left(\mathrm{t}, J=7.2 \mathrm{~Hz}, 3 \mathrm{H}, \mathrm{CH}_{2} \mathrm{C}_{3}\right), 1.38\left(\mathrm{~s}, 9 \mathrm{H}, \mathrm{C}\left(\mathrm{CH}_{3}\right)_{3}\right)$, $1.52-1.56\left(\mathrm{~m}, J=7.2 \mathrm{~Hz}, 2 \mathrm{H}, \mathrm{CH}_{2} \mathrm{CH}_{2} \mathrm{CH}_{3}\right), 2.81\left(\mathrm{t}, J=7.6 \mathrm{~Hz}, 2 \mathrm{H}, \mathrm{C}_{2} \mathrm{CH}_{2} \mathrm{CH}_{3}\right), 4.00(\mathrm{~s}, 2 \mathrm{H}$, $\left.\mathrm{C}_{2} \mathrm{Ph}\right), 6.96$ (t, $\left.J=8.4 \mathrm{~Hz}, 2 \mathrm{H}, \mathrm{ArH}\right), 7.02$ (d, $\left.J=8.8 \mathrm{~Hz}, 1 \mathrm{H}, \mathrm{H}-6\right), 7.07$ (s, 1H, H-8), 7.20-7.23 (m, $2 \mathrm{H}, \mathrm{ArH}), 7.59$ (d, $J=8.8 \mathrm{~Hz}, 1 \mathrm{H}, \mathrm{H}-5) .{ }^{13} \mathrm{C}-\mathrm{NMR}\left(\mathrm{CDCl}_{3}\right): \delta 14.48,22.53,27.07,31.14,32.02$, $39.25,110.33,115.24,115.45,117.28,118.05,123.98,125.42,129.59,129.67,134.60,134.63$,

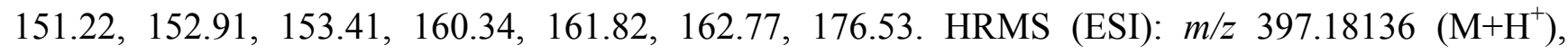
$419.16318\left(\mathrm{M}+\mathrm{Na}^{+}\right)$.

3-Benzyl-4-methyl-2-oxo-2H-chromen-7-yl benzoate (62). Yield: 0.180 g, 97\%, white solid, m.p.: 149-150 ${ }^{\circ} \mathrm{C} .{ }^{1} \mathrm{H}-\mathrm{NMR}\left(\mathrm{CDCl}_{3}\right): \delta 2.47$ (s, 3H, $\left.\underline{\mathrm{CH}}_{3}\right), 4.08$ (s, 2H, $\left.\mathrm{CH}_{2} \mathrm{Ph}\right), 7.18-7.27$ (m, 7H, ArH), $7.53(\mathrm{t}, 2 \mathrm{H}, \mathrm{ArH}), 7.67(\mathrm{t}, 2 \mathrm{H}, \mathrm{ArH}), 8.21(\mathrm{~d}, J=7.6 \mathrm{~Hz}, 2 \mathrm{H}, \mathrm{ArH}) .{ }^{13} \mathrm{C}-\mathrm{NMR}\left(\mathrm{CDCl}_{3}\right): \delta 15.55,33.01$, 
$110.33,118.18,118.55,124.88,125.49,126.41,128.29,128.62,128.72,128.91,130.33,134.02$, 138.72, 147.03, 152.69, 152.99, 161.64, 164.62. HRMS (ESI): $m / z 371.12762\left(\mathrm{M}+\mathrm{H}^{+}\right), 393.10954$ $\left(\mathrm{M}+\mathrm{Na}^{+}\right), 409.08341\left(\mathrm{M}+\mathrm{K}^{+}\right)$.

3-Benzyl-6-chloro-4-methyl-2-oxo-2H-chromen-7-yl benzoate (63). Yield: $0.179 \mathrm{~g}, 88.6 \%$, white solid, m.p.: $133-135{ }^{\circ} \mathrm{C} .{ }^{1} \mathrm{H}-\mathrm{NMR}\left(\mathrm{CDCl}_{3}\right): \delta 2.46\left(\mathrm{~s}, 3 \mathrm{H}, \mathrm{CH}_{3}\right), 4.08\left(\mathrm{~s}, 2 \mathrm{H}, \mathrm{C}_{2} \mathrm{Ph}\right), 7.21-7.32(\mathrm{~m}, 6 \mathrm{H}$, $\operatorname{ArH}), 7.53-7.57(\mathrm{~m}, 2 \mathrm{H}, \operatorname{ArH}), 7.67-7.72(\mathrm{~m}, 2 \mathrm{H}, \mathrm{ArH}), 8.23-8.25(\mathrm{~m}, J=7.2 \mathrm{~Hz}, 2 \mathrm{H}, \operatorname{ArH})$. ${ }^{13} \mathrm{C}-\mathrm{NMR}\left(\mathrm{CDCl}_{3}\right): \delta 15.59,33.10,112.47,119.71,123.11,125.71,126.08,126.54,128.27,128.68$, 128.78, 130.53, 134.26, 138.36, 145.94, 148.67, 151.21, 161.08, 163.77. HRMS (ESI): $m / z ~ 405.08872$ $\left(\mathrm{M}+\mathrm{H}^{+}\right), 427.07096\left(\mathrm{M}+\mathrm{Na}^{+}\right), 443.04450\left(\mathrm{M}+\mathrm{K}^{+}\right)$.

3-Benzyl-4-ethyl-2-oxo-2H-chromen-7-yl benzoate (64). Yield: $0.149 \mathrm{~g}, 78 \%$, white solid, m.p.: $138{ }^{\circ} \mathrm{C}$. ${ }^{1} \mathrm{H}-\mathrm{NMR}\left(\mathrm{CDCl}_{3}\right): \delta 1.17\left(\mathrm{t}, J=6.8 \mathrm{~Hz}, 3 \mathrm{H}, \mathrm{CH}_{2} \mathrm{C}_{3}\right), 2.88-2.90\left(\mathrm{~m}, J=7.2 \mathrm{~Hz}, 2 \mathrm{H}, \mathrm{C}_{2} \mathrm{CH}_{3}\right), 4.06$ (s, 2H, $\left.\underline{\mathrm{H}}_{2} \mathrm{Ph}\right), 7.18-7.27$ (m, 7H, ArH), 7.52-7.55 (m, 2H, ArH), 7.65-7.69 (m, 2H, ArH), 8.21 (d, $J=6.4 \mathrm{~Hz}, 2 \mathrm{H}, \mathrm{ArH}) .{ }^{13} \mathrm{C}-\mathrm{NMR}\left(\mathrm{CDCl}_{3}\right): \delta 18.20,27.29,37.60,115.58,122.32,123.18,128.94$, $130.41,131.38,133.21,133.58,133.69,133.94,135.31,138.99,143.94,157.50,157.60,158.57$, 166.90, 169.60. HRMS (ESI): $m / z 385.14322\left(\mathrm{M}+\mathrm{H}^{+}\right), 407.12515\left(\mathrm{M}+\mathrm{Na}^{+}\right), 423.09884\left(\mathrm{M}+\mathrm{K}^{+}\right)$.

3-Benzyl-2-oxo-4-propyl-2H-chromen-7-yl benzoate (65). Yield: $0.159 \mathrm{~g}, 80.3 \%$, white solid, m.p.: $120{ }^{\circ} \mathrm{C}$. ${ }^{1} \mathrm{H}-\mathrm{NMR}\left(\mathrm{CDCl}_{3}\right): \delta 1.05\left(\mathrm{t}, J=7.2 \mathrm{~Hz}, 3 \mathrm{H}, \mathrm{CH}_{2} \underline{\mathrm{C}}_{3}\right), 1.52-1.57\left(\mathrm{~m}, J=7.2 \mathrm{~Hz}, 2 \mathrm{H}, \mathrm{C}_{2} \mathrm{CH}_{3}\right), 2.83$ (t, $\left.J=7.6 \mathrm{~Hz}, 2 \mathrm{H}, \mathrm{C}_{2} \mathrm{CH}_{2} \mathrm{CH}_{3}\right), 4.06$ (s, 2H, $\underline{\mathrm{C}}_{2} \mathrm{Ph}$ ), 7.18-7.27 (m, 7H, ArH), 7.48-7.55 (m, 2H, $\mathrm{ArH}), 7.64-7.68(\mathrm{~m}, 2 \mathrm{H}, \mathrm{ArH}), 8.21(\mathrm{~d}, J=7.2 \mathrm{~Hz}, 2 \mathrm{H}, \mathrm{ArH}) .{ }^{13} \mathrm{C}-\mathrm{NMR}\left(\mathrm{CDCl}_{3}\right): \delta 14.51,22.50$, $31.19,32.79,110.56,117.66,118.18,124.30,125.56,126.42,128.21,128.60,128.72,130.34,134.03$, 138.98, 151.24, 152.57, 153.46, 161.92, 164.64. HRMS (ESI): $m / z 399.15917\left(\mathrm{M}+\mathrm{H}^{+}\right), 421.14128$ $\left(\mathrm{M}+\mathrm{Na}^{+}\right), 437.11514\left(\mathrm{M}+\mathrm{K}^{+}\right)$.

3-(4-Fluorobenzyl)-4-methyl-2-oxo-2H-chromen-7-yl benzoate (66). Yield: $0.13 \mathrm{~g}, 67 \%$, white solid, m.p.: $151-153{ }^{\circ} \mathrm{C} .{ }^{1} \mathrm{H}-\mathrm{NMR}\left(\mathrm{CDCl}_{3}\right): \delta 2.48\left(\mathrm{~s}, 3 \mathrm{H}, \mathrm{C}_{3}\right), 4.04\left(\mathrm{~s}, 2 \mathrm{H}, \mathrm{C}_{2} \mathrm{Ph}\right), 6.97(\mathrm{t}, J=8.4 \mathrm{~Hz}$, 2H, ArH), 7.20-7.26 (m, 4H, ArH), 7.52-7.56 (m, 2H, ArH), 7.65-7.69 (m, 2H, ArH), 8.21 (d, J = 7.6 Hz, $2 \mathrm{H}, \mathrm{ArH}) .{ }^{13} \mathrm{C}-\mathrm{NMR}\left(\mathrm{CDCl}_{3}\right): \delta 15.51,32.25,110.39,115.29,115.50,118.26,118.44,124.75,125.53$, $128.72,128.87,129.69,129.77,130.33,134.04,134.35,146.99,152.79,152.99,160.35,161.56$, 162.78, 164.61. HRMS (ESI): $m / z$ 389.11849 $\left(\mathrm{M}+\mathrm{H}^{+}\right), 411.10049\left(\mathrm{M}+\mathrm{Na}^{+}\right), 427.07456\left(\mathrm{M}+\mathrm{K}^{+}\right)$.

4-Ethyl-3-(4-fluorobenzyl)-2-oxo-2H-chromen-7-yl benzoate (67). Yield: $0.073 \mathrm{~g}, 36 \%$, white solid, m.p.: $70-71{ }^{\circ} \mathrm{C} .{ }^{1} \mathrm{H}-\mathrm{NMR}\left(\mathrm{CDCl}_{3}\right): \delta 1.18\left(\mathrm{t}, J=7.2 \mathrm{~Hz}, 3 \mathrm{H}, \mathrm{CH}_{2} \mathrm{CH}_{3}\right), 2.89$ (q, $J=7.2 \mathrm{~Hz}, 2 \mathrm{H}$, $\left.\mathrm{C}_{2} \mathrm{CH}_{3}\right), 4.02\left(\mathrm{~s}, 2 \mathrm{H}, \mathrm{CH}_{2} \mathrm{Ph}\right), 6.96(\mathrm{t}, J=8.0 \mathrm{~Hz}, 2 \mathrm{H}, \mathrm{ArH}), 7.22-7.25$ (m, 4H, ArH), 7.53-7.69 (m, $4 \mathrm{H}, \mathrm{ArH}), 8.21(\mathrm{~d}, J=7.2 \mathrm{~Hz}, 2 \mathrm{H}, \mathrm{ArH}) .{ }^{13} \mathrm{C}-\mathrm{NMR}\left(\mathrm{CDCl}_{3}\right): \delta 18.27,27.27,36.85,115.62,120.24$, $120.46,122.21,123.27,128.77,130.45,133.70,133.90,134.61,134.69,135.31,139.01,139.54$, $157.53,157.70,158.55,166.82,167.78,169.59$. HRMS (ESI): $m / z 403.13421\left(\mathrm{M}+\mathrm{H}^{+}\right)$.

3-(4-Fluorobenzyl)-2-oxo-4-propyl-2H-chromen-7-yl benzoate (68). Yield: $0.176 \mathrm{~g}, 85 \%$, white solid, m.p.: $95-96{ }^{\circ} \mathrm{C} .{ }^{1} \mathrm{H}-\mathrm{NMR}\left(\mathrm{CDCl}_{3}\right): \delta 1.06\left(\mathrm{t}, J=7.2 \mathrm{~Hz}, 3 \mathrm{H}, \mathrm{CH}_{2} \mathrm{C}_{3}\right), 1.53-1.58(\mathrm{~m}, J=7.2 \mathrm{~Hz}, 2 \mathrm{H}$, $\left.\mathrm{CH}_{2} \underline{\mathrm{C}}_{2} \mathrm{CH}_{3}\right), 2.83$ (t, $\left.J=7.6 \mathrm{~Hz}, 2 \mathrm{H}, \underline{\mathrm{C}}_{2} \mathrm{CH}_{2} \mathrm{CH}_{3}\right), 4.02\left(\mathrm{~s}, 2 \mathrm{H}, \underline{\mathrm{C}}_{2} \mathrm{Ph}\right), 6.96$ (t, $J=8.4 \mathrm{~Hz}, 2 \mathrm{H}$, 
ArH), 7.19-7.25 (m, 4H, ArH), 7.52-7.55 (m, 2H, ArH), 7.65-7.69 (m, 2H, ArH), 8.21 (d, J= 8.0 Hz, $2 \mathrm{H}, \mathrm{ArH}) .{ }^{13} \mathrm{C}-\mathrm{NMR}\left(\mathrm{CDCl}_{3}\right): \delta 14.51,22.56,31.18,32.04,110.60,115.26,115.47,117.54,118.26$, $124.13,125.60,128.73,128.87,129.61,129.68,130.33,134.05,134.59,134.62,151.26,152.66$, 153.45, 160.35, 161.83, 162.78, 164.62. HRMS (ESI): $m / z 417.14989\left(\mathrm{M}^{+} \mathrm{H}^{+}\right), 439.13191\left(\mathrm{M}^{+} \mathrm{Na}^{+}\right)$, $455.10528\left(\mathrm{M}+\mathrm{K}^{+}\right)$.

3-Benzyl-4-methyl-2-oxo-2H-chromen-7-yl benzenesulfonate (69). Yield: $0.138 \mathrm{~g}, 68 \%$, white solid, m.p.: 131-132 ${ }^{\circ} \mathrm{C} .{ }^{1} \mathrm{H}-\mathrm{NMR}\left(\mathrm{CDCl}_{3}\right): \delta 2.43$ (s, 3H, $\left.\underline{\mathrm{C}}_{3}\right), 4.04$ (s, 2H, $\left.\underline{\mathrm{C}}_{2} \mathrm{Ph}\right), 6.84(\mathrm{~s}, 1 \mathrm{H}, \mathrm{H}-8), 7.06$ (d, $J=8.8 \mathrm{~Hz}, 1 \mathrm{H}, \mathrm{H}-6), 7.19-7.29\left(\mathrm{~m}, 5 \mathrm{H}, \mathrm{CH}_{2} \mathrm{Ph}\right), 7.53-7.58\left(\mathrm{~m}, 3 \mathrm{H}, \mathrm{H}-5\right.$ and $\left.\mathrm{PhSO}_{3}\right), 7.70$ (t, $\left.J=7.6 \mathrm{~Hz}, 1 \mathrm{H}, \mathrm{PhSO}_{3}\right), 7.86\left(\mathrm{~d}, J=7.6 \mathrm{~Hz}, 2 \mathrm{H}, \mathrm{PhSO}_{3}\right) .{ }^{13} \mathrm{C}-\mathrm{NMR}\left(\mathrm{CDCl}_{3}\right): \delta 15.54,33.03,110.61$, $118.69,119.57,125.67,125.80,126.51,128.31,128.46,128.64,129.43,134.70,135.03,138.45$, 146.56, 150.76, 152.59, 161.20. HRMS (ESI): $m / z 407.09446\left(\mathrm{M}^{+} \mathrm{H}^{+}\right), 429.07635\left(\mathrm{M}^{+} \mathrm{Na}^{+}\right)$, $445.05041\left(\mathrm{M}+\mathrm{K}^{+}\right)$.

3-Benzyl-6-chloro-4-methyl-2-oxo-2H-chromen-7-yl benzenesulfonate (70). Yield: $0.165 \mathrm{~g}, 75 \%$, white solid, m.p.: $154-155{ }^{\circ} \mathrm{C} .{ }^{1} \mathrm{H}-\mathrm{NMR}\left(\mathrm{CDCl}_{3}\right): \delta 2.41$ (s, 3H, $\left.\underline{\mathrm{C}}_{3}\right), 4.05$ (s, 2H, $\left.\underline{\mathrm{H}}_{2} \mathrm{Ph}\right), 7.19-7.25$ (m, 6H, ArH), 7.58-7.60 (m, 3H, ArH), 7.73 (m, 1H, ArH), 7.93 (d, $J=6.4 \mathrm{~Hz}, 2 \mathrm{H}, \mathrm{ArH}) .{ }^{13} \mathrm{C}-\mathrm{NMR}$ $\left(\mathrm{CDCl}_{3}\right): \delta 15.54,33.13,112.33,120.38,123.50,126.11,126.62,126.78,128.30,128.60,128.70$, $129.47,134.91,135.37,138.15,145.50,146.48,150.83,160.73$. HRMS (ESI): $\mathrm{m} / z \quad 441.05606$ $\left(\mathrm{M}+\mathrm{H}^{+}\right), 463.03794\left(\mathrm{M}+\mathrm{Na}^{+}\right), 479.01170\left(\mathrm{M}+\mathrm{K}^{+}\right)$.

3-Benzyl-4-ethyl-2-oxo-2H-chromen-7-yl benzenesulfonate (71). Yield: 0.187 g, 89\%, white solid, m.p.: 57-58 ${ }^{\circ} \mathrm{C} .{ }^{1} \mathrm{H}-\mathrm{NMR}\left(\mathrm{CDCl}_{3}\right): \delta 1.11\left(\mathrm{t}, J=7.2 \mathrm{~Hz}, 3 \mathrm{H}, \mathrm{CH}_{2} \mathrm{CH}_{3}\right), 2.84\left(\mathrm{t}, J=7.2 \mathrm{~Hz}, 2 \mathrm{H}, \mathrm{C}_{2} \mathrm{CH}_{3}\right)$, 4.01 (s, 2H, $\left.\underline{\mathrm{H}}_{2} \mathrm{Ph}\right), 6.88$ (s, 1H, H-8), 7.03 (d, $\left.J=8.8 \mathrm{~Hz}, 1 \mathrm{H}, \mathrm{H}-6\right), 7.16-7.24$ (m, 5H, $\left.\mathrm{CH}_{2} \mathrm{Ph}\right)$, 7.52-7.58 (m, 3H, H-5 and $\left.\mathrm{PhSO}_{3}\right), 7.67-7.70\left(\mathrm{~m}, J=7.2 \mathrm{~Hz}, 1 \mathrm{H}, \mathrm{PhSO}_{3}\right), 7.86(\mathrm{~d}, J=8.0 \mathrm{~Hz}, 2 \mathrm{H}$, $\left.\mathrm{PhSO}_{3}\right) .{ }^{13} \mathrm{C}-\mathrm{NMR}\left(\mathrm{CDCl}_{3}\right): \delta 18.15,27.28,37.62,115.83,123.38,123.66,129.67,130.88,131.48$, 133.24, 133.42, 133.61, 134.48, 139.76, 140.02, 143.69, 155.63, 157.23, 158.14, 166.51. HRMS (ESI): $\mathrm{m} / \mathrm{z} 421.11015\left(\mathrm{M}+\mathrm{H}^{+}\right), 443.09190\left(\mathrm{M}+\mathrm{Na}^{+}\right), 459.06604\left(\mathrm{M}+\mathrm{K}^{+}\right)$.

3-Benzyl-2-oxo-4-propyl-2H-chromen-7-yl benzenesulfonate (72). Yield: $0.155 \mathrm{~g}, 71 \%$, white solid, m.p.: $96{ }^{\circ} \mathrm{C} .{ }^{1} \mathrm{H}-\mathrm{NMR}\left(\mathrm{CDCl}_{3}\right): \delta 1.03$ (br s, $3 \mathrm{H}, \mathrm{CH}_{2} \mathrm{CH}_{3}$ ), 1.49 (br s, $2 \mathrm{H}, \mathrm{CH}_{2} \mathrm{CH}_{3}$ ), 2.79 (br s, 2H, $\left.\mathrm{C}_{2} \mathrm{CH}_{2} \mathrm{CH}_{3}\right), 4.02\left(\mathrm{~s}, 2 \mathrm{H}, \underline{\mathrm{C}}_{2} \mathrm{Ph}\right), 6.84(\mathrm{~s}, 1 \mathrm{H}, \mathrm{H}-8), 7.06$ (d, J = 6.8 Hz, 1H, H-6), 7.24 (m, 5H, $\mathrm{CH}_{2} \mathrm{Ph}$ ), 7.56 (br s, $3 \mathrm{H}, \mathrm{H}-5$ and $\mathrm{PhSO}_{3}$ ), 7.71 (br s, $\left.1 \mathrm{H}, \mathrm{PhSO}_{3}\right), 7.87$ (d, $J=6.0 \mathrm{~Hz}, 2 \mathrm{H}, \mathrm{PhSO}_{3}$ ). ${ }^{13} \mathrm{C}-\mathrm{NMR}\left(\mathrm{CDCl}_{3}\right): \delta 14.48,22.43,31.15,32.81,110.81,118.71,125.07,125.86,126.52,128.21$, $128.46,128.62,129.45,134.71,135.09,138.69,150.64,150.80,153.06,161.48$. HRMS (ESI): $\mathrm{m} / z$ $435.12627\left(\mathrm{M}+\mathrm{H}^{+}\right), 457.10839\left(\mathrm{M}+\mathrm{Na}^{+}\right), 473.08227\left(\mathrm{M}+\mathrm{K}^{+}\right)$.

4-Ethyl-3-(4-fluorobenzyl)-2-oxo-2H-chromen-7-yl benzenesulfonate (73). Yield: $0.195 \mathrm{~g}, 89 \%$, white solid, m.p.: 93-94 ${ }^{\circ} \mathrm{C} .{ }^{1} \mathrm{H}-\mathrm{NMR}\left(\mathrm{CDCl}_{3}\right): \delta 1.14\left(\mathrm{t}, J=7.6 \mathrm{~Hz}, 3 \mathrm{H}, \mathrm{CH}_{2} \mathrm{CH}_{3}\right), 2.85(\mathrm{q}, J=7.6 \mathrm{~Hz}, 2 \mathrm{H}$, $\left.\mathrm{C}_{2} \mathrm{CH}_{3}\right), 3.97$ (s, 2H, $\left.\underline{\mathrm{H}}_{2} \mathrm{Ph}\right), 6.87(\mathrm{~s}, 1 \mathrm{H}, \mathrm{H}-8), 6.94$ (t, $\left.J=8.4 \mathrm{~Hz}, 2 \mathrm{H}, \mathrm{CH}_{2} \mathrm{Ph}\right), 7.07$ (d, J=8.4 Hz, 1H, H-6), 7.19-7.23 (m, 2H, $\mathrm{CH}_{2} \mathrm{Ph}$ ), 7.55-7.60 (m, 3H, H-5 and $\mathrm{PhSO}_{3}$ ), 7.69-7.73 (m, 1H, $\mathrm{PhSO}_{3}$ ), $7.87\left(\mathrm{~d}, J=8.0 \mathrm{~Hz}, 2 \mathrm{H}, \mathrm{PhSO}_{3}\right) \cdot{ }^{13} \mathrm{C}-\mathrm{NMR}\left(\mathrm{CDCl}_{3}\right): \delta 13.22,22.26,31.87,110.89,115.28,115.49$, $118.26,118.79,124.53,125.83,128.44,129.45,129.65,129.73,134.27,134.30,134.74,135.08$, 
150.73, 152.19, 153.15, 160.36, 161.44, 162.79. HRMS (ESI): $m / z 439.10053\left(\mathrm{M}+\mathrm{H}^{+}\right), 461.08240$ $\left(\mathrm{M}+\mathrm{Na}^{+}\right), 477.05639\left(\mathrm{M}+\mathrm{K}^{+}\right)$.

3-(4-Fluorobenzyl)-4-methyl-2-oxo-2H-chromen-7-yl benzenesulfonate (74). Yield: $0.153 \mathrm{~g}, 72 \%$, white solid, m.p.: $108-109{ }^{\circ} \mathrm{C} .{ }^{1} \mathrm{H}-\mathrm{NMR}\left(\mathrm{CDCl}_{3}\right): \delta 2.44$ (s, 3H, $\left.\underline{\mathrm{C}}_{3}\right), 3.99\left(\mathrm{~s}, 2 \mathrm{H}, \mathrm{C}_{2} \mathrm{Ph}\right), 6.85$ (s, $1 \mathrm{H}, \mathrm{H}-8), 6.93-6.97$ (m, $\left.J=8.4 \mathrm{~Hz}, 2 \mathrm{H}, \mathrm{CH}_{2} \mathrm{Ph}\right), 7.07$ (d, $\left.J=8.8 \mathrm{~Hz}, 1 \mathrm{H}, \mathrm{H}-6\right), 7.19-7.23$ (m, 2H, $\left.\mathrm{CH}_{2} \mathrm{Ph}\right), 7.54-7.59\left(\mathrm{~m}, 3 \mathrm{H}, \mathrm{H}-5\right.$ and $\left.\mathrm{PhSO}_{3}\right), 7.69-7.71\left(\mathrm{~m}, 1 \mathrm{H}, \mathrm{PhSO}_{3}\right), 7.86(\mathrm{~d}, J=7.6 \mathrm{~Hz}, 2 \mathrm{H}$, $\left.\mathrm{PhSO}_{3}\right) .{ }^{13} \mathrm{C}-\mathrm{NMR}\left(\mathrm{CDCl}_{3}\right): \delta 15.50,32.27,110.65,115.31,115.52,118.76,119.47,125.52,125.86$, $128.45,129.44,129.72,129.80,134.05,134.09,134.72,135.03,146.56,150.84,152.59,160.36$, 161.13, 162.80. HRMS (ESI): $m / z 425.08559\left(\mathrm{M}+\mathrm{H}^{+}\right), 447.06760\left(\mathrm{M}+\mathrm{Na}^{+}\right), 463.04156\left(\mathrm{M}^{+} \mathrm{K}^{+}\right)$.

3-(4-Fluorobenzyl)-2-oxo-4-propyl-2H-chromen-7-yl benzenesulfonate (75). Yield: $0.104 \mathrm{~g}, 46 \%$, white solid, m.p.: ${ }^{109-110}{ }^{\circ} \mathrm{C} .{ }^{1} \mathrm{H}-\mathrm{NMR}\left(\mathrm{CDCl}_{3}\right): \delta 1.04\left(\mathrm{t}, J=7.2 \mathrm{~Hz}, 3 \mathrm{H}, \mathrm{CH}_{2} \mathrm{CH}_{3}\right), 1.48-1.54(\mathrm{~m}$, $\left.J=7.6 \mathrm{~Hz}, 2 \mathrm{H}, \mathrm{CH}_{2} \underline{\mathrm{C}}_{2} \mathrm{CH}_{3}\right), 2.79$ (t, $\left.J=7.6 \mathrm{~Hz}, 2 \mathrm{H}, \underline{\mathrm{C}}_{2} \mathrm{CH}_{2} \mathrm{CH}_{3}\right), 3.97$ (s, 2H, $\left.\underline{\mathrm{H}}_{2} \mathrm{Ph}\right), 6.86(\mathrm{~s}, 1 \mathrm{H}$, $\mathrm{H}-8), 6.95$ (t, $J=8.4 \mathrm{~Hz}, 2 \mathrm{H}, \mathrm{CH}_{2} \mathrm{Ph}$ ), 7.07 (d, $\left.J=8.8 \mathrm{~Hz}, 1 \mathrm{H}, \mathrm{H}-6\right), 7.19-7.22$ (m, 2H, $\mathrm{CH}_{2} \mathrm{Ph}$ ), 7.55-7.59 $\left(\mathrm{m}, 3 \mathrm{H}, \mathrm{H}-5\right.$ and $\left.\mathrm{PhSO}_{3}\right), 7.69-7.73\left(\mathrm{~m}, 1 \mathrm{H}, \mathrm{PhSO}_{3}\right), 7.88\left(\mathrm{~d}, J=7.6 \mathrm{~Hz}, 2 \mathrm{H}, \mathrm{PhSO}_{3}\right) .{ }^{13} \mathrm{C}-\mathrm{NMR}$ $\left(\mathrm{CDCl}_{3}\right): \delta 14.48,22.48,31.13,32.05,110.85,115.29,115.50,118.56,118.76,124.89,125.90,128.45$, $129.45,129.63,129.70,134.32,134.72,135.10,150.72,150.82,153.07,160.37,161.40,162.81$. HRMS (ESI): $m / z 453.11683\left(\mathrm{M}+\mathrm{H}^{+}\right), 475.09903\left(\mathrm{M}+\mathrm{Na}^{+}\right), 491.07253\left(\mathrm{M}+\mathrm{K}^{+}\right)$.

3-Benzyl-4-methyl-2-oxo-2H-chromen-7-yl 4-methylbenzenesulfonate (76). Yield: $0.103 \mathrm{~g}$, 49\%, white solid, m.p.: $138-139{ }^{\circ} \mathrm{C} .{ }^{1} \mathrm{H}-\mathrm{NMR}\left(\mathrm{CDCl}_{3}\right): \delta 2.43\left(\mathrm{~s}, 3 \mathrm{H}, \mathrm{C}_{3}\right), 2.46\left(\mathrm{~s}, 3 \mathrm{H}, \mathrm{C}_{3}\right), 4.03(\mathrm{~s}, 2 \mathrm{H}$, $\left.\mathrm{CH}_{2} \mathrm{Ph}\right), 6.82(\mathrm{~s}, 1 \mathrm{H}, \mathrm{H}-8), 7.08$ (d, $\left.J=8.8 \mathrm{~Hz}, 1 \mathrm{H}, \mathrm{H}-6\right), 7.18-7.28\left(\mathrm{~m}, 5 \mathrm{H}, \mathrm{CH}_{2} \mathrm{Ph}\right), 7.33$ (d, $J=8.0 \mathrm{~Hz}$, $\left.2 \mathrm{H}, \mathrm{PhSO}_{3}\right), 7.57$ (d, $\left.J=8.8 \mathrm{~Hz}, 1 \mathrm{H}, \mathrm{H}-5\right), 7.72$ (d, $\left.J=8.0 \mathrm{~Hz}, 2 \mathrm{H}, \mathrm{PhSO}_{3}\right) .{ }^{13} \mathrm{C}-\mathrm{NMR}\left(\mathrm{CDCl}_{3}\right): \delta$ $15.54,21.79,33.02,110.59,118.80,119.49,125.57,125.79,126.50,128.31,128.48,128.63,130.07$,

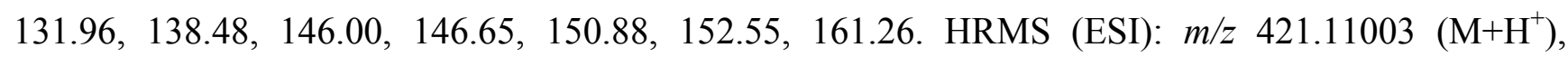
$443.09190\left(\mathrm{M}+\mathrm{Na}^{+}\right), 459.06602\left(\mathrm{M}+\mathrm{K}^{+}\right)$.

3-Benzyl-6-chloro-4-methyl-2-oxo-2H-chromen-7-yl 4-methylbenzenesulfonate (77). Yield: $0.136 \mathrm{~g}$, 60\%, white solid, m.p.: $173-174{ }^{\circ} \mathrm{C} .{ }^{1} \mathrm{H}-\mathrm{NMR}\left(\mathrm{CDCl}_{3}\right): \delta 2.41\left(\mathrm{~s}, 3 \mathrm{H}, \mathrm{C}_{3}\right), 2.48\left(\mathrm{~s}, 3 \mathrm{H}, \mathrm{C}_{3}\right), 4.04$ (s, $2 \mathrm{H}, \mathrm{C}_{2} \mathrm{Ph}$ ), 7.16 (s, 1H, H-8), 7.19-7.27 (m, 5H, $\left.\mathrm{CH}_{2} \mathrm{Ph} \underline{\mathrm{H}}\right), 7.36$ (d, J=8.0 Hz, 2H, ArH), 7.60 (s, $1 \mathrm{H}, \mathrm{H}-5), 7.80$ (d, $J=7.6 \mathrm{~Hz}, 2 \mathrm{H}, \mathrm{ArH}) .{ }^{13} \mathrm{C}-\mathrm{NMR}\left(\mathrm{CDCl}_{3}\right): \delta 15.54,21.83,33.11,112.23,120.28$, $123.60,126.10,126.61,126.68,128.30,128.63,128.69,130.10,132.32,138.17,145.57,146.26$, 146.61, 150.81, 160.78. HRMS (ESI): $m / z 455.07186\left(\mathrm{M}+\mathrm{H}^{+}\right)$.

3-Benzyl-4-ethyl-2-oxo-2H-chromen-7-yl 4-methylbenzenesulfonate (78). Yield: $0.169 \mathrm{~g}$, 78\%, white solid, m.p.: $66-68{ }^{\circ} \mathrm{C} .{ }^{1} \mathrm{H}-\mathrm{NMR}\left(\mathrm{CDCl}_{3}\right): \delta 1.13\left(\mathrm{t}, J=7.6 \mathrm{~Hz}, 3 \mathrm{H}, \mathrm{CH}_{2} \mathrm{CH}_{3}\right), 2.46\left(\mathrm{~s}, 3 \mathrm{H}, \mathrm{CH}_{3}\right), 2.85$ (q, $\left.J=7.6 \mathrm{~Hz}, 2 \mathrm{H}, \underline{\mathrm{C}}_{2} \mathrm{CH}_{3}\right), 4.01\left(\mathrm{~s}, 2 \mathrm{H}, \underline{\mathrm{C}}_{2} \mathrm{Ph}\right), 6.84$ (d, $\left.J=1.6 \mathrm{~Hz}, 1 \mathrm{H}, \mathrm{H}-8\right), 7.07-7.10$ (dd, $J=1.6,8.8 \mathrm{~Hz}, 1 \mathrm{H}, \mathrm{H}-6), 7.18-7.26$ (m, 5H, $\left.\mathrm{CH}_{2} \mathrm{Ph}\right), 7.34$ (d, $\left.J=8.0 \mathrm{~Hz}, 2 \mathrm{H}, \mathrm{PhSO}_{3}\right), 7.57$ (d, $J=8.8 \mathrm{~Hz}$, $1 \mathrm{H}, \mathrm{H}-5), 7.74\left(\mathrm{~d}, J=8.0 \mathrm{~Hz}, 2 \mathrm{H}, \mathrm{PhSO}_{3}\right) .{ }^{13} \mathrm{C}-\mathrm{NMR}\left(\mathrm{CDCl}_{3}\right): \delta 18.14,26.77,27.26,37.60,115.83$, $123.27,123.83,129.61,130.74,131.48,133.22$, 133.46, 133.60, 135.06, 137.05, 143.67, 150.98, 155.77, 157.18, 158.12, 166.55. HRMS (ESI): $m / z$ 435.12593 (M+H'), $457.10761\left(\mathrm{M}^{+} \mathrm{Na}^{+}\right)$, $473.08160\left(\mathrm{M}+\mathrm{K}^{+}\right)$. 
3-Benzyl-2-oxo-4-propyl-2H-chromen-7-yl 4-methylbenzenesulfonate (79). Yield: $0.159 \mathrm{~g}, 80 \%$, white solid, m.p.: $120{ }^{\circ} \mathrm{C} .{ }^{1} \mathrm{H}-\mathrm{NMR}\left(\mathrm{CDCl}_{3}\right): \delta 1.04\left(\mathrm{t}, J=7.2 \mathrm{~Hz}, 3 \mathrm{H}, \mathrm{CH}_{2} \mathrm{CH}_{3}\right), 1.48(\mathrm{q}, J=7.2 \mathrm{~Hz}, 3 \mathrm{H}$, $\left.\mathrm{C}_{2} \mathrm{CH}_{3}\right), 2.47$ (s, 3H, $\left.\mathrm{CH}_{3}\right), 2.79$ (q, $\left.J=7.6 \mathrm{~Hz}, 2 \mathrm{H}, \mathrm{C}_{2} \mathrm{CH}_{2} \mathrm{CH}_{3}\right), 4.02\left(\mathrm{~s}, 2 \mathrm{H}, \mathrm{CH}_{2} \mathrm{Ph}\right), 6.81(\mathrm{~s}, 1 \mathrm{H}$, $\mathrm{H}-8$ ), 7.09 (d, $J=8.4 \mathrm{~Hz}, 1 \mathrm{H}, \mathrm{H}-6), 7.19-7.25$ (m, 5H, $\left.\mathrm{CH}_{2} \mathrm{Ph}\right), 7.34$ (d, $\left.J=7.6 \mathrm{~Hz}, 2 \mathrm{H}, \mathrm{PhSO}_{3}\right), 7.55$ $(\mathrm{d}, J=8.8 \mathrm{~Hz}, 1 \mathrm{H}, \mathrm{H}-5), 7.74\left(\mathrm{~d}, J=7.6 \mathrm{~Hz}, 2 \mathrm{H}, \mathrm{PhSO}_{3}\right) .{ }^{13} \mathrm{C}-\mathrm{NMR}\left(\mathrm{CDCl}_{3}\right): \delta 14.48,21.80,22.44$, $31.15,32.80,110.80,118.59,118.84,124.98,125.83,126.51,128.21,128.48,128.61,130.07,132.04$, 138.71, 145.99, 150.76, 150.86, 153.03, 161.54. HRMS (ESI): $m / z 449.14190\left(\mathrm{M}+\mathrm{H}^{+}\right), 471.12381$ $\left(\mathrm{M}+\mathrm{Na}^{+}\right), 487.09789\left(\mathrm{M}+\mathrm{K}^{+}\right)$.

4-Ethyl-3-(4-fluorobenzyl)-2-oxo-2H-chromen-7-yl 4-methylbenzenesulfonate (80). Yield: $0.132 \mathrm{~g}$, 58\%, white solid, m.p.: $96-97{ }^{\circ} \mathrm{C} .{ }^{1} \mathrm{H}-\mathrm{NMR}\left(\mathrm{CDCl}_{3}\right): \delta 1.15\left(\mathrm{t}, J=7.2 \mathrm{~Hz}, 3 \mathrm{H}, \mathrm{CH}_{2} \mathrm{CH}_{3}\right), 2.47$ (s, 2H, $\mathrm{CH}_{3}$ ), 2.85 (q, $\left.J=7.2 \mathrm{~Hz}, 2 \mathrm{H}, \underline{\mathrm{C}}_{2} \mathrm{CH}_{3}\right), 3.97\left(\mathrm{~s}, 2 \mathrm{H}, \underline{\mathrm{C}}_{2} \mathrm{Ph}\right), 6.84$ (s, $\left.1 \mathrm{H}, \mathrm{H}-8\right), 6.95$ (t, $J=8.0 \mathrm{~Hz}$, $2 \mathrm{H}, \mathrm{CH}_{2} \mathrm{Ph}$ ), 7.10 (d, J=8.4 Hz, 1H, H-6), 7.21 (m, 2H, $\left.\mathrm{CH}_{2} \mathrm{Ph}\right), 7.35$ (t, J=7.6 Hz, 2H, $\left.\mathrm{PhSO}_{3}\right), 7.59$ $(\mathrm{d}, J=8.8 \mathrm{~Hz}, 1 \mathrm{H}, \mathrm{H}-5), 7.74\left(\mathrm{~d}, J=7.6 \mathrm{~Hz}, 2 \mathrm{H}, \mathrm{PhSO}_{3}\right) .{ }^{13} \mathrm{C}-\mathrm{NMR}\left(\mathrm{CDCl}_{3}\right): \delta 13.22,21.80,22.27$, $31.86,110.89,115.29,115.50,118.17,118.96,124.45,125.77,128.47,129.64,129.72,130.08$, $132.04,134.27,134.30,146.02,150.85,152.23,153.12,160.37,161.50,162.80$. HRMS (ESI): $\mathrm{m} / z$ $453.11738\left(\mathrm{M}+\mathrm{H}^{+}\right)$.

3-(4-Fluorobenzyl)-4-methyl-2-oxo-2H-chromen-7-yl 4-methylbenzenesulfonate (81). Yield: $0.145 \mathrm{~g}$, 66\%, white solid, m.p.: 95-96 ${ }^{\circ} \mathrm{C} .{ }^{1} \mathrm{H}-\mathrm{NMR}\left(\mathrm{CDCl}_{3}\right): \delta 2.44$ (s, 3H, $\left.\underline{\mathrm{C}}_{3}\right), 2.47$ (s, 3H, $\left.\mathrm{C}_{3}\right), 3.99$ (s, $2 \mathrm{H}, \mathrm{CH}_{2} \mathrm{Ph}$ ), 6.83 (s, 1H, H-8), 6.93-6.97 (m, $J=8.4 \mathrm{~Hz}, 2 \mathrm{H}, \mathrm{CH}_{2} \mathrm{Ph}$ ), 7.09 (d, $\left.J=8.8 \mathrm{~Hz}, 1 \mathrm{H}, \mathrm{H}-6\right)$, $7.20-7.22\left(\mathrm{~m}, 2 \mathrm{H}, \mathrm{CH}_{2} \mathrm{Ph}\right), 7.34$ (d, $\left.J=7.6 \mathrm{~Hz}, 2 \mathrm{H}, \mathrm{PhSO}_{3}\right), 7.58$ (d, $\left.J=8.4 \mathrm{~Hz}, 1 \mathrm{H}, \mathrm{H}-5\right), 7.72$ (d, $\left.J=8.0 \mathrm{~Hz}, 2 \mathrm{H}, \mathrm{PhSO}_{3}\right) .{ }^{13} \mathrm{C}-\mathrm{NMR}\left(\mathrm{CDCl}_{3}\right): \delta 15.51,21.79,32.26,110.64,115.31,115.52,118.88$, $119.38,125.42,125.83,128.47,129.72,129.80,130.07,131.98,134.08,134.11,146.02,146.63$, 150.95, 152.56, 160.36, 161.19, 162.79. HRMS (ESI): $m / z 439.10127\left(\mathrm{M}^{+} \mathrm{H}^{+}\right), 461.08292\left(\mathrm{M}^{+} \mathrm{Na}^{+}\right)$, $477.05669\left(\mathrm{M}+\mathrm{K}^{+}\right)$.

3-(4-Fluorobenzyl)-2-oxo-4-propyl-2H-chromen-7-yl 4-methylbenzenesulfonate (82). Yield: $0.134 \mathrm{~g}$, 58\%, white solid, m.p.: $110-111^{\circ} \mathrm{C} .{ }^{1} \mathrm{H}-\mathrm{NMR}\left(\mathrm{CDCl}_{3}\right): \delta 1.05\left(\mathrm{t}, J=7.2 \mathrm{~Hz}, 3 \mathrm{H}, \mathrm{CH}_{2} \mathrm{C}_{3}\right), 1.49-1.54$ (m, $\left.J=7.2 \mathrm{~Hz}, 2 \mathrm{H}, \mathrm{CH}_{2} \mathrm{CH}_{2} \mathrm{CH}_{3}\right), 2.47$ (s, 3H, $\mathrm{CH}_{3}$ ), 2.79 (t, $J=7.6 \mathrm{~Hz}, 2 \mathrm{H}, \mathrm{CH}_{2} \mathrm{CH}_{2} \mathrm{CH}_{3}$ ), 3.98 (s, $\left.2 \mathrm{H}, \underline{\mathrm{C}}_{2} \mathrm{Ph}\right), 6.83$ (s, 1H, H-8), 6.93-6.97 (m, $\left.J=6.8 \mathrm{~Hz}, 2 \mathrm{H}, \mathrm{CH}_{2} \mathrm{Ph}\right), 7.10$ (d, $\left.J=8.8 \mathrm{~Hz}, 1 \mathrm{H}, \mathrm{H}-6\right)$, 7.19-7.22 (m, 2H, $\left.\mathrm{CH}_{2} \mathrm{Ph}\right), 7.35$ (d, $\left.J=7.2 \mathrm{~Hz}, 2 \mathrm{H}, \mathrm{PhSO}_{3}\right), 7.56$ (d, $\left.J=8.8 \mathrm{~Hz}, 1 \mathrm{H}, \mathrm{H}-5\right), 7.74$ (d, $\left.J=6.8 \mathrm{~Hz}, 2 \mathrm{H}, \mathrm{PhSO}_{3}\right) .{ }^{13} \mathrm{C}-\mathrm{NMR}\left(\mathrm{CDCl}_{3}\right): \delta 14.48,21.80,22.49,31.14,32.05,110.84,115.28$, $115.50,118.48,118.90,124.80,125.87,128.47,129.62,129.70,130.07,132.05,134.31,134.34$, $146.01,150.84,150.89,153.03,160.37,161.46,162.80$. HRMS (ESI): $m / z 467.13229\left(\mathrm{M}^{+} \mathrm{H}^{+}\right)$, $489.11399\left(\mathrm{M}+\mathrm{Na}^{+}\right), 505.08809\left(\mathrm{M}+\mathrm{K}^{+}\right)$.

3.2.6. Procedure for the Preparation of 3-Benzyl-7-methoxy-2H-chromen-2-one (83) [25]

Step 1: Preparation of 2-hydroxy-4-methoxybenzaldehyde (6) [35]

To the solution of compound 2,4-dimethoxybenzaldehyde (5, $10 \mathrm{~g}, 60 \mathrm{mmol}, 1$ equiv.) in dry dichloromethane $(200 \mathrm{~mL})$ was added dropwise $\mathrm{AlCl}_{3}(20$ g. $150 \mathrm{mmol}, 2.5$ equiv. $)$ at room temperature, the mixture was stirred for $1 \mathrm{~h}$ and poured into $3 \mathrm{~mol} / \mathrm{L} \mathrm{HCl}$ solution. The reaction 
mixture was extractrd with $\mathrm{CH}_{2} \mathrm{Cl}_{2}$ three times and the organic extracts were combined, washed with brine and dried over $\mathrm{MgSO}_{4}$. The solvent was removed under reduced pressure. Purification of the residue by flash column chromatography (PE-EA $=20: 1)$ to afford 2-hydroxy-4-methoxybenzaldehyde (6) as a white powder $(7.917 \mathrm{~g}, 86.7 \%)$, m.p.: $35-36{ }^{\circ} \mathrm{C} .{ }^{1} \mathrm{H}-\mathrm{NMR}\left(\mathrm{CDCl}_{3}\right): \delta 3.86\left(\mathrm{~s}, 3 \mathrm{H}, \mathrm{CH}_{3}\right), 6.43$ (d, $J=2.4 \mathrm{~Hz}, 1 \mathrm{H}, \mathrm{PhH}), 6.53-6.56$ (dd, $J=2.4,8.8 \mathrm{~Hz}, 1 \mathrm{H}, \mathrm{PhH}), 7.43$ (d, $J=8.8 \mathrm{~Hz}, 1 \mathrm{H}, \mathrm{PhH}), 9.72$ (s, 1H, OH), 11.49 (s, 1H, CHO).

Step 2: Preparation of ethoxycarbonylbenzylmethylene triphenylphosphorane (8a)

To a solution of benzyl bromide $(0.3 \mathrm{~mL}, 2.53 \mathrm{mmol}, 1.05$ equiv. $)$ in dry chloroform $(20 \mathrm{~mL})$, ethoxycarbonyl methylene triphenylphosphorane (7, $0.835 \mathrm{~g}, 2.4 \mathrm{mmol}, 1$ equiv.) was added at room temperature. After stirring for $30 \mathrm{~min}$ at r.t., the mixture was refluxed for $15 \mathrm{~h}$. The solvent was removed under reduced pressure to afford the phosphonium salt as an oil. This salt was dissolved in water $(50 \mathrm{~mL})$ and dichloromethane $(50 \mathrm{~mL})$ was added. It was then made alkaline (phenolphthalein colorless to pink) with $2 \mathrm{M} \mathrm{NaOH}$. The dichloromethane layer was separated and the aqueous layer was extracted with dichloromethane $(50 \mathrm{~mL} \times 2)$. The combined dichloromethane extract was dried over $\mathrm{MgSO}_{4}$ and solvent was removed to give the phosphorane, which was recrystallised from chloroform-hexane as yellowish needles (0.680 g, 81.3\%), m.p.: $133-134{ }^{\circ} \mathrm{C}$. MS (ESI): $\mathrm{m} / z 439.2$ $\left(\mathrm{M}+\mathrm{H}^{+}\right)$.

Step 3: Preparation of (E)-ethyl 2-benzyl-3-(2-hydroxy-4-methoxyphenyl) acrylate (9a)

A mixture of compound 6 (0.858 g, 5.645 mmol, 1 equiv.) and compound 8a (3.045 g, 6.944 mmol, 1.23 equiv.) was refluxed at $85{ }^{\circ} \mathrm{C}$ in dry benzene $(30 \mathrm{~mL})$ for $15 \mathrm{~h}$. The solvent was removed under reduced pressure. The residue obtained was purified by flash column chromatography (PE-EA $=5: 1$ ) to afford the crude product, which was recrystallised from chloroform-hexane as a white solid (1.233 $\mathrm{g}$, 70\%), m.p.:104-105 ${ }^{\circ} \mathrm{C} .{ }^{1} \mathrm{H}-\mathrm{NMR}\left(\mathrm{CDCl}_{3}\right): \delta 1.22\left(\mathrm{t}, J=7.2 \mathrm{~Hz}, 3 \mathrm{H}, \mathrm{CH}_{2} \mathrm{CH}_{3}\right), 3.77\left(\mathrm{~s}, 3 \mathrm{H}, \mathrm{OCH}_{3}\right)$, 3.87 (s, 2H, $\left.\mathrm{CH}_{2} \mathrm{Ph}\right), 4.19$ (q, J=7.2 Hz, 2H, $\underline{\mathrm{C}}_{2} \mathrm{CH}_{3}$ ), 5.34-5.65 (br s, 1H, OH), 6.41-6.44 (m, 2H, $\mathrm{PhH}), 7.12-7.28(\mathrm{~m}, 6 \mathrm{H}, \mathrm{PhH}), 7.94(\mathrm{~s}, 1 \mathrm{H}, \mathrm{C} \underline{\mathrm{H}}=\mathrm{C})$. MS (ESI): $m / z 313.1\left(\mathrm{M}+\mathrm{H}^{+}\right), 330.1\left(\mathrm{M}+\mathrm{H}_{2} \mathrm{O}\right)$, $335.1\left(\mathrm{M}+\mathrm{Na}^{+}\right), 351.1\left(\mathrm{M}+\mathrm{K}^{+}\right), 647.2\left(2 \mathrm{M}+\mathrm{Na}^{+}\right)$.

Step 4: Preparation of 3-benzyl-7-methoxy-2H-chromen-2-one (83)

Compound 9a (6 mmol, $1.884 \mathrm{~g})$ was heated at $220{ }^{\circ} \mathrm{C}$ for $2 \mathrm{~h}$ under nitrogen atmosphere, The residue obtained was purified by flash column chromatography (PE-EA $=10: 1)$ to afford the product, a white to light green powder $(1.449 \mathrm{~g}, 90 \%)$, m.p.: 102-103 ${ }^{\circ} \mathrm{C} .{ }^{1} \mathrm{H}-\mathrm{NMR}\left(\mathrm{CDCl}_{3}\right): \delta 3.85(\mathrm{~s}, 5 \mathrm{H}$, $\left.\mathrm{OCH}_{3}, \mathrm{CH}_{2} \mathrm{Ph}\right), 6.77-6.81(\mathrm{~m}, 2 \mathrm{H}, \mathrm{PhH}), 7.22-7.36$ (m, 7H, PhH). MS (ESI): $m / z 267.1\left(\mathrm{M}+\mathrm{H}^{+}\right)$, $289.1\left(\mathrm{M}+\mathrm{Na}^{+}\right)$.

\subsubsection{Procedure for the Preparation of 3-(4-Fluorobenzyl)-7-methoxy-2H-chromen-2-one (84) [25]}

Step 1: Preparation of ethoxycarbonyl-(4-fluorobenzyl)-methylenetriphenylphosphorane (8b) [35]

To the solution of 4-fluorobenzyl bromide $(0.378 \mathrm{~g}, 2 \mathrm{mmol})$ in dry chloroform (16 $\mathrm{mL})$, ethoxycarbonylmethylene triphenylphosphorane $(7,0.68 \mathrm{~g}, 1.9 \mathrm{mmol})$ was added at room temperature. After stirring for $30 \mathrm{~min}$ at $\mathrm{rt}$, it was refluxed for $15 \mathrm{hr}$. The solvent was removed under reduced pressure to give the phosphonium salt as an oil. This salt was dissolved in water $(50 \mathrm{~mL})$ and 
dichloromethane $(50 \mathrm{~mL})$ was added to it. It was then made alkaline (phenolphthalein colouless to pink) with $2 \mathrm{M} \mathrm{NaOH}$. The dichloromethane layer was separated and the aqueous layer was extracted with dichloromethane $(50 \mathrm{~mL} \times 2)$. The combined dichloromethane extract was dried over $\mathrm{MgSO}_{4}$ and solvent was removed to give the phosphorane which was used without further purification for the next step.

Step 2: Preparation of (E)-ethyl 2-(4-fluorobenzyl)-3-(2-hydroxy-4-methoxyphenyl) acrylate (9b)

A mixture of $6(0.189 \mathrm{~g}, 1.24 \mathrm{mmol})$ and $\mathbf{8 b}(1.52 \mathrm{mmol})$ was refluxed at $85{ }^{\circ} \mathrm{C}$ in dry benzene $(12 \mathrm{~mL})$ for $15 \mathrm{~h}$. The solvent was removed under reduced pressure. The residue obtained was purified by flash column chromatography (PE-EA $=5: 1$ ) to afford the crude product, which was recrystallised from chloroform-hexane as a white solid (0.206 g, 50\%), m.p.: $114-115{ }^{\circ} \mathrm{C} .{ }^{1} \mathrm{H}-\mathrm{NMR}\left(\mathrm{CDCl}_{3}\right): \delta 1.24(\mathrm{t}$, $\left.J=7.2 \mathrm{~Hz}, 3 \mathrm{H}, \mathrm{CH}_{2} \mathrm{CH}_{3}\right), 3.79\left(\mathrm{~s}, 3 \mathrm{H}, \mathrm{OCH}_{3}\right), 3.82\left(\mathrm{~s}, 2 \mathrm{H}, \mathrm{CH}_{2} \mathrm{Ph}\right), 4.20$ (q, J = 7.2 Hz, 2H, $\left.\underline{\mathrm{H}}_{2} \mathrm{CH}_{3}\right)$, 5.10 (br s, 1H, OH), 6.44-6.47 (m, 2H, PhH), 6.92-6.97 (m, 2H, PhH), 7.00-7.13 (m, 3H, PhH), 7.90 $(\mathrm{s}, 1 \mathrm{H}, \mathrm{CH}=\mathrm{C})$. MS (ESI): $m / z 331.1\left(\mathrm{M}+\mathrm{H}^{+}\right), 348.1\left(\mathrm{M}+\mathrm{H}_{2} \mathrm{O}\right), 353.1\left(\mathrm{M}+\mathrm{Na}^{+}\right), 369.1\left(\mathrm{M}^{+} \mathrm{K}^{+}\right)$.

Step 3: Preparation of 3-(4-fluorobenzyl)-7-methoxy-2H-chromen-2-one (84)

Compound 9b (0.66 g, $2 \mathrm{mmol})$ was heated at $220{ }^{\circ} \mathrm{C}$ for $3 \mathrm{~h}$ under a nitrogen atmosphere, The residue obtained was purified by flash column chromatography (PE-EA $=10: 1)$ to afford the product, a white powder (0.408 g, 72\%), m.p.: 94-95 ${ }^{\circ} \mathrm{C} .{ }^{1} \mathrm{H}-\mathrm{NMR}$ (DMSO- $\left.d 6\right): \delta 3.76\left(\mathrm{~s}, 2 \mathrm{H}, \mathrm{CH}_{2} \mathrm{Ph}\right), 3.84$ (s, $3 \mathrm{H}, \mathrm{OCH}_{3}$ ), 6.92 (dd, $\left.J=8.6,2.4 \mathrm{~Hz}, 1 \mathrm{H}, \mathrm{H}-6\right), 6.98$ (d, $\left.J=2.4 \mathrm{~Hz}, 1 \mathrm{H}, \mathrm{H}-8\right), 7.11-7.16$ (m, 2H, PhH), 7.33 (dd, $J=8.6,5.4 \mathrm{~Hz}, 2 \mathrm{H}, \mathrm{Ph}-\mathrm{H}) 7.57$ (d, $J=8.6 \mathrm{~Hz}, 1 \mathrm{H}, \mathrm{H}-5), 7.75$ (s, 1H, H-4). ${ }^{13} \mathrm{C}-\mathrm{NMR}$ (DMSO-d6): $\delta 35.46,56.33,100.85,112.82,113.13,115.49,115.70,124.91,129.45,131.13,135.21$, 140.71, 154.92, 160.22, 161.41, 162.27, 162.62. HRMS (ESI): $m / z 285.09185\left(\mathrm{M}+\mathrm{H}^{+}\right)$.

\subsubsection{Preparation of 3-Benzoyl-7-hydroxycoumarin (85) [26]}

To a mixture of 2,4-dihydroxybenzylaldehyde $(\mathbf{1 0 b}, 0.138 \mathrm{~g}, 1 \mathrm{mmol})$ and ethyl benzoylacetate (16, $0.192 \mathrm{~g}, 1.1 \mathrm{mmol})$ in acetonitrile $(4 \mathrm{~mL})$ was added 2 drops of piperidine. The neat mixture was kept stirring for $24 \mathrm{~h}$ at room temperature. The solvent was removed under reduced pressure. The products were purified by flash column chromatography (PE-EA $=3: 1)$ to afford a yellow solid $(0.23 \mathrm{~g}, 86.5 \%)$, m.p.: $220-221{ }^{\circ} \mathrm{C} .{ }^{1} \mathrm{H}-\mathrm{NMR}$ (DMSO-d6): $\delta 6.81(\mathrm{~d}, J=2.0 \mathrm{~Hz}, 1 \mathrm{H}, \mathrm{H}-8), 6.87(\mathrm{dd}, J=8.8,2.0 \mathrm{~Hz}, 1 \mathrm{H}$, H-6), $7.53(\mathrm{t}, J=7.6 \mathrm{~Hz}, 2 \mathrm{H}, m-\mathrm{Ph}), 7.65-7.73(\mathrm{~m}, 2 \mathrm{H}, p-\mathrm{Ph}, \mathrm{H}-5), 7.86$ (d, $J=7.2 \mathrm{~Hz}, 2 \mathrm{H}, o-\mathrm{Ph}), 8.35$ (s, 1H, H-4), 11.05 (s, 0.11H, OH). MS (ESI): $m / z 267.1\left(\mathrm{M}+\mathrm{H}^{+}\right), 289.0\left(\mathrm{M}+\mathrm{Na}^{+}\right), 305.0\left(\mathrm{M}^{+} \mathrm{K}^{+}\right)$.

\subsubsection{Preparation of 3-benzoyl-7-methoxycoumarin (86) [26]}

To a mixture of 2-hydroxyl-4-methoxybenzylaldehyde (10a, $0.152 \mathrm{~g}, 1 \mathrm{mmol}, 1$ equiv.) and ethyl benzoylacetate (11, $0.192 \mathrm{~g}, 1 \mathrm{mmol}, 1$ equiv.) was added piperidine $(0.25 \mathrm{~mL})$ dropwise. The neat mixture was kept stirring at room temperature until a pink solid was formed. The solid was then dissolved in $\mathrm{CH}_{2} \mathrm{Cl}_{2}$ and neutralised with $20 \mathrm{~mL} \mathrm{HCl}(1 \mathrm{M})$. After extracting with $\mathrm{CH}_{2} \mathrm{Cl}_{2}$, the organic phase was dried over $\mathrm{MgSO}_{4}$ and concentrated. The crude product was then recrystallised from $\mathrm{CH}_{2} \mathrm{Cl}_{2}-\mathrm{PE}$ to give a pure product as yellow needle-like crystals $(0.269 \mathrm{~g}, 96 \%)$, m.p.: $149-150{ }^{\circ} \mathrm{C}$. ${ }^{1} \mathrm{H}-\mathrm{NMR}\left(\mathrm{CDCl}_{3}\right)$ : $\delta 3.92\left(\mathrm{~s}, 3 \mathrm{H}, \mathrm{OCH}_{3}\right), 6.87(\mathrm{~d}, J=2.0 \mathrm{~Hz}, 1 \mathrm{H}, \mathrm{H}-8), 6.90-6.93(\mathrm{dd}, J=8.8,2.0 \mathrm{~Hz}$, 
1H, H-6), 7.46-7.51 (m, 3H, m-Ph, H-5), 7.58-7.60 (m, 1H, p-Ph), 7.85-7.87 (m, 2H,o-Ph), 8.10 $(\mathrm{s}, 1 \mathrm{H}, \mathrm{H}-4) .{ }^{13} \mathrm{C}-\mathrm{NMR}\left(\mathrm{CDCl}_{3}\right): \delta 56.0,100.7,111.9,113.6,123.0,128.5,129.5,130.5,133.4,136.8$, 146.4, 157.2, 158.8, $164.7(\mathrm{C}=\mathrm{O}), 192.0(\mathrm{C}=\mathrm{O})$. MS (ESI): $m / z 281.1\left(\mathrm{M}+\mathrm{H}^{+}\right), 303.1\left(\mathrm{M}+\mathrm{Na}^{+}\right), 319.0$ $\left(\mathrm{M}+\mathrm{K}^{+}\right)$.

\subsubsection{Preparation of 3-Benzoyl-4-cyano-7-hydroxycoumarin (87) [27]}

To the solution of M19 (0.266 g, $1 \mathrm{mmol})$ in DMF (2 mL) was added sodium cyanide (0.098 g, $2 \mathrm{mmol}$ ), and the mixture was stirred at $\mathrm{rt}$ for $6 \mathrm{~h}$. Then iodine was added to the solution and stirring at r.t. continued for $3 \mathrm{~h}$. This solution was filtered and the residue washed with water and methanol and dried. The mixture was purified by flash column chromatography (PE-EA $=10: 1)$ to afford the product as a yellow solid (0.097 g, 33.3\%). M.p.: $193-194{ }^{\circ} \mathrm{C} .{ }^{1} \mathrm{H}-\mathrm{NMR}$ (DMSO- $\left.d 6\right): \delta 6.90(\mathrm{~d}, J=2.4 \mathrm{~Hz}, 1 \mathrm{H}$, H-8), 7.02 (dd, $J=8.8,2.4 \mathrm{~Hz}, 1 \mathrm{H}, \mathrm{H}-6), 7.58$ (t, $J=7.6 \mathrm{~Hz}, 2 \mathrm{H}, m-\mathrm{Ph}), 7.70-7.78$ (m, 2H, $p-\mathrm{Ph}, \mathrm{H}-5$ ), 8.06 (d, $J=7.2 \mathrm{~Hz}, 2 \mathrm{H}, o-\mathrm{Ph}), 11.33$ (s, 1H, OH). HRMS (ESI): $m / z 292.06037\left(\mathrm{M}+\mathrm{H}^{+}\right)$.

\subsubsection{Preparation of 3-Benzoyl-4-cyano-7-methoxycoumarin (88) [27]}

To the solution of 86 (2.523 g, 9 mmol, 1 equiv.) in DMF (20 mL) was added sodium cyanide ( $0.864 \mathrm{~g}, 18 \mathrm{mmol}, 2$ equiv.), and the mixture was stirred at $\mathrm{rt}$ for $1 \mathrm{~h}$. Then iodine $(1.143 \mathrm{~g}, 9 \mathrm{mmol}$, 1 equiv.) was added to the solution and stirring continued at $\mathrm{rt}$ for $1 \mathrm{~h}$. The mixture was processed by routine procedures and purified by flash column chromatography $(\mathrm{PE}-\mathrm{EA}=30: 1)$ to afford the product as a yellow solid $(0.76 \mathrm{~g}, 28 \%)$, m.p.: $175-176{ }^{\circ} \mathrm{C} .{ }^{1} \mathrm{H}-\mathrm{NMR}$ (DMSO- $\left.d 6\right): \delta 3.93\left(\mathrm{~s}, 3 \mathrm{H}, \mathrm{OCH}_{3}\right), 7.14-7.17$ $(\mathrm{dd}, J=8.8,2.0 \mathrm{~Hz}, 1 \mathrm{H}, \mathrm{H}-6), 7.2(\mathrm{~d}, J=2.0 \mathrm{~Hz}, 1 \mathrm{H}, \mathrm{H}-8), 7.56-7.60$ (t, $J=7.6 \mathrm{~Hz}, 2 \mathrm{H}, m-\mathrm{Ph}), 7.74-7.77$ (m, 2H, $p$-Ph, H-5), 8.08 (d, $J=7.2 \mathrm{~Hz}, 2 \mathrm{H}, o-\mathrm{Ph}$ ). ${ }^{13} \mathrm{C}-\mathrm{NMR}$ (DMSO- $d 6$ ): $\delta 101.93,109.79,112.76$, $114.53,124.86,128.32,129.54,130.26,130.52$, 135.42, 135.50, 156.12, 157.48, 165.15, 190.22. HRMS (ESI): $m / z 306.07637\left(\mathrm{M}+\mathrm{H}^{+}\right), 328.05802\left(\mathrm{M}+\mathrm{Na}^{+}\right)$.

\subsubsection{Preparation of 3-Benzoyl-4-carboxy-7-methoxycoumarin (89) [28]}

Compound $88(100 \mathrm{mg}, 0.33 \mathrm{mmol})$ in $50 \% \mathrm{H}_{2} \mathrm{SO}_{4}(5 \mathrm{~mL})$ was stirred at $100{ }^{\circ} \mathrm{C}$ for $15 \mathrm{~h}$. The mixture was processed by routine procedures and purified by flash column chromatography $\left(\mathrm{CH}_{2} \mathrm{Cl}_{2}\right.$-ethanol $\left.=10: 1\right)$ to afford the product as a yellow solid $(0.03 \mathrm{~g}, 28 \%)$, m.p.: 196-197 ${ }^{\circ} \mathrm{C}$. ${ }^{1} \mathrm{H}-\mathrm{NMR}$ (DMSO-d6): $\delta 3.92$ (s, 3H, $\mathrm{OCH}_{3}$ ), 7.07 (dd, $\left.J=8.8,2.4 \mathrm{~Hz}, 1 \mathrm{H}, \mathrm{H}-6\right), 7.15$ (d, $J=2.4 \mathrm{~Hz}$, $1 \mathrm{H}, \mathrm{H}-8), 7.52$ (t, $J=8.0 \mathrm{~Hz}, 2 \mathrm{H}, m-\mathrm{Ph}), 7.65$ (t, $J=7.6 \mathrm{~Hz}, 1 \mathrm{H}, p-\mathrm{Ph}), 7.83$ (d, $J=8.8 \mathrm{~Hz}, 1 \mathrm{H}, \mathrm{H}-5)$, $7.90(\mathrm{~d}, J=8.0 \mathrm{~Hz}, 2 \mathrm{H}, o-\mathrm{Ph}) .{ }^{13} \mathrm{C}-\mathrm{NMR}$ (DMSO- $\left.d 6\right): \delta 56.70,101.58,109.23,113.83,128.93,129.15$,

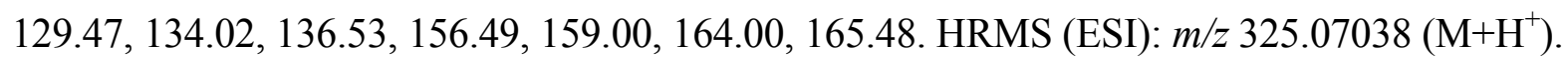

\subsection{MEK1 Binding Assay}

The homogeneous time resolved fluorescence (HTRF) assay was performed on a Proxiplate-384 F plus solid back plate (Perkin Elmer, Waltham, MA. USA) with $5 \mathrm{nM}$ GST tagged phosphorylated MEK1 (GST-MEK1), 2 nM europium-labeled anti-GST antibody (Eu-anti-GST), $20 \mathrm{nM}$ kinase tracer 236 and test compound at a variety of concentrations. In the reaction mixture, GST-MEK1 forms a complex with the Eu-anti-GST and the tracer. Excitation of europium (the donor) using a 340-nm 
excitation filter results in energy transfer to the fluorophore of the tracer. This energy transfer is detected by an increase in the fluorescence emission of the tracer at $665 \mathrm{~nm}$ and a decrease in the fluorescence emission of europium at $615 \mathrm{~nm}$. The FRET ratio was calculated by dividing the emission signal at $665 \mathrm{~nm}$ by the emission signal at $615 \mathrm{~nm}$. A competitor compound such as a MEK inhibitor replaces the tracer from the complex and decreases the FRET ratio accordingly. The plate was incubated in dark at room temperature for $30 \mathrm{~min}$ before measuring the fluorescent emission of each well at 665 and $615 \mathrm{~nm}$ using a 340-nm excitation filter, 100- $\mu$ s delay time, and 200- $\mu$ s integration time, on a PHERAStar plate reader (BMG Labtech, Durham, NC, USA). AZD6244 (ARRY-142886) was used as positive control with $100.00 \% \pm 1.45 \%$ inhibition at $100 \mu \mathrm{M}$. Data shown as \%Inhibition normalized to AZD6244 at $100 \mu \mathrm{M}$. The curve-fitting software GraphPad Prism 4.0 was used to generate the curves and determine the $\mathrm{IC}_{50}$ values for individual compounds tested. \%Inhibition = $100 \% \times($ DMSO-chemical)/(DMSO-AZD6244@100 $\mu \mathrm{M})$.

\subsection{Cell-Based Assays}

\subsubsection{Cell Culture}

Human Embryonic Kidney 293 cells (HEK 293) or rhabdomyosarcoma (RD) cells were grown in Dulbecco's modified Eagle's medium (DMEM, Thermo Scientific Hyclone, Logan, UT, USA) supplemented with $2 \%$ or $10 \%$ fetal bovine serum (FBS, GIBCO, Gaithersburg, MD, USA) at $37{ }^{\circ} \mathrm{C}$ in a humidified $5 \% \mathrm{CO}_{2}$ incubator.

\subsubsection{AP-1 Luciferase Reporter Gene Assay}

pAP1-Luc was constructed with pGL3-basic (Promega, Madison, WI. USA) and a fragment including the AP-1 response element (2× TRE) and T7 promoter. HEK 293 cells in 96-well plates were cultured at $5 \% \mathrm{CO}_{2}$ at $37{ }^{\circ} \mathrm{C}$ in DMEM containing $10 \% \mathrm{FBS}$. When the confluence was up to $80 \%$, cells were transinfected with pAP1-Luc using lipofectamine 2000 (Life Technologies, Carlsbad, CA. USA). At $24 \mathrm{~h}$ post transinfection, individual compounds with different concentrations $(5,10,20$, $30 \mu \mathrm{M})$ were added into cells using three wells for each concentration used. After incubation for $1 \mathrm{~h}$, TPA (50 nM) was added. The cells were harvested after $4 \mathrm{~h}$ and luciferase activity was measured by using luciferase assay kit (Promega) with a luminometer. The concentration of $50 \%$ inhibition $\left(\mathrm{IC}_{50}\right)$ of each compound was calculated.

\subsubsection{Antiviral Assay}

RD cells were cultured in DMEM and up to 70\%-80\% confluence in 96-well plates. Compounds were added into the culture medium for $1 \mathrm{~h}$ prior to virus infection using four wells for each concentration used. The compounds were added at the following concentrations: 1.25, 2.5, 5, 10, 20, $40 \mu \mathrm{M}$. Then cells were infected withEV71 (a clinical strain denoted as EV71-BC08, GU475127) at a multiplicity of infection (MOI) of 1. Virus controls (untreated wells of infected cells), cell controls (cells and drugs only, using the same dilution range for each compound as the test wells) were included on the plate. The cytopathic effect (CPE) were examined at every $12 \mathrm{~h}$ intervals postinfection by using phase-contrast microscopy. At $48 \mathrm{~h}$ after infection, the virus control wells showed 
$100 \%$ cytopathology. The $50 \%$ effective concentration $\left(\mathrm{EC}_{50}\right)$ was determined for each compound through Reed-Muench method. The cytotoxicity $\left(\mathrm{CC}_{50}\right)$ was assayed by the MTT method.

\section{Conclusions}

Compounds 13, 18, 19 and 33 have shown good activity in all the above assays. The common sub-structure they share is $N, N$-dimethylcarbamoyloxyl or acetoxyl substitution at the $\mathrm{C} 7$ position, and this implies the importance of substituents at this position. Besides the hydrogen bond formed by the carbonyl group of the $N, N$-dimethylcarbamoyloxyl or acetoxyl groups and Asp208, the activity may be related to the steric hindrances and specific carbon chain lengths of these substituent groups.

In summary, using a computer-aided drug design (CADD) method, we have developed a series of novel 3-substituted benzylcoumarins as allosteric MEK1 inhibitors. Some of the compounds showed excellent MEK1 binding affinity and displayed obvious inhibitory effects on the ERK pathway. Functionally, they could significantly inhibit replication of viruses such as EV71 in a cell-based assay. These compounds may overcome the drug resistance problem caused by virus variation and might be potential candidates for the treatment of viral diseases. Further structure optimizations and investigations to improve the potency and explore the pharmacological properties of these new MEK1 inhibitors are ongoing in our group.

\section{Supplementary Materials}

Results for the in vitro biological studies of all compounds. Supplementary materials can be accessed at: http://www.mdpi.com/1420-3049/18/5/6057/s1.

\section{Acknowledgments}

This work was supported by the National Natural Science Foundation of China (21172012), the National Basic Research Program of China (2012CB518000), National High-Tech Research and Development Program of China (863 Program, no. 2007AA02Z317) and the Specialized Research Fund for the Doctoral Program of Higher Education of China (20120001110010).

\section{Conflict of Interest}

The authors declare no conflict of interest.

\section{References}

1. Johnson, R.A.; Ma, X.L.; Yurochko, A.D.; Huang, E.S. The role of MKK1/2 kinase activity in human cytomegalovirus infection. J. Gen. Virol. 2001, 82, 493-497.

2. Ludwig, S.; Wolff, T.; Ehrhardt, C.; Wurzer, W.J.; Reinhardt, J.; Planz, O.; Pleschka, S. MEK inhibition impairs influenza $\mathrm{B}$ virus propagation without emergence of resistant variants. FEBS Lett. 2004, 561, 37-43.

3. Yi, T.; Zhang, H.; Peng, Y.-H.; Zhu, M.; He, X.-Y.; Huang, X.-T. Activation of MEK1-ERKs is essential for herpes simplex virus type 2 (HSV2) replication. Zhongguo Shengwu Huaxue Yu Fenzi Shengwu Xuebao 2011, 27, 142-147. 
4. Pei, R.; Zhang, X.; Xu, S.; Meng, Z.; Roggendorf, M.; Lu, M.; Chen, X. Regulation of Hepatitis C virus replication and gene expression by the MAPK-ERK pathway. Virol. Sin. 2012, 27, 278-285.

5. Andrade, A.A.; Silva, P.N.G.; Pereira, A.C.T.C.; de Sousa, L.P.; Ferreira, P.C.P.; Gazzinelli, R.T.; Kroon, E.G.; Ropert, C.; Bonjardim, C.A. The vaccinia virus-stimulated mitogen-activated protein kinase (MAPK) pathway is required for virus multiplication. Biochem. J. 2004, 381, 437-446.

6. Price, S. Putative allosteric MEK1 and MEK2 inhibitors. Expert Opin. Ther. Pat. 2008, 18, 603-627.

7. Fremin, C.; Meloche, S. From basic research to clinical development of MEK1/2 inhibitors for cancer therapy. J. Hematol. Oncol. 2010, 3, doi:10.1186/1756-8722-3-8.

8. Ohren, J.F.; Chen, H.F.; Pavlovsky, A.; Whitehead, C.; Zhang, E.L.; Kuffa, P.; Yan, C.H.; McConnell, P.; Spessard, C.; Banotai, C.; et al. Structures of human MAP kinase kinase 1 (MEK1) and MEK2 describe novel noncompetitive kinase inhibition. Nat. Struct. Mol. Biol. 2004, 11, 1192-1197.

9. Cozza, G.; Bortolato, A.; Menta, E.; Cavalletti, E.; Spinelli, S.; Moro, S. ATP non-competitive Ser/Thr kinase inhibitors as potential anticancer agents. Anticancer Agents Med. Chem. 2009, 9, 778-786.

10. Wang, D.; Boerner, S.A.; Winkler, J.D.; LoRusso, P.M. Clinical experience of MEK inhibitors in cancer therapy. Biochim. Biophys. Acta 2007, 1773, 1248-1255.

11. Kiselyov, A.; Balakin, K.V.; Tkachenko, S.E.; Savchuk, N.P. Recent progress in development of non-ATP competitive small-molecule inhibitors of protein kinases. Mini Rev. Med. Chem. 2006, 6, 711-717.

12. Harrison, S.; Das, K.; Karim, F.; Maclean, D.; Mendel, D. Non-ATP-competitive kinase inhibitors-enhancing selectivity through new inhibition strategies. Expert Opin. Drug Discov. 2008, 3, 761-774.

13. Trujillo, J.I. MEK inhibitors: A patent review 2008-2010. Expert Opin. Ther. Pat. 2011, 21, 1045-1069.

14. Heald, R.A.; Jackson, P.; Savy, P.; Jones, M.; Gancia, E.; Burton, B.; Newman, R.; Boggs, J.; Chan, E.; Chan, J.; et al. Discovery of novel allosteric mitogen-activated protein kinase kinase (MEK) 1,2 inhibitors possessing bidentate Ser212 interactions. J. Med. Chem. 2012, 55, 4594-4604.

15. Wang, J.; Wilcoxen, K.M.; Nomoto, K.; Wu, S. Recent advances of MEK inhibitors and their clinical progress. Curr. Top. Med. Chem. 2007, 7, 1364-1378.

16. Dudley, D.T.; Pang, L.; Decker, S.J.; Bridges, A.J.; Saltiel, A.R. A synthetic inhibitor of the mitogen-activated protein kinase cascade. Proc. Natl. Acad. Sci. USA 1995, 92, 7686-7689.

17. Wang, B.; Ding, L.; Deng, J.; Zhang, H.; Zhu, M.; Yi, T.; Liu, J.; Xu, P.; Lu, F.; Peng, Y. Replication of EV71 was suppressed by MEK1/2 inhibitor U0126. Chin. J. Biochem. Mol. Biol. 2010, 26, 538-545.

18. Tu, J.; Zhang, H.; Zhou, Q.; Wang, B.; Cao, M.; Huang, H.; Peng, Y. Key role of MEK1/2-ERK pathway in replication of type II herpes simplex virus (HSV-2). Chin. J. Biochem. Mol. Biol. 2008, 24, 839-845.

19. Luo, L.; Tu, J.; Feng, H.; Zhang, H.; Peng, Y. Effects of the host cell ERK signal transduction pathway on replication of type II herpes simplex virus (HSV-2). Chin. J. Biochem. Mol. Biol. 2007, 27, 779-782. 
20. Peng, Y. ERK signal cascade: The host cell's mechinery for viral reproduction and its implication as the potential anti-viral target. Chin. J. Viral Dis. 2012, 404-408.

21. He, J.; Duan, H.; Peng, Y. ERK/MAPK pathway and replication, pathogenesis of human RNA virus:a short review. Chin. J. Viral Dis. 2012, 465-470.

22. Wang, B.; Zhang, H.; Zhu, M.; Luo, Z.; Peng, Y. MEK1-ERKs signal cascade is required for the replication of Enterovirus 71 (EV71). Antiviral Res. 2012, 93, 110-117.

23. Han, S.; Zhou, V.; Pan, S.; Liu, Y.; Hornsby, M.; McMullan, D.; Klock, H.E.; Haugen, J.; Lesley, S.A.; Gray, N.; et al. Identification of coumarin derivatives as a novel class of allosteric MEK1 inhibitors. Bioorg. Med. Chem. Lett. 2005, 15, 5467-5473.

24. Cheng, J.F.; Arrhenius, T.; Wallace, D.; Chen, M.; Tith, S.; Kashiwagi, H.; Ono, Y.; Watanabe, Y. Preparation of Coumarin Derivatives Useful as TNF $\alpha$ Inhibitors. W.O. Patent WO2002008217A2, 31 Janurary 2002.

25. Britto, N.; Gore, V.G.; Mali, R.; Ranade, A. A convenient synthesis of 3-behzyl, 3-benzyl-4substituted coumarins and their benzo derivatives. Synth. Commun. 1989, 19, 1899-1910.

26. Tang, X.; Blake, A.J.; Lewis, W.; Woodward, S. Asymmetric conjugate additions to 1,1'diactivated cyclic enones-A comparative study. Tetrahedron Asymmetry 2009, 20, 1881-1891.

27. Lee, S.; Sivakumar, K.; Shin, W.-S.; Xie, F.; Wang, Q. Synthesis and anti-angiogenesis activity of coumarin derivatives. Bioorg. Med. Chem. Lett. 2006, 16, 4596-4599.

28. Brubaker, A.N.; de Ruiter, J.; Whitmer, W.L. Synthesis and rat lens aldose reductase inhibitory activity of some benzopyran-2-ones. J. Med. Chem. 1986, 29, 1094-1099.

29. Muller, K.; Faeh, C.; Diederich, F. Fluorine in pharmaceuticals: Looking beyond intuition. Science 2007, 317, 1881-1886.

30. Purser, S.; Moore, P.R.; Swallow, S.; Gouverneur, V. Fluorine in medicinal chemistry. Chem. Soc. Rev. 2008, 37, 320-330.

31. Hagmann, W.K. The many roles for fluorine in medicinal chemistry. J. Med. Chem. 2008, 51, 4359-4369.

32. Ameyar, M.; Wisniewska, M.; Weitzman, J.B. A role for AP-1 in apoptosis: The case for and against. Biochimie 2003, 85, 747-752.

33. Karin, M.; Liu, Z.G.; Zandi, E. AP-1 function and regulation. Curr. Opin. Cell Biol. 1997, 9, 240-246.

34. Favata, M.F.; Horiuchi, K.Y.; Manos, E.J.; Daulerio, A.J.; Stradley, D.A.; Feeser, W.S.; van Dyk, D.E.; Pitts, W.J.; Earl, R.A.; Hobbs, F.; et al. Identification of a novel inhibitor of mitogen-activated protein kinase kinase. J. Biol. Chem. 1998, 273, 18623-18632.

35. Mali, R.S.; Yadav, V.J.; Zaware, R.N. An improved synthesis of naturally occurring coumarins: Synthesis of herniarin, scoparone \& 7-methoxy-6-methylcoumarin. Indian J. Chem. Sect. B: Org. Chem. Incl. Med. Chem. 1982, 21, 759-760.

Sample Availability: Samples of the compounds 13-89 are available from the authors.

(C) 2013 by the authors; licensee MDPI, Basel, Switzerland. This article is an open access article distributed under the terms and conditions of the Creative Commons Attribution license (http://creativecommons.org/licenses/by/3.0/). 